\title{
Progress and challenges towards additive manufacturing of SiC ceramic
}

\author{
Rujie $\mathrm{HE}^{a,{ }^{*}}$, Niping ZHOU ${ }^{a, b}$, Keqiang ZHANG ${ }^{a, b}$, Xueqin ZHANG ${ }^{a, b}$, \\ $\mathrm{Lu} \mathrm{ZHANG}^{a, b}$, Wenqing WANG ${ }^{a, b}$, Daining FANG ${ }^{a}$ \\ ${ }^{a}$ Institute of Advanced Structure Technology, Beijing Institute of Technology, Beijing 100081, China \\ ${ }^{b}$ School of Materials Science and Engineering, Beijing Institute of Technology, Beijing 100081, China
}

Received: January 5, 2021; Revised: March 25, 2021; Accepted: April 12, 2021

(C) The Author(s) 2021.

\begin{abstract}
Silicon carbide $(\mathrm{SiC})$ ceramic and related materials are widely used in various military and engineering fields. The emergence of additive manufacturing (AM) technologies provides a new approach for the fabrication of $\mathrm{SiC}$ ceramic products. This article systematically reviews the additive manufacturing technologies of $\mathrm{SiC}$ ceramic developed in recent years, including Indirect Additive Manufacturing (Indirect AM) and Direct Additive Manufacturing (Direct AM) technologies. This review also summarizes the key scientific and technological challenges for the additive manufacturing of $\mathrm{SiC}$ ceramic, and also forecasts its possible future opportunities. This paper aims to provide a helpful guidance for the additive manufacturing of $\mathrm{SiC}$ ceramic and other structural ceramics.
\end{abstract}

Keywords: silicon carbide (SiC); additive manufacturing (AM); structural ceramics

\section{Introduction}

Silicon carbide $(\mathrm{SiC})$ ceramic and related materials have been widely used in different military and engineering fields, such as aerospace, armor, space mirror, nuclear, chemical industry and semiconductor, and so on (as shown in Fig. 1), owing to their unique promising properties of low density, high melting point, good mechanical and thermal properties, and excellent oxidation and chemical stability [1-4]. Usually, three-dimensional (3D) complex-shaped $\mathrm{SiC}$ ceramic components are needed when it is applied in military and engineering fields [5,6], which brings great challenges to their forming.

Usually, the traditional fabrication of $\mathrm{SiC}$ ceramic is

* Corresponding author.

E-mail: herujie@bit.edu.cn consisted of four steps, including raw materials, forming of green body, sintering, and machining. At present, 3D complex-shaped $\mathrm{SiC}$ ceramic components are always produced through two approaches. (1) Sintering and machining approach [7]: bulk $\mathrm{SiC}$ ceramic is firstly fabricated by using various sintering technologies, such as pressureless sintering, hot pressing, reaction sintering, and so on. Then complex-shaped SiC ceramic components are obtained through different machining methods including grinding, turning, and so on. (2) Near-net forming and sintering approach [8]: complexshaped $\mathrm{SiC}$ green body is firstly prepared by using near-net forming technologies, such as slip casting, tape casting, injection molding, gel casting, and so on. After that, complex-shaped $\mathrm{SiC}$ ceramic component is subsequently prepared by using pressureless sintering method. However, there are obvious short-comings for both the above-mentioned two approaches. For the 


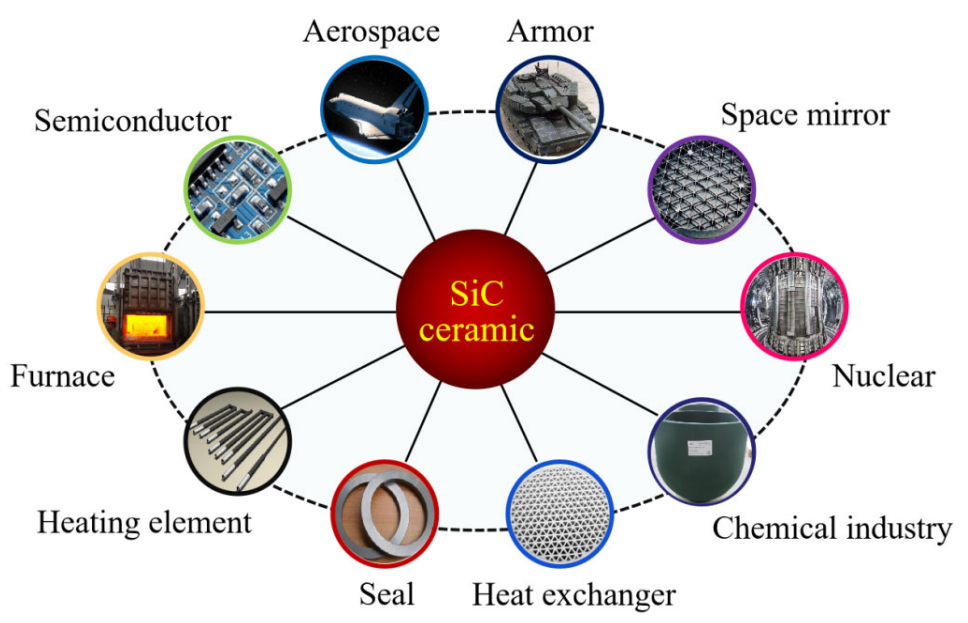

Fig. 1 Applications of SiC ceramic in military and engineering fields.

sintering and machining approach, inevitable machining defects and damages usually exist owing to the obvious intrinsic brittleness and hardness of $\mathrm{SiC}$ ceramic, which will greatly deteriorate their service properties and life [9]. Besides, expensive diamond or super alloy machining tools are always needed for the machining, which increases the manufacturing costs of $\mathrm{SiC}$ ceramic. For the near-net forming and sintering approach, complex-shaped $\mathrm{SiC}$ green body is firstly prepared by using colloidal processing method, and then $\mathrm{SiC}$ ceramic component is obtained after pyrolysis and sintering. However, molds are usually needed, which increase the production cycles and cost. Moreover, extreme complex-shaped $\mathrm{SiC}$ ceramic components maybe contain internal holes or internal surfaces, which are very difficult to achieve. For example, the slip casting of $\mathrm{SiC}$ ceramic components usually needs molds, and both the forming precision and material density/strength are relatively low. The tape casting usually produces thin $\mathrm{SiC}$ ceramic films or sheets. The injection molding must use mold, whereas complexshaped internal holes cannot be obtained. The monomers using in gel casting are always poisonous and harmful to scientists [8]. Therefore, both the sintering-machining and near-net forming-sintering approaches cannot meet the manufacturing requirement of 3D complex-shaped $\mathrm{SiC}$ ceramic components. Therefore, it is deemed necessary to develop novel advanced manufacturing technologies for $\mathrm{SiC}$ ceramic, finally promoting its application in military and engineering fields.

Additive manufacturing technologies, also called as 3D printing, solid free-form fabrication, or rapid prototyping, have been developing rapidly and dramatically, and drawn great attentions in the past decades. As shown in Fig. 2, the principle of additive manufacturing is based on the discretization and accumulation mechanism. Compared with traditional equivalent manufacturing and subtractive manufacturing technologies, additive manufacturing cannot be restricted by mold making or processing technology, solves the formation of complex-shaped structure products, and greatly reduces the processing procedures and shortens the processing cycle. Moreover, the more complex the product's structure, the more significant the advantages of additive manufacturing. Therefore, it has been widely applied for polymers, metals, and some ceramics. Specifically, additive manufacturing can not only realize the high-efficiency, low-cost, and rapid fabrication of complex-shaped products, but also achieve the integration of design and manufacturing, the integration of materials and structure, and the integration of structure and function [10]. Therefore, it

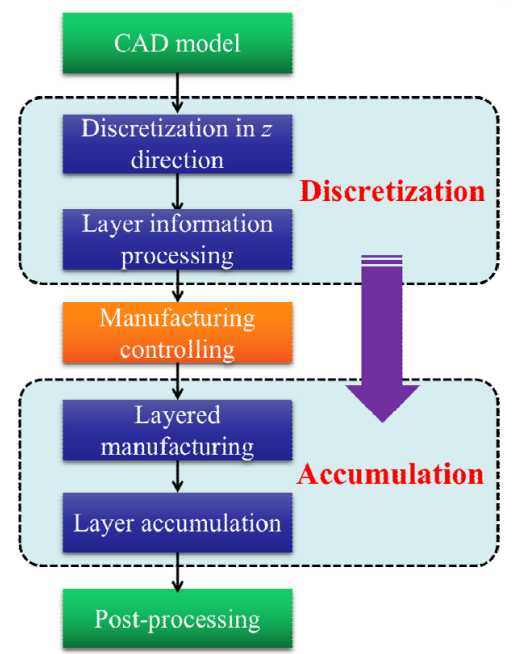

Fig. 2 Schematic diagram of additive manufacturing. 
has drawn great attentions and invest from governments and scholars all over the world.

Recently, great progress and breakthroughs have been made for the additive manufacturing of polymers and metals [10-12], and there have also been some reports on the additive manufacturing of ceramics. Typical oxide ceramics $\left(\mathrm{SiO}_{2}[13,14], \mathrm{Al}_{2} \mathrm{O}_{3}[15,16]\right.$, $\mathrm{ZrO}_{2}$ [17-19], and their composite ceramics [20-22], etc.), precursor derived ceramics (SiOC [23,24], SiCN $[25,26]$, etc.), bioceramics (hydroxyapatite [27,28], calcium phosphate [29,30], and their composite ceramics [31], etc.) have been reported to be prepared by using different additive manufacturing technologies. However, unfortunately, the additive manufacturing of $\mathrm{SiC}$ ceramic has been merely reported till now. In the past decade, the additive manufacturing of $\mathrm{SiC}$ ceramic has draw great attentions and subjected to intensive research. Figure 3 shows the number of published articles on the additive manufacturing of $\mathrm{SiC}$ ceramic and related materials, which is based on Web of Science database from 2000 to 2020 . It can be seen that the research on the additive manufacturing of $\mathrm{SiC}$ ceramic has received more and more attention.
However, it should be pointed out that, although there have been many research reports on different additive manufacturing technologies of $\mathrm{SiC}$ ceramic in recent years, there are still many challenges and basic scientific issues. Therefore, this paper aims to systematically review the recent state-of-the-art, to summarize the key scientific and technological challenges, and to forecast possible future opportunities of the additive manufacturing technologies of $\mathrm{SiC}$ ceramic. The authors hope to provide a deep review and helpful guidance for the related scientists in this field.

We notice that the reported additive manufacturing technologies of $\mathrm{SiC}$ ceramic usually have two types: Indirect Additive Manufacturing (Indirect AM) and Direct Additive Manufacturing (Direct AM). The following will systematically review their research status and progress.

\section{Indirect Additive Manufacturing (indirect AM)}

As shown in Fig. 4, the Indirect Additive Manufacturing

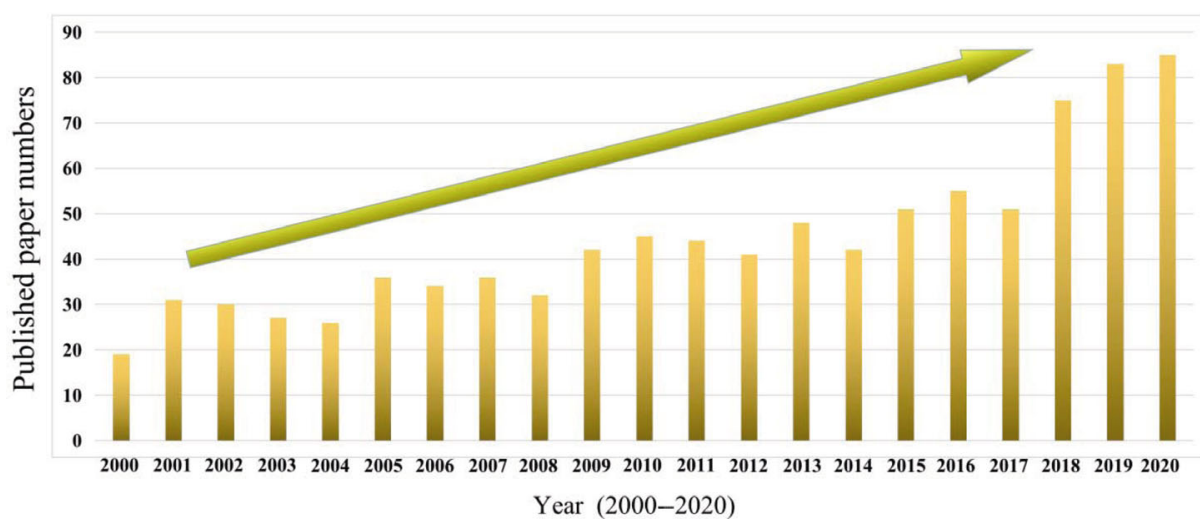

Fig. 3 Published papers on the additive manufacturing of $\mathrm{SiC}$ ceramic (based on Web of Science database from 2000.01 to 2020.12).

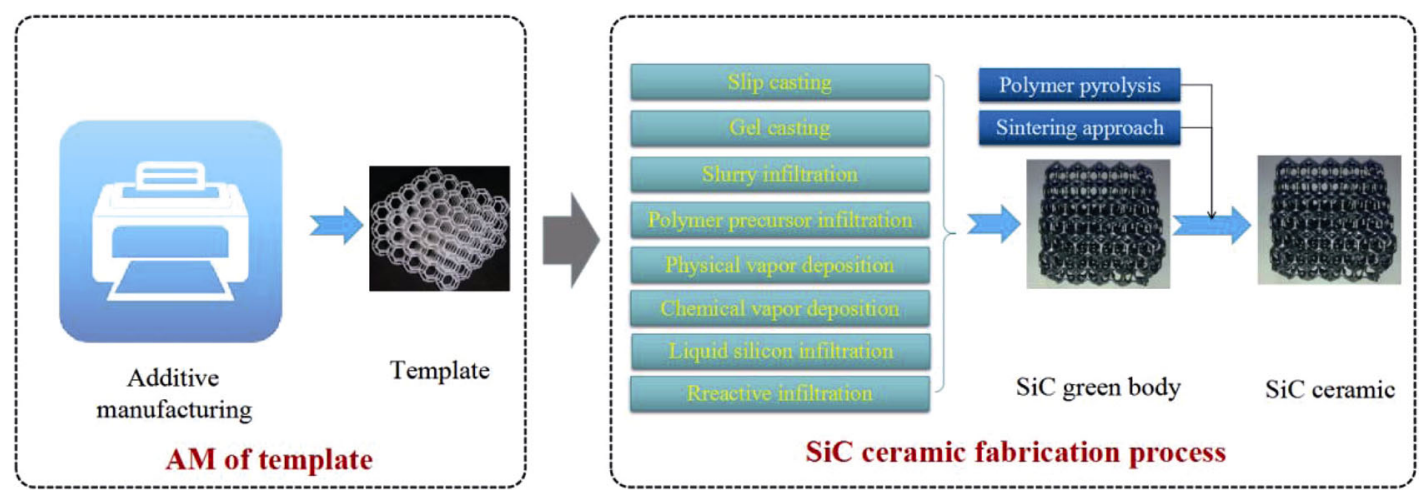

Fig. 4 Indirect additive manufacturing of $\mathrm{SiC}$ ceramic. 
(indirect $\mathrm{AM}$ ) of $\mathrm{SiC}$ ceramic generally consists of three steps: firstly, template, including polymer matrix composite template, ice template, carbon template, even some metal or ceramic template with low melting point, is fabricated through common additive manufacturing methods; after that, $\mathrm{SiC}$ ceramic green body is prepared by using traditional technology, such as slip casting, gel casting, slurry infiltration, polymer precursor infiltration (PIP), physical vapor deposition (PVD), chemical vapor deposition (CVD), liquid silicon infiltration (LSI), reactive infiltration, slurry replication, and so on. At last, $\mathrm{SiC}$ ceramic is obtained after polymer pyrolysis and the following sintering $[15,32,33]$. The indirect AM can reduce the cost of mold, realize complex-shaped $\mathrm{SiC}$ ceramic products which cannot be obtained by traditional methods, and meet the needs of personalized design.

As shown in Fig. 5(a), the as-prepared $\mathrm{Si}-\mathrm{SiC}$ ceramic lattice structure had better surface precision, higher density and mechanical properties. Chen et al. [34] used a light-curing additive manufacturing method to prepare a polymer template and improved its surface state by adding PEG. Based on the polymer template, $\mathrm{SiC}$ ceramic green body was prepared by means of gel casting. After debinding of the polymer template, pressureless sintering was conducted at $2150{ }^{\circ} \mathrm{C}$ to obtain the final $\mathrm{SiC}$ ceramic. As shown in Fig. 5(b), Tu and Jiang [35] also prepared $\mathrm{SiC}$ ceramic green body through additive manufacturing of polymer template combined with gel casting. Firstly, they prepared a PVA polymer template by using fused deposition modeling (FDM), one kind of additive manufacturing technologies. After that, gel casting was conducted and $\mathrm{SiC}$ ceramic green body was obtained. The polymer template was burned out at $600{ }^{\circ} \mathrm{C}$ after liquid phase drying. At last, $\mathrm{SiC}$ ceramic was obtained after pressureless sintering at $1600{ }^{\circ} \mathrm{C}$, as shown in Fig. 5(c). In addition, Zhang et al. [36] also reported the indirect additive manufacturing of short carbon fiber reinforced $\mathrm{SiC}$ ceramic matrix composites $\left(\mathrm{C}_{\mathrm{s}} / \mathrm{SiC}\right)$. Firstly, they fabricated a short carbon fiber-resin template by using stereolithography (SL) method from a photosensitive resin slurry containing short carbon fibers. After debinding and liquid silicon infiltration (LSI) treatment based on the short carbon fiber-resin template, lightweight $\mathrm{C}_{\mathrm{sf}} / \mathrm{SiC}$ ceramic matrix composite mirrors were obtained.

Besides, replica process (or replication) based on the resin template is another important method to obtain $\mathrm{SiC}$ ceramic [37,38]. Ortona et al. [39] used stereolithographybased additive manufacturing and selective laser curing based additive manufacturing to prepare porous resin template with designed lattice structure. Then they used a ceramic slurry mixture of $\alpha$-SiC powder, adhesive and organic solvent to infiltrate the resin template. After pyrolyzed at $1000{ }^{\circ} \mathrm{C}$, the resin template was burned out, and $\mathrm{Si}$-rich $\mathrm{Si}-\mathrm{SiC}$ ceramic with porous lattice structure was finally obtained through LSI at $1500{ }^{\circ} \mathrm{C}$, as shown in

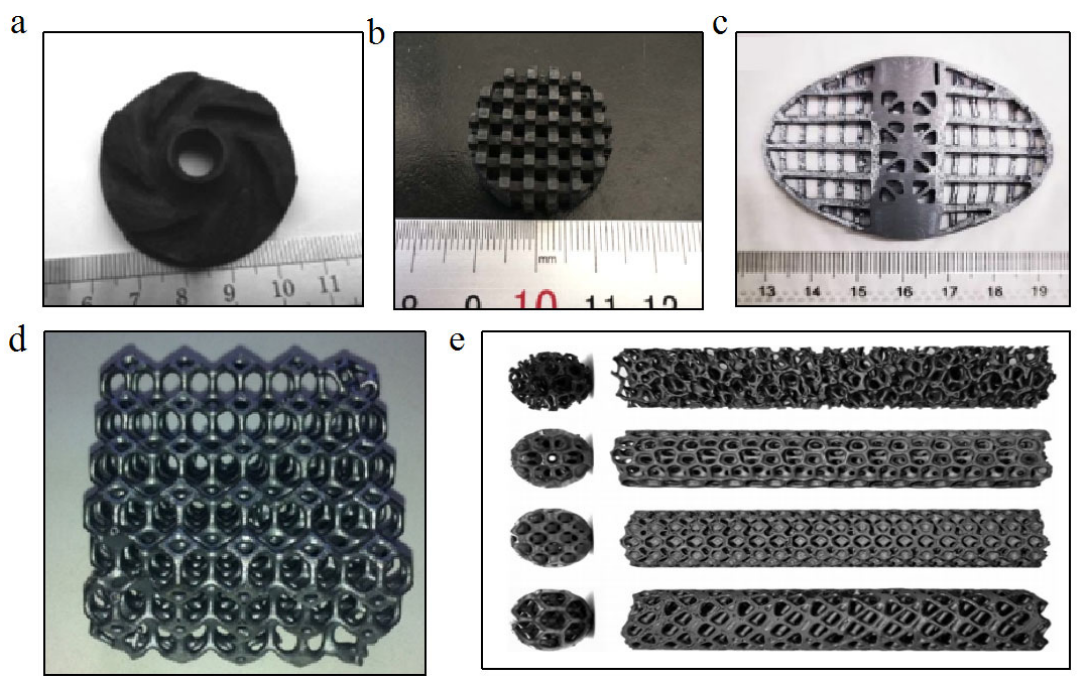

Fig. 5 Indirect additive manufacturing of SiC ceramic: (a) SL prepared polymer template, gel casting, and pressureless sintering. Reproduced with permission from Ref. [34], (C) Elsevier Ltd and Techna Group S.r.l. 2017. (b) FDM prepared polymer template, gel casting, and pressureless sintering. Reproduced with permission from Ref. [35], (C) Elsevier Ltd and Techna Group S.r.l. 2017. (c) Indirect additive manufacturing of lightweight $\mathrm{C}_{\mathrm{sf}} / \mathrm{SiC}$ ceramic matrix composite mirror: SL prepared short carbon fiber template, and LSI. Reproduced with permission from Ref. [36], (C) Elsevier B.V. 2020. (d, e) SL prepared polymer template, slurry infiltration, and LSI or PIP. Reproduced with permission from Ref. [39], C Elsevier B.V. 2012, and Ref. [40], C ASME 2020. 
Fig. 5(d). Besides, they also used this method to prepare resin template with different structural configuration. After ceramic slurry infiltration and template pyrolysis, precursor infiltration and pyrolysis (PIP) was used. After that, porous $\mathrm{Si}-\mathrm{SiC}$ ceramic lattice structure was prepared, as shown in Fig. 5(e) [40]. Ortona et al. [39-42] further successfully produced cellular $\mathrm{Si}-\mathrm{SiC}$ ceramic and its heat ex-changers by using a rapid prototyping technology of the template, combined with the replication method and following pyrolysis and silicon infiltration, as shown in Fig. 6.

Certainly, the use of indirect additive manufacturing method to prepare $\mathrm{SiC}$ ceramic can make full use of the existing mature polymer additive manufacturing technology and traditional $\mathrm{SiC}$ ceramic fabrication technologies, reduce processing difficulty, and have high technological applicability and maturity. However, the indirect additive manufacturing of $\mathrm{SiC}$ ceramic usually has a very complicated process flow, a long processing cycle, and a high processing cost. In addition, the indirect additive manufacturing generally faces the difficulties of burning out of the polymer templates, which can easily affect the accuracy and easily form inevitable defects among the final $\mathrm{SiC}$ ceramic. Therefore, the indirect additive manufactured $\mathrm{SiC}$ ceramic usually has the shortcoming such as low density, poor mechanical properties, and low manufacturing accuracy. With the rapid development and technological breakthrough of additive manufacturing,

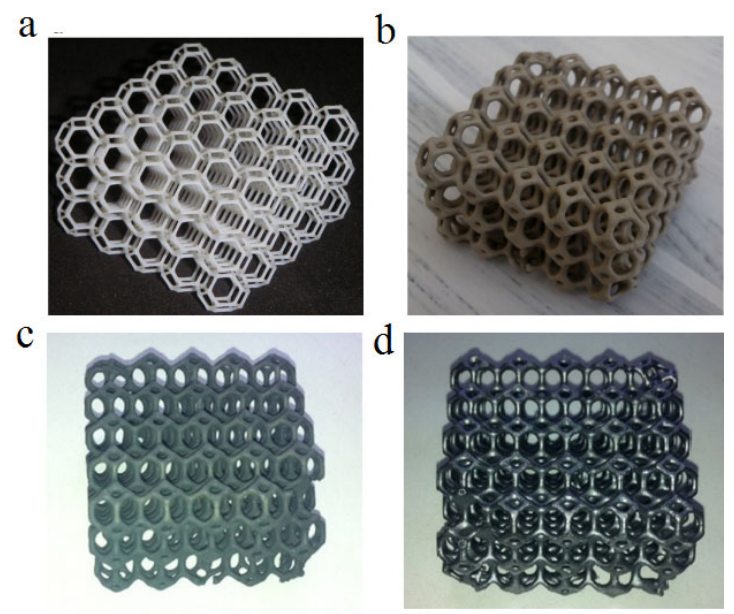

Fig. 6 Indirect additive manufacturing of $\mathrm{Si}-\mathrm{SiC}$ ceramic: (a) template 3D printing; (b) slurry replication; (c) pyrolysis; (d) silicon infiltration. Reproduced with permission from Ref. [39], (C) Elsevier B.V. 2012.

direct additive manufacturing of $\mathrm{SiC}$ ceramic has received more and more attention.

\section{Direct Additive Manufacturing (direct AM)}

Direct Additive Manufacturing (direct AM) means directly obtaining $\mathrm{SiC}$ ceramic or green body through additive manufacturing. Generally, it can be divided into several steps, including ceramic raw materials, additive manufacturing, debinding, sintering, and post-processing [43], as illustrated in Fig. 7. Whether

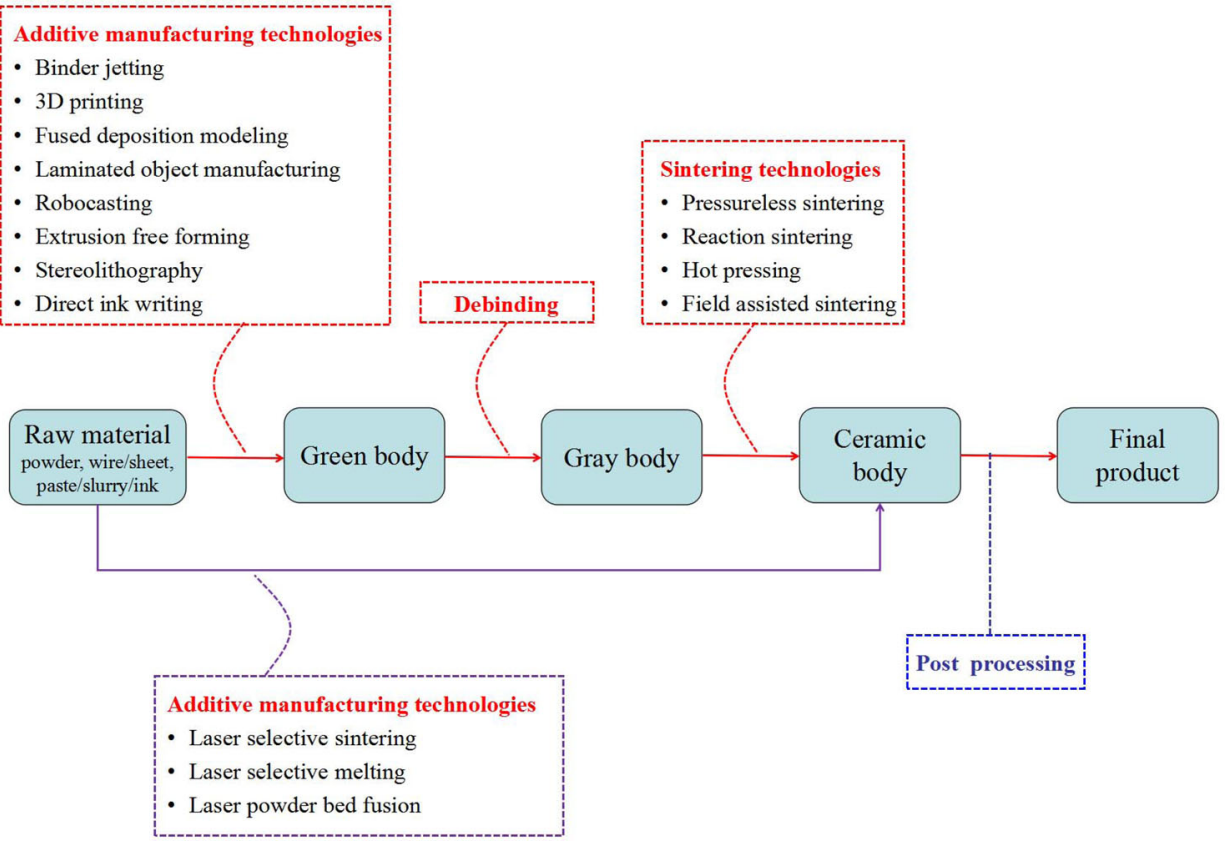

Fig. 7 Direct additive manufacturing of SiC ceramic. 
there is debinding or sintering mainly depends on which direct AM technology used. Specifically, the direct $\mathrm{AM}$ of $\mathrm{SiC}$ ceramic can be divided into different kinds according to the state of the used raw materials [6,12], as shown in Fig. 8: (1) Powder-based raw material: selective laser sintering (SLS), selective laser melting (SLM), laser powder bed fusion (LPBF), binder jetting (BJ), and 3D printing (3DP), etc. (2) Wire or sheet based raw material: fused deposition modeling (FDM), laminated object manufacturing (LOM), etc. (3) Paste-based raw material: robocasting, extrusion free forming (EFF), etc. (4) Slurry or ink based raw material: stereolithography (SL, usually including stereolithography apparatus, SLA, and digital light processing, DLP), direct ink writing (DIW), etc.

\section{1 Powder-based direct AM technologies}

\subsubsection{Selective laser sintering (SLS)}

The basic principle for the selective laser sintering (SLS) of SiC ceramic is shown in Fig. 9(a). Firstly, SiC

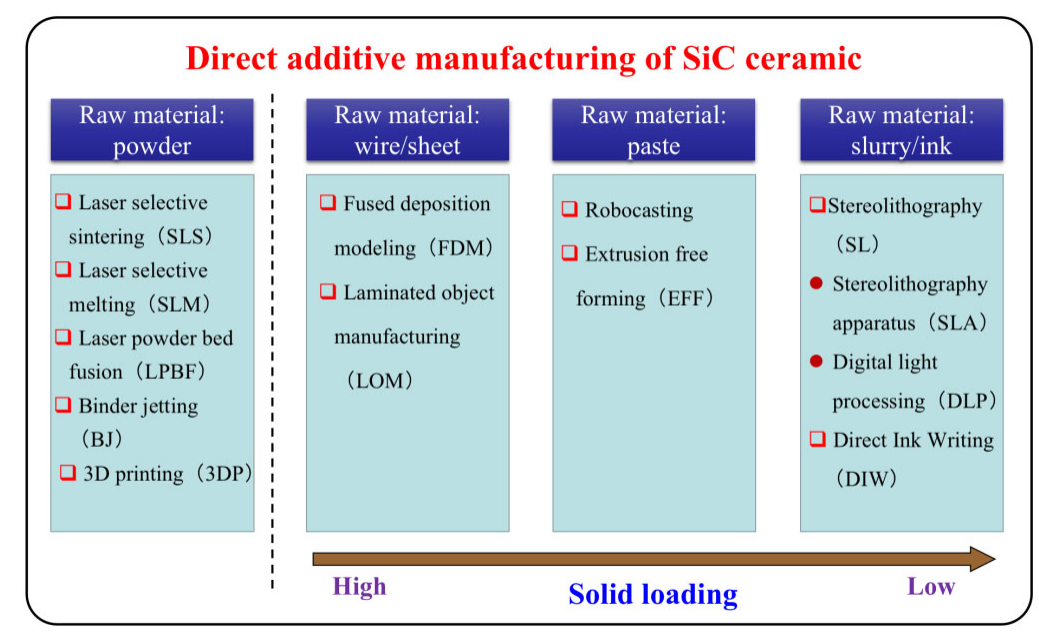

Fig. 8 Different direct $\mathrm{AM}$ technologies of $\mathrm{SiC}$ ceramic based on the state of the used raw materials.

a

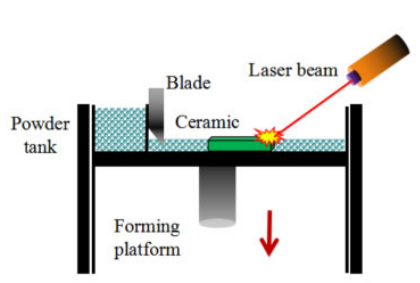

d
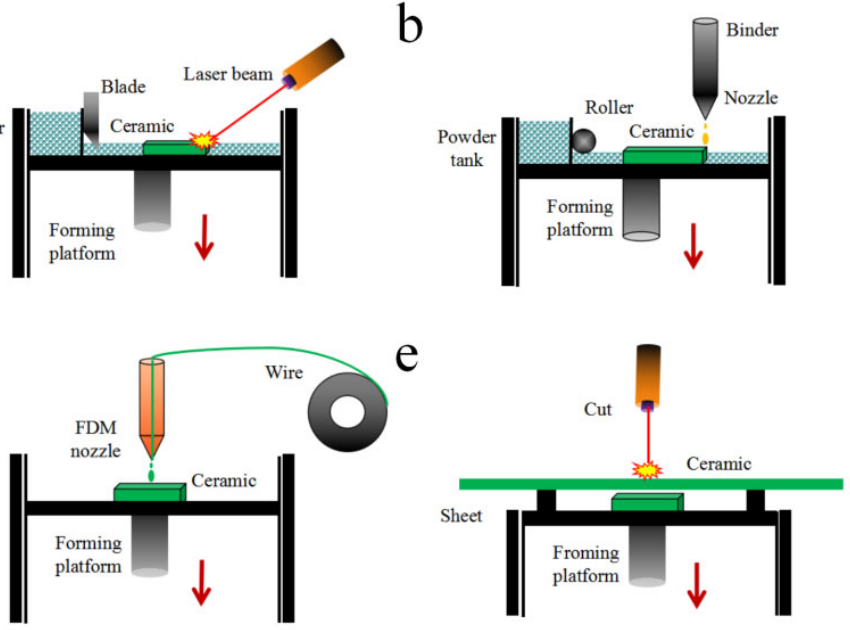

g

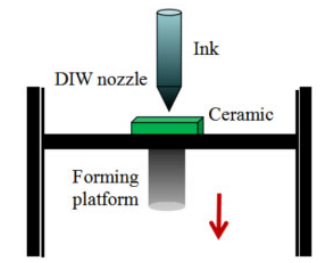

$\mathrm{h}$

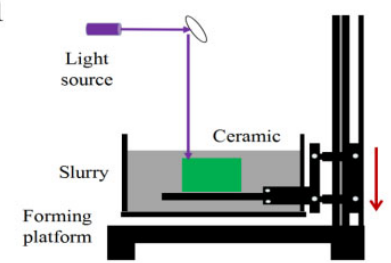

C

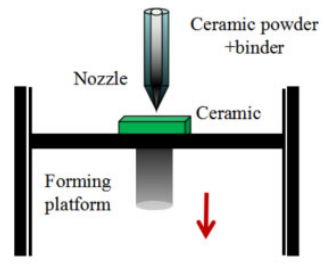

f

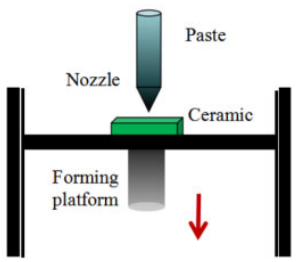

i

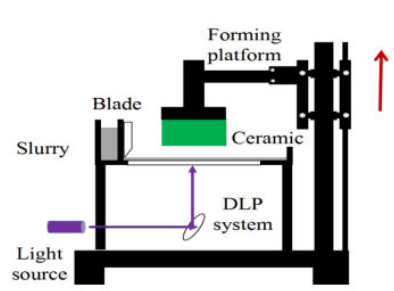

Fig. 9 Schematic drawing of various direct additive manufacturing technologies of SiC ceramic: (a) SLS, SLM, LPBF; (b) BJ; (c) 3DP; (d) FDM; (e) LOM; (f) robocasting, EFF; (g) DIW; (h) SLA; (i) DLP. 
powders are laid on the forming platform. Under the control of the AM program, the heat source (laser, plasma, etc.) moves according to the setting path to irradiate the ceramic powders. The temperature of the irradiated ceramic powders hence rises sharply to a temperature lower than the melting point (generally about $0.6-0.7$ times the melting point), and sintering is finally happened. Then, the ceramic powders are spread by a doctor blade and sintered layer by layer, and finally form a $3 \mathrm{D}$ complex-shaped $\mathrm{SiC}$ ceramic component.

As early as 1995, Nelson et al. [44] tried to coat PMMA polymer on the surface of $\mathrm{SiC}$ powders to reduce the sintering temperature. By using $\mathrm{CO}_{2}$ laser, a complex ring and frame-like shaped $\mathrm{SiC}$ ceramic component was prepared by SLS, as shown in Fig. 10(a). Moreover, they also explored the influences of laser power, scanning speed, laser beam diameter, scanning distance, and temperature on the SLS-prepared SiC ceramic. Evans et al. [45] also developed a novel SLS equipment in 2005, and got high-performance and complex-shaped $\mathrm{SiC}$ ceramic products through powder processing, SLS, low-temperature LSI, post-processing, and high-temperature LSI, as shown in Fig. 10(b).

However, the melting point of $\mathrm{SiC}$ ceramic is very high; therefore current laser power is difficult to make $\mathrm{SiC}$ ceramic powders reach the temperature of $0.6-0.7$ times the melting point. In order to enable $\mathrm{SiC}$ ceramic particles to be bonded with each other by laser, a low-melting phase (such as Si powder or other low melt point phases, etc.) is usually added into the $\mathrm{SiC}$ ceramic powders, or a low-melting phase (such as phenolic resin and other polymers, ceramic precursors, etc.) is used to coat on the surface of $\mathrm{SiC}$ ceramic particles. By adopting these approaches, the bonding between $\mathrm{SiC}$ ceramic powders can be realized by SLS. Exner et al. [46] developed an improved SLS method, called laser micro sintering (LMS), to further improve the surface quality of the as-prepared ceramic products. They successfully prepared high-quality, high-density $\mathrm{Si}-\mathrm{SiC}$ ceramic products by using LMS through adding $\mathrm{Si}$ powders into the $\mathrm{SiC}$ powders (as shown in Fig. 10(c)). Owing to the low density of the SLSprepared $\mathrm{SiC}$ ceramic, many technical approaches were tried to improve its density. Liu et al. [47] firstly used phenol formaldehyde resin (PF) coated $\mathrm{SiC}$ ceramic powders to prepare a $\mathrm{C}$-rich $\mathrm{SiC}$ ceramic body by using SLS. Then, the SiC ceramic body was processed through cold isostatic pressing and reaction sintering (RS) to promote its densification. Finally, a SiC ceramic
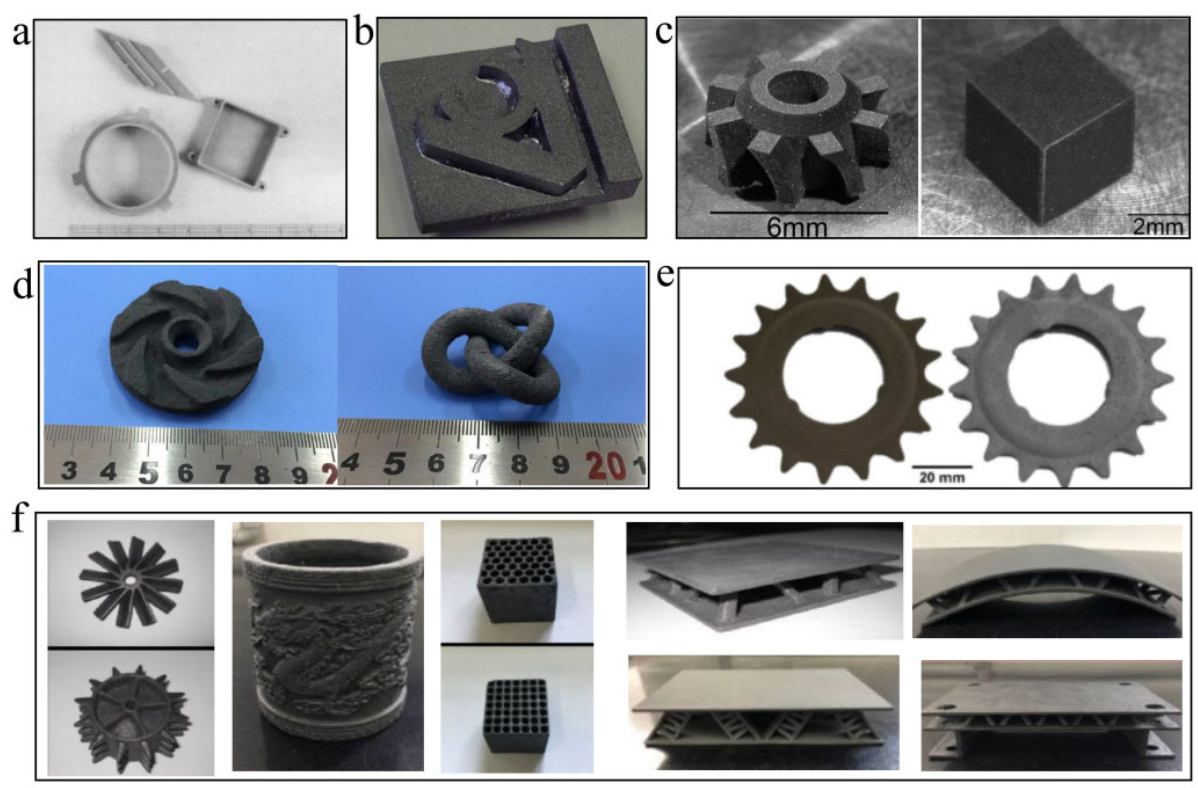

Fig. 10 SLS of SiC ceramic: (a) PMMA coated SiC powder, SLS. Reproduced with permission from Ref. [44], (C) American Chemical Society 1995. (b) SiC powder, SLS+high-temperature LSI. Reproduced with permission from Ref. [45], (C) Emerald Group Publishing Limited 2005. (c) SiC powder+Si powder, LMS. Reproduced with permission from Ref. [46], (C) Taylor \& Francis 2008. (d) PF coated SiC powder, SLS+CIP+RS. Reproduced with permission from Ref. [47], (C) Elsevier Ltd and Techna Group S.r.l. 2018. (e) SiC powder+Si powder, SLS+resin infiltration+LSI. Reproduced with permission from Ref. [49], (C) Elsevier Ltd. 2018. (f) $\mathrm{SiC}$ powder, SLS+PIP. Reproduced with permission from Ref. [50], (c) The American Ceramic Society 2019. 
with high density was realized, and its three-point bending strength reached up to $348 \mathrm{MPa}$. Complexshaped $\mathrm{SiC}$ ceramic components were also successfully prepared in their study, as shown in Fig. 10(d). In addition, $\mathrm{Fu}$ et al. [48] also used the mixture of phenolic resin-wrapped chopped carbon fibers and $\mathrm{Si}$ ceramic powders to prepare $\mathrm{C}$-rich chopped carbon fiber-reinforced $\mathrm{SiC}\left(\mathrm{C}_{\mathrm{f}} / \mathrm{SiC}\right)$ ceramic matrix composites through SLS. At last, $\mathrm{C}_{\mathrm{f}} / \mathrm{SiC}$ composites were obtained through some densification and sintering approaches, such as LSI.

Meyers et al. [49] used a powder mixture of $\mathrm{SiC}$ and $\mathrm{Si}$ to prepare Si-rich $\mathrm{SiC}$ ceramic body by using SLS. Then, phenolic resin was infiltrated into the SLSprepared SiC ceramic body and LSI was subsequently conducted. Finally, SiC ceramic gear products with high density and less residual $\mathrm{Si}$ were prepared, as shown in Fig. 10(e). Xu et al. [50] also used SLS to prepare $\mathrm{SiC}$ ceramic body, and finally obtained high-density $\mathrm{SiC}$ ceramic components after precursor infiltration and pyrolysis (PIP) process, as shown in Fig. 10(f). They further investigated the high temperature mechanical properties of the $\mathrm{SiC}$ ceramic, and found it had excellent high temperature strength. More interestingly, Sun et al. [51] used SiC ceramic powders as raw material, hollow $\mathrm{SiO}_{2}$ ceramic microspheres as filler, $\mathrm{Al}_{2} \mathrm{O}_{3}$ ceramic powders and kaolin as sintering aids, and E12 epoxy resin powders as adhesive, respectively. Then, they finally prepared a macromicro hierarchically porous $\mathrm{SiC}$ ceramic structure through SLS, as shown in Fig. 11.

In summary, the densification road-map for SLS of $\mathrm{SiC}$ ceramic is illustrated in Fig. 12. Simply, the SLS of $\mathrm{SiC}$ ceramic can generally be divided into three major stages, namely powder processing, SLS processing, and densification. Under normal circumstances, the sintering of $\mathrm{SiC}$ ceramic can be promoted by adding a low melting point phase (such as Si powders, etc.) into the $\mathrm{SiC}$ ceramic powders or coating a low melting point phase (such as phenolic resin and other polymers, ceramic precursors, etc.) on the surface of the $\mathrm{SiC}$ ceramic particles, thereby reducing the sintering temperature. However, the SLS-prepared SiC ceramic always faces deficiencies such as low density and poor mechanical properties. Therefore, it is necessary to adopt a suitable densification process to improve its density. Usually, typical densification technologies, including cold isostatic pressing (CIP), hot isostatic pressing (HIP), LSI, PIP, reactive infiltration (RS), chemical vapor deposition (CVD), and chemical vapor
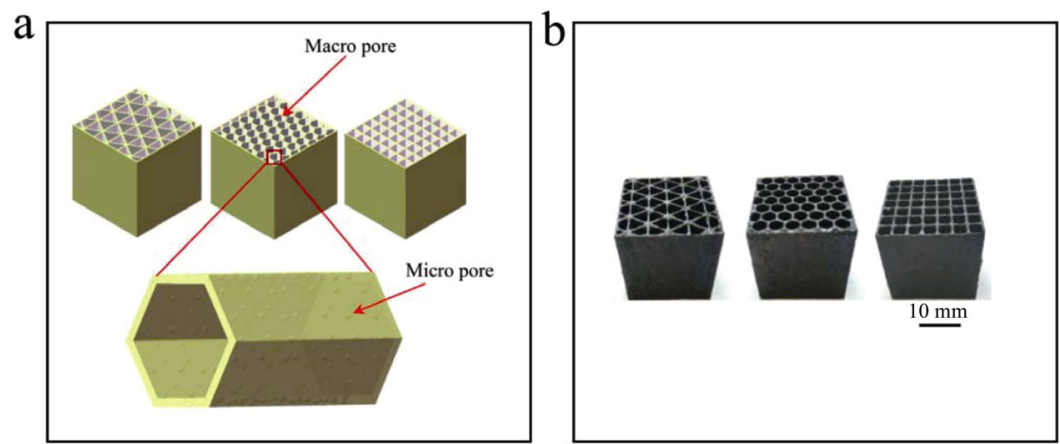

Fig. 11 (a) Schematic diagrams and (b) photographs of macro-micro hierarchically porous SiC structures prepared by SLS. Reproduced with permission from Ref. [51], (C) Elsevier Ltd and Techna Group S.r.1. 2020.

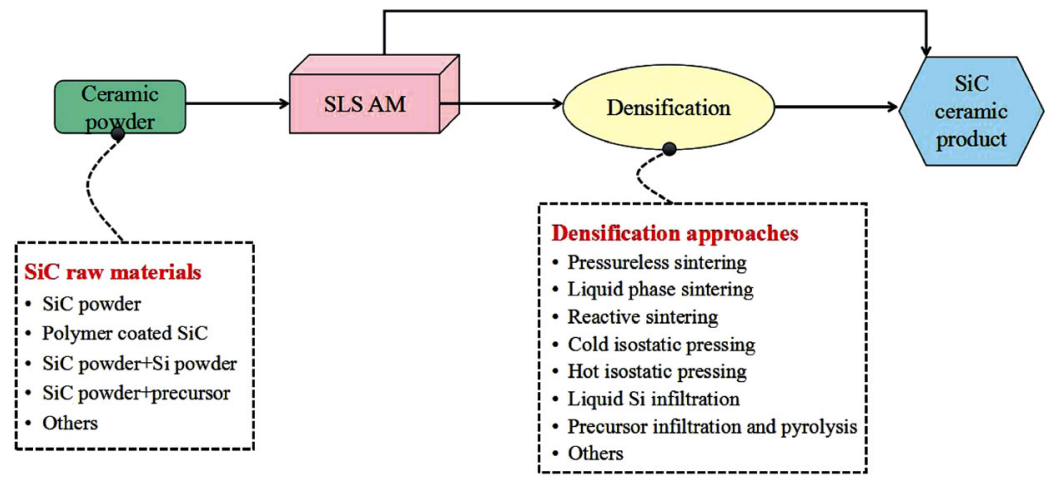

Fig. 12 Schematic drawing of the SLS of SiC ceramic. 
infiltration (CVI), were reported. Most importantly, some major issues involved in SLS of ceramics, including the balling phenomenon, the distribution of stress field caused by temperature gradient, and the limitation of printing accuracy caused by the fluidity of powder, are complicated and easily induced defects and cracks among the final ceramic products, which will finally affect the properties and the life of the ceramic products. How to avoid or control these issues is the main challenge towards the SLS of ceramics.

\subsubsection{Selective laser melting (SLM)}

The selective laser melting (SLM) of ceramic is similar to SLS, as shown in Fig. 9(a). Firstly, ceramic powders are laid on the forming platform. Under the control of the AM program, the heat source (laser, plasma, etc.) moves according to the setting path to irradiate the ceramic powders. The temperature of the irradiated ceramic powders rises sharply to its melting point. Then the ceramic powders are melted and finally formed to a compact after cooling. Then, the powders are laid, melted, and accumulated layer by layer. At last, the final ceramic product is produced. Till now, SLM has been reported to be applied to the manufacturing of ceramics with lower melting points (such as quartz, some oxide ceramics, etc.). However, due to the extremely high melting point of $\mathrm{SiC}$, it is very difficult to directly melt $\mathrm{SiC}$ ceramic particles together through current laser power. On the other words, it is very difficult to achieve bulk $\mathrm{SiC}$ ceramic by using SLM. That is the reason why there is merely report on the SLM of SiC ceramic and related materials. Interestingly, some scholars tried to prepare SiC coating by SLM. King et al. [52] reported the successful fabrication of $\mathrm{SiC}$ ceramic coating and $\mathrm{ZrB}_{2}-\mathrm{ZrC}-\mathrm{B}_{4} \mathrm{C}$ ultra-high temperature ceramic coatings by using SLM, as shown in Fig. 13(a), and they studied the effects of laser power on the microstructure and performance of the as-prepared coatings in detail.

\subsubsection{Laser powder bed fusion (LPBF)}

The mechanism for the laser powder bed fusion (LPBF) of ceramic is also similar to SLS or SLM, as shown in Fig. 9(a). However, just as mentioned above, due to the extremely high melting point of $\mathrm{SiC}$, it is very difficult to directly fuse $\mathrm{SiC}$ ceramic particles by means of the current laser power. Therefore, previous reports were mainly about the LPBF fabrication of composites consisted of $\mathrm{SiC}$ and metals. The relatively low melting point of metal among the composite make the LPBF becomes possible. Wits et al. [53] added $\mathrm{SiC}$ ceramic particles into magnesium alloy (WE43), and
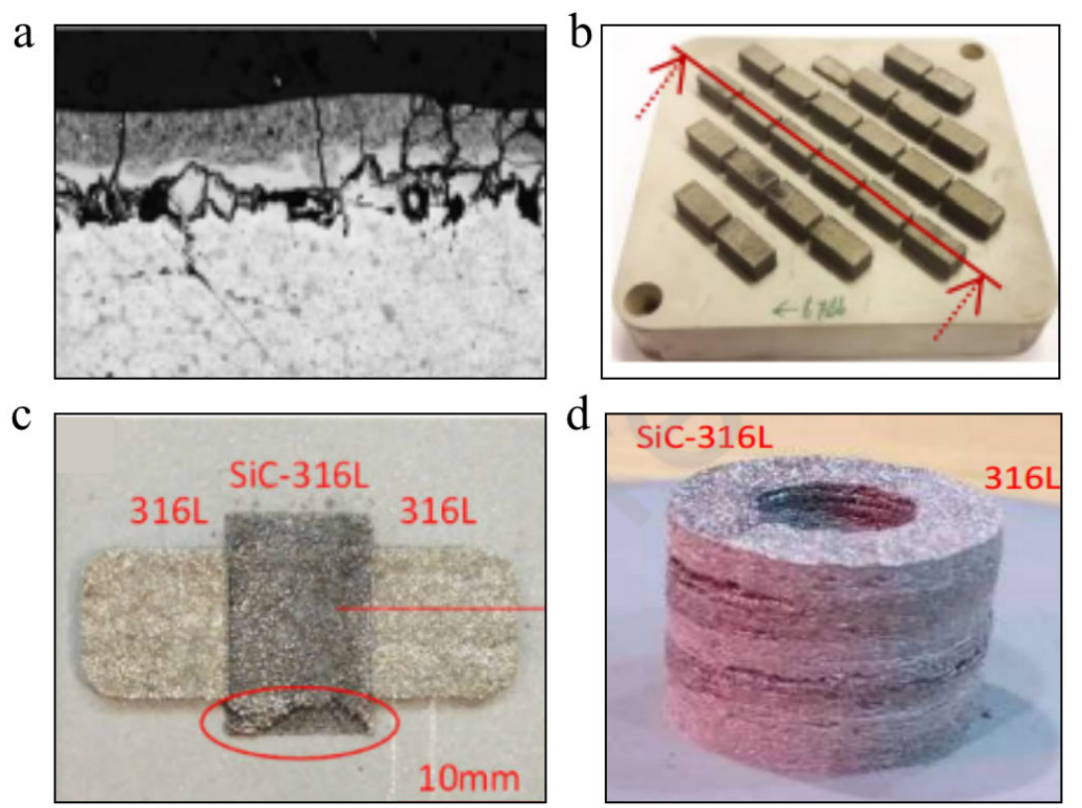

Fig. 13 SLM and LPBF of SiC ceramic: (a) SLS of SiC coating. Reproduced with permission from Ref. [52], (C) Elsevier Ltd and Techna Group S.r.1. 2018. (b) LPBF of SiC-Mg metal matrix composite. Reproduced with permission from Ref. [53], (C) The Author(s) 2019. (c) LPBF of SiC-316L metal matrix composite. Reproduced with permission from Ref. [54], (C) ASME International 2019. (d) LPBF and SLM of SiC-Mg metal matrix composite. Reproduced with permission from Ref. [55], C) Elsevier B.V. 2020. 
successfully prepared $\mathrm{SiC}-\mathrm{Mg}$ metal matrix composites by using LPBF, as shown in Fig. 13(b). And they further investigated the influences of the powder sphericity, morphology, and fluidity on the microstructure and performance of the LPBF-prepared $\mathrm{SiC}-\mathrm{Mg}$ composite. Wei et al. [54] also tried to add $\mathrm{SiC}$ ceramic particles to $316 \mathrm{~L}$ stainless steel, and successfully prepared SiC-316L composites by using LPBF, as shown in Fig. 13(c). During the preparation, they innovatively used ultrasonic vibration and mechanical vibration to improve the fluidity of the powder bed. And they also discussed the influences of different $\mathrm{SiC}$ particles on the microstructure of the LPBF-prepared $\mathrm{SiC}-316 \mathrm{~L}$ composite. They also reported the manufacturing of SiC-316L composite through a combination of LPBF and SLM, as shown in Fig. 13(d) [55].

However, most of the above reported work was focused on the manufacturing of metal matrix composites. Due to the extremely high melting point of $\mathrm{SiC}$ ceramic, both its melting and fusion are difficult to achieve, so there is merely no report on the fabrication of pure $\mathrm{SiC}$ ceramic by using LPBF or SLM.

\subsubsection{Binder jetting (BJ)}

The schematic mechanism for binder jetting (BJ) of ceramic is illustrated in Fig. 9(b). During BJ, a layer of ceramic powders is laid on the forming platform firstly through a blade. Then, a special adhesive is sprayed through the nozzle to the setting points. After that, the platform is lowered, and the powder continues to be laid and the adhesive continues to spray. After repeating for several cycles, a 3D ceramic green body is formed on the forming platform, and the final ceramic is obtained after following debinding and sintering.

$\mathrm{Lv}$ et al. [56] reported a porous $\mathrm{SiC}$ whisker preform by using $\mathrm{BJ}$ from $\mathrm{SiC}$ whisker raw materials. Then, $\mathrm{SiC}$ matrix was introduced into the porous preform through CVI. At last, $\mathrm{SiC}_{\mathrm{w}} / \mathrm{SiC}$ ceramic matrix composite gear products were successfully obtained, as shown in Fig. 14(a). In addition, the influences of the $\mathrm{SiC}$ whiskers on the porosity, microstructure, and mechanical properties of the final $\mathrm{SiC}_{\mathrm{w}} / \mathrm{SiC}$ ceramic matrix composite were investigated and discussed in detail. However, the reported mechanical properties of the $\mathrm{SiC}_{\mathrm{w}} / \mathrm{SiC}$ ceramic matrix composite were still relatively low. The three-point bending strength was only about $200 \mathrm{MPa}$ and the fracture toughness was as low as $3.4 \mathrm{MPa} \cdot \mathrm{m}^{1 / 2}$. Baux et al. [57] prepared a macroporous $\mathrm{SiC}$ ceramic framework by using BJ. Then, a combination process of CVD and CVI was used to obtain the final large-pored $\mathrm{SiC}$ ceramic component, as shown in Fig. 14(b). Besides, advanced characterization methods, such as micro computed tomography (micro-CT), high-speed camera, etc., were applied to evaluate the defects among the ceramic and assess its performance. Fleisher et al. [58] also used BJ to prepare $\mathrm{SiC}$ ceramic green body, and then obtained reactive bonded $\mathrm{SiC}$ ceramic (RBSC) by using phenolic resin binder
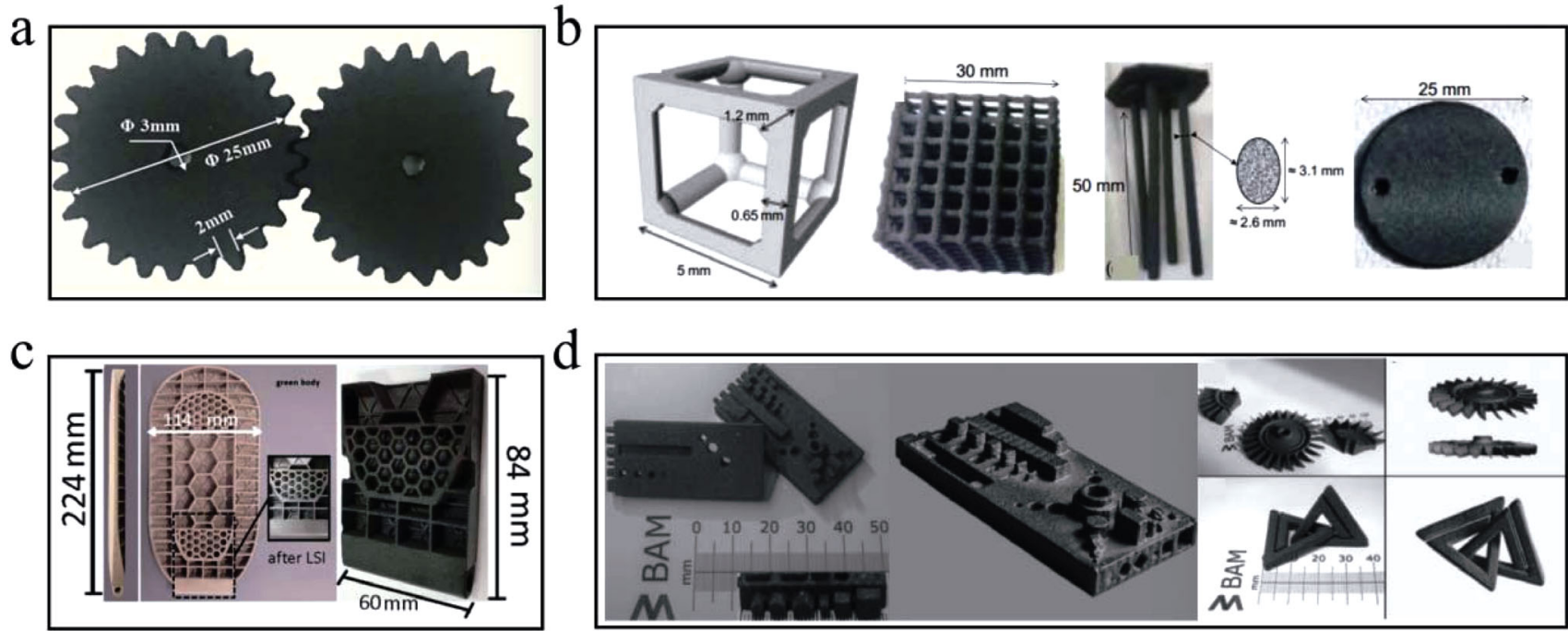

Fig. 14 BJ of SiC ceramic: (a) BJ combined with CVI. Reproduced with permission from Ref. [56], (C) Elsevier Ltd. 2019. (b) BJ combined with CVI and CVD. Reproduced with permission from Ref. [57], (C) Elsevier Ltd. 2020. (c) BJ combined with PRBI and CLSI. Reproduced with permission from Ref. [58], (C) Elsevier Ltd and Techna Group S.r.1. 2019. (d) LSD combined with BJ. Reproduced with permission from Ref. [59], C Elsevier Ltd. 2019. 
impregnation (PRBI) combined with capillary liquid silicon infiltration (CLSI), as shown in Fig. 14(c). They further discussed the influences of the phenolic resin addition and CLSI processing parameters on the microstructure and mechanical properties of the RBSC ceramic. It was also reported that Zocca et al. [59] once prepared complex-shaped $\mathrm{SiSiC}$ ceramic products by using an innovative method combined layerwise slurry deposition (LSD) with BJ, as shown in Fig. 14(d).

However, BJ-prepared SiC ceramic usually faces the disadvantage of low density and low strength. Usually, BJ-prepared SiC ceramic has many defects among the body and exhibits poor shape accuracy. Subsequent densification processes (such as CVI, CVD, CLSI, PIP, etc.) after BJ will inevitably cause a large number of material defects. Figures 15(a) and 15(b) show the non-destructive micro-CT scanning images of $\mathrm{SiC}$ ceramic lattice structures prepared through $\mathrm{BJ}$ followed by PIP and CVI/CVD, respectively [57]. It can be clearly found that there are a large number of manufacturing defects among the ceramic, which will greatly affect the performance of the $\mathrm{SiC}$ ceramic.

\subsubsection{D printing $(3 D P)$}

The procedure for the $3 \mathrm{D}$ printing (3DP) of ceramic is presented in Fig. 9(c). Here, the concept of 3DP is specific to one certain category of various additive manufacturing technologies, rather than the abbreviation of additive manufacturing. During the 3DP process, a ceramic slurry with high solid content and certain viscosity is firstly prepared from ceramic powder and adhesive. Then, the slurry is extruded by a mechanical or gas pressure device through a nozzle with a specific diameter, and subsequently deposited on the forming platform. After that, the nozzle lifts up and down to extrude and deposit layer by layer to form a three-dimensional ceramic green body. At last, ceramic
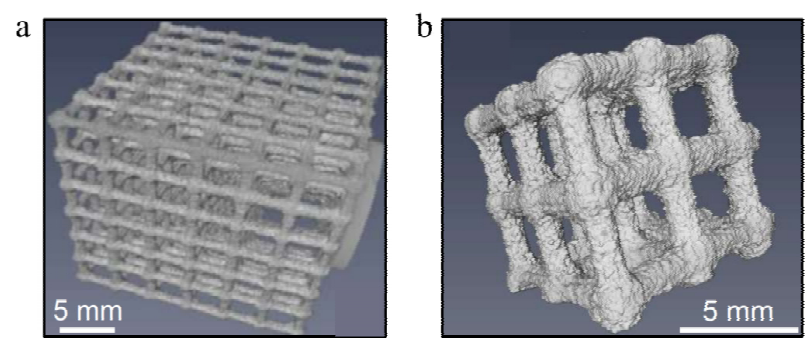

Fig. 15 Micro-CT images of $\mathrm{SiC}$ ceramic: (a) BJ combined with PIP; (b) BJ combined with CVI and CVD. Reproduced with permission from Ref. [57], (C) Elsevier Ltd. 2020. product is finally produced after high temperature debinding and sintering.

Zhu et al. [60] used 3DP to prepare $\mathrm{SiC}$ ceramic green bodies, and subsequently impregnated the green bodies by using polycarbosilane (PCS) precursor, a mixture of polycarbosilane (PCS) and StarPCS SMP-10 precursors, and a mixture of StarPCS SMP-10 and nano-sized $\mathrm{SiC}$ particles, respectively. After impregnation, final $\mathrm{SiC}$ ceramic was obtained after pyrolysis at high temperature. The effect of the precursor composition on the microstructure of the $\mathrm{SiC}$ ceramic was discussed in detail. It was also reported that Polzin et al. [61] prepared porous $\mathrm{SiC}$ ceramic by using 3DP combined with following debinding, liquid phase sintering, and high temperature re-crystallization process, as shown in Fig. 16(a). In addition, for some 3DP studies, SiC ceramic was often used as the second phase. Duan et al. [62] once prepared in-situ $\mathrm{SiC}$ nanowire reinforced $\mathrm{Si}_{3} \mathrm{~N}_{4}$ ceramic by using 3DP combined with PIP method, as shown in Fig. 16(b). The in-situ generation of $\mathrm{SiC}$ nanowires achieved good strengthening and toughening effects, and interestingly, the as-prepared $\mathrm{SiC}_{\mathrm{nw}} / \mathrm{Si}_{3} \mathrm{~N}_{4}$ ceramic exhibited excellent microwave absorption performance.

However, as shown in Fig. 16(a), the 3DP-preprared $\mathrm{SiC}$ ceramic generally has poor shape accuracy and surface performance. In recent years, with the development and progress of 3DP equipment and technology, the accuracy of the 3DP-prepared materials are having promising improvement, but it still cannot meet the accuracy requirements in some special service environment. Meanwhile, the 3DP-preprared $\mathrm{SiC}$ ceramic always faces the shortcomings of obvious inter-layer interface, low density, and poor mechanical properties, which severely restrict its development and engineering application.
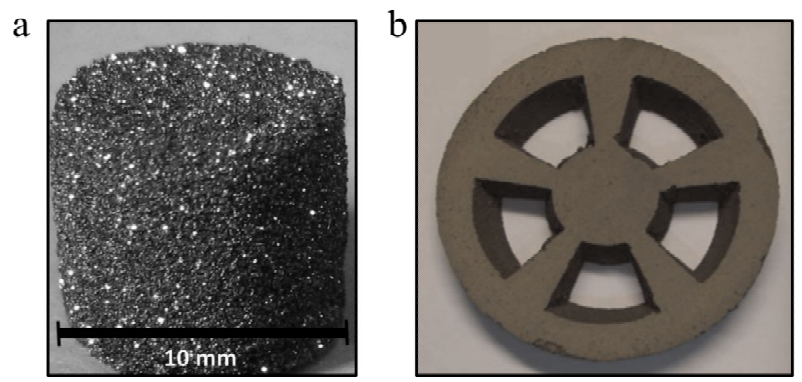

Fig. 16 3DP of $\mathrm{SiC}$ ceramic: (a) Porous $\mathrm{SiC}$ ceramic. Reproduced with permission from Ref. [61], (C) Göller Verlag 2015. (b) $\mathrm{SiC}_{\mathrm{nw}} / \mathrm{Si}_{3} \mathrm{~N}_{4}$ ceramic. Reproduced with permission from Ref. [62], (c) Elsevier B.V. GmbH 2015. 


\section{2 Wire or sheet based direct AM technologies}

\subsubsection{Fused deposition modeling (FDM)}

Imitating the fused deposition modeling (FDM) of polymers, the FDM of $\mathrm{SiC}$ ceramic from $\mathrm{SiC}$ wire is shown in Fig. 9(d). Firstly, through a specific process, $\mathrm{SiC}$ ceramic powder is mixed with a polymer material and formed into a thermoplastic polymer-ceramic wire with a certain diameter. Next, the as-prepared $\mathrm{SiC}$ wire is placed in an FDM equipment, and extruded from the nozzle heated by the equipment. The thermoplastic $\mathrm{SiC}$ wire is melt-deposited on the equipment's forming platform, and cooled rapidly to solidify and form a solid. Then, the forming platform is lowered, and the $\mathrm{SiC}$ ceramic green body is finally formed after several fusion and deposition cycles. At last, SiC ceramic components are obtained after debinding and sintering at high temperatures.

Singh et al. [63] mixed $\mathrm{Al}_{2} \mathrm{O}_{3}$ and $\mathrm{SiC}$ ceramic particles with high-density waste recycled polyethylene, and formed into polymer-ceramic wires (as shown in Fig. 17(a)). After that, flexible mold with good mechanical properties was fabricated by using FDM from the polymer-ceramic wires, as shown in Fig. 17(b). The schematic drawing of the FDM equipment is given in Fig. 17(c). Then, the flexible mold was used to prepare a casting mold through sacrificial method, and metal casting was subsequently conducted. It was found that the addition of ceramic particles greatly improved the mechanical properties of the polymerceramic wires, and finally obtained a mold with higher precision, higher mechanical properties, and flexibility.
However, it should be pointed out that the reported FDM [63] was not a real ceramic since the amount of ceramic added was small and there was even no sintering process. Masuda et al. [64] also successfully mixed water-soluble resole phenolic resin with $\mathrm{SiC}$ ceramic particles to prepare polymer-ceramic wires. Then FDM was conducted based on the polymerceramic wires, and the effects of polymer-ceramic viscosity, $\mathrm{SiC}$ ceramic particle type and composition, forming angle, forming shape, and other processing parameters on the properties of the FDM-prepared material were discussed in detail, as shown in Fig. 17(d). Finally, "unsupported" SiC ceramic components were obtained through FDM (as shown in Fig. 17(d)). However, typical key issues, including the debinding and sintering process, especially the densification and strengthening, of the FDM-prepared product were not studied in their work.

However, the FDM process generally requires mixing and co-smelting ceramic particles with thermoplastic polymers, and finally drawing them into polymerceramic wires. This step greatly increases the processing difficulty and cost, and also limits the types of ceramic materials. Report on the manufacturing of $\mathrm{SiC}$ ceramic by FDM is still rare. In addition, during FDM, the fused deposition morphology of the polymer-ceramic wire is also affected by many factors, and its accuracy is relatively low [64], which also greatly restricts its applications for the fabrication of $\mathrm{SiC}$ ceramic.

\subsubsection{Laminated object manufacturing (LOM)}

Figure 9(e) shows the laminated object manufacturing
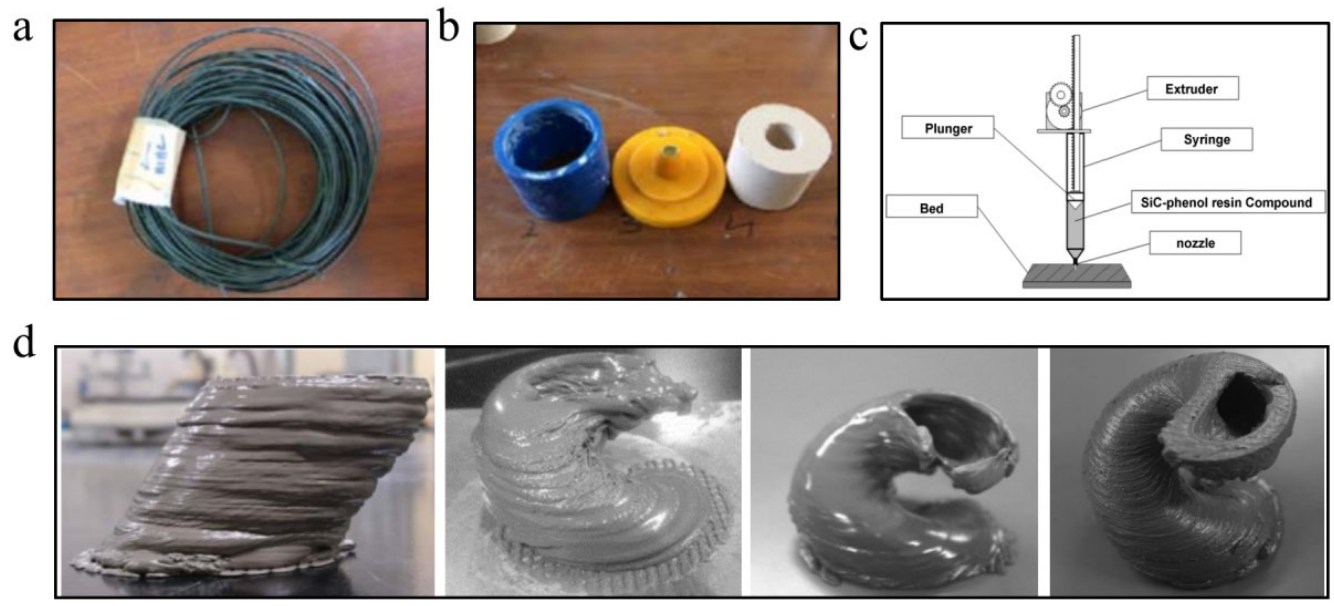

Fig. 17 FDM of SiC ceramic: (a) Filament wires, (b) flexible molds. Reproduced with permission from Ref. [63], (C) IOP Publishing Ltd. 2019. (c) FDM equipment, (d) effects of forming angle during FDM. Reproduced with permission from Ref. [64], (C) Authors and Scientific Research Publishing Inc. 2020. 
(LOM) procedure of SiC ceramic. The LOM process generally contains the following steps: Firstly, layered ceramic sheets or tapes are prepared by using traditional methods, such as casting, roll molding, and so on. Then, the ceramic sheets or tapes are cut into desired shapes for each layer, and subsequently stacked together lay by layer on the forming platform to form the as-designed 3D ceramic green body. Finally, the final ceramic product is achieved after high-temperature debinding and sintering. At present, however, research on the LOM of SiC ceramic is rare. As early as 2007, Travitzky et al. [65] prepared a sheet-like water-based ceramic paper tape with an average thickness of about $240 \mu \mathrm{m}$ from a mixture of $76.8 \mathrm{wt} \% \mathrm{SiC}$ ceramic powder, $20 \mathrm{wt} \%$ cellulose pulp, and $3.2 \mathrm{wt} \%$ binder, as shown in Fig. 18(a). Then, SiC ceramic green body was produced by using LOM based on these sheet-like water-based ceramic paper tapes. And $\mathrm{Si}-\mathrm{SiC}$ ceramic was finally obtained after debinding and LSI [66]. The microscopic observation showed that the pores among the ceramic body were basically filled by the chemical reaction generated $\mathrm{SiC}$ particles, and there was only a part of Si remaining along the interface between each layer (as shown in Fig. 18(b)). Besides, Travitzky et al. also discussed the relationship between the stacking direction during LOM and the mechanical properties of $\mathrm{Si}-\mathrm{SiC}$ ceramic in detail.

Unfortunately, however, LOM technology has obvious technical disadvantages. The ceramic sheet required for LOM must be obtained through other traditional methods in the early stage, which increases the processing complexity, time cost, and material cost. In addition, the performance of the ceramic material formed by LOM is also greatly affected by the interface between each layer. Technical problems, such as layer separation, high interface porosity, and large difference in shrinkage between layers, are easily found for LOM-prepared ceramic.

\section{3 Paste-based direct AM technologies}

\subsubsection{Robocasting}

Figure 9(f) shows the robocasting of ceramics. The process of robocasting generally contains the following steps. Firstly, ceramic raw materials with solvents, dispersants, and other phases are mixed together to prepare a high solid loading ceramic paste, and then the paste is extruded through a nozzle by means of mechanical extrusion or air pressure to form a 3D shape. After that, ceramic green body is obtained. At last, the green body is debinded and sintered at high temperature to achieve the final ceramic product. Cai et al. [67] used robocasting to prepare 3D complexshaped SiC ceramic structures as early as 2012, and then realized the sintering of $\mathrm{SiC}$ ceramic with the help of low-temperature SPS process (as shown in Fig. 19(a)). They discussed the influences of SiC paste preparation, zeta potential, $\mathrm{pH}$ value, viscosity, rheological properties, robocasting processing parameters, and SPS temperature on the microstructure and macrostructure of the final complex-shaped $\mathrm{SiC}$ ceramic in detail. Wahl et al. [68] also developed a $\mathrm{SiC}$ ceramic paste containing $\mathrm{C}$, then used robocasting to prepare a $\mathrm{SiC} / \mathrm{C}$ ceramic green body, and finally achieved a $\mathrm{SiC}$ ceramic by using reaction sintering and LSI, as shown in Fig. 19(b). Interestingly, Feilden et al. [69] even successfully prepared a $\mathrm{HfB}_{2}$-based ultrahigh temperature ceramic (UHTC) green body by robocasting, and finally obtained $\mathrm{HfB}_{2}$-based UHTC components after debinding and pressureless sintering, as shown in Fig. 19(c). And they also summarized the development history and trend of ceramic green bodies from traditional plastic molding to robocasting in their paper [70]. It was found that some key issues, such as viscosity, processing parameters, shape geometry, and sintering, greatly affected the final ceramic product. Finally, complex-shaped $\alpha-\mathrm{SiC} / \mathrm{B}_{4} \mathrm{C}$ ceramic parts were
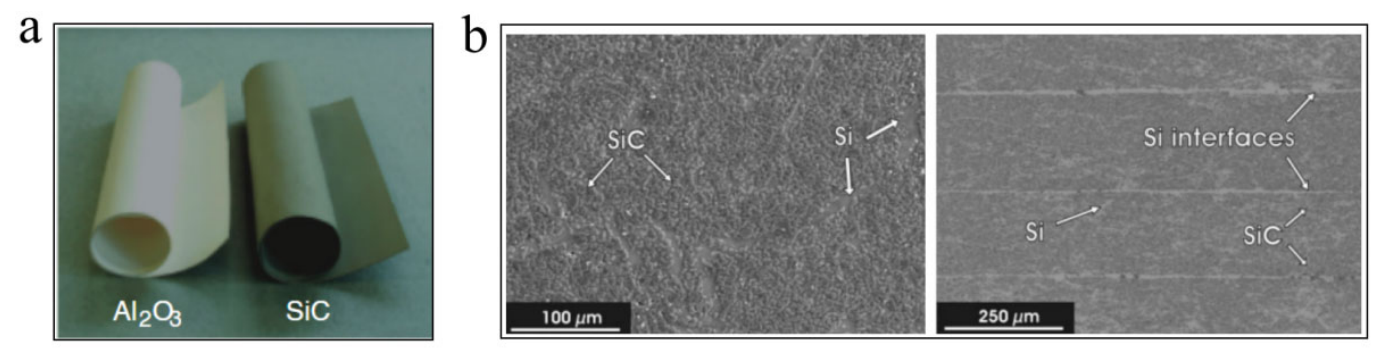

Fig. 18 LOM fabricated SiC ceramic: (a) Preceramic papers. Reproduced with permission from Ref. [65], (C) The American Ceramic Society 2008. (b) Layer-by-layer microstructure. Reproduced with permission from Ref. [66], (C) WILEY - VCH Verlag GmbH \& Co. KGaA, Weinheim 2007. 


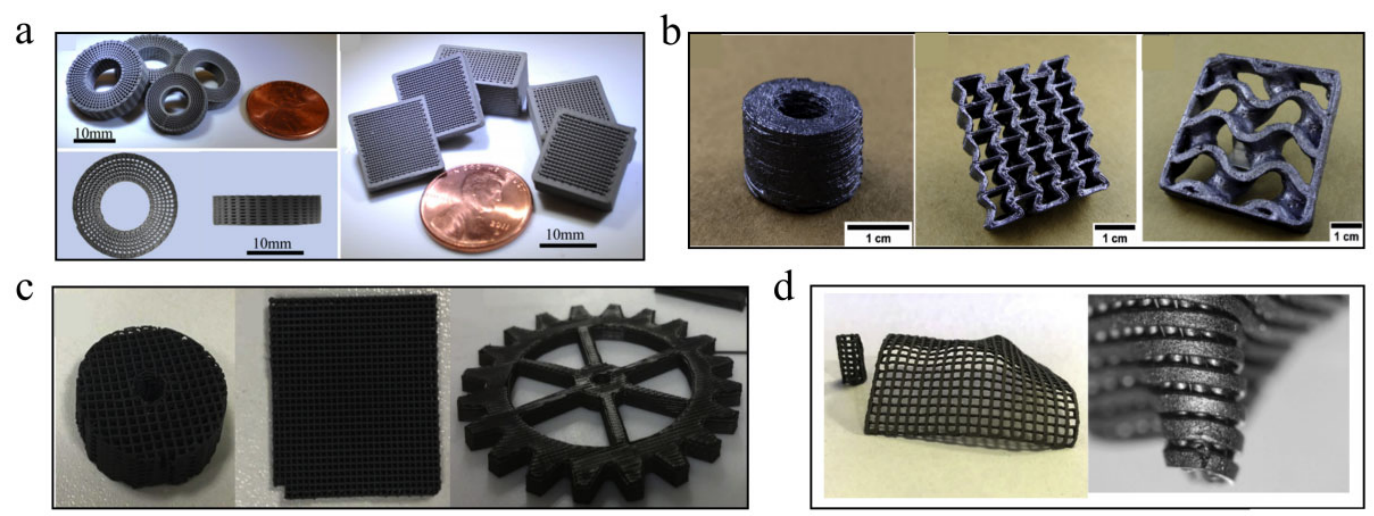

Fig. 19 Robocasting of SiC ceramic: (a) Robocasting + SPS. Reproduced with permission from Ref. [67], (C) The American Ceramic Society 2012. (b) Robocasting + pressureless sintering. Reproduced with permission from Ref. [68], (C) Elsevier Ltd. 2019. (c) Robocasting manufactured ultra-high temperature ceramic. Reproduced with permission from Ref. [69], (C) Elsevier Ltd. 2019. (d) Robocasting manufactured $\alpha-S i C / B_{4} \mathrm{C}$ ceramic. Reproduced with permission from Ref. [70], C Elsevier Ltd. 2019.

successfully prepared, as shown in Fig. 19(d), which further demonstrate the unique advantages and capabilities of robocasting for the manufacturing of complex-shaped ceramics.

Robocasting has been widely used for the additive manufacturing of ceramics due to its unique advantages, such as low equipment requirements and simple process. However, the precision and shape accuracy of the Robocasting-prepared products are relatively low because the equipment and the manufacturing controlling are relatively simple. Ceramic components with high accuracy and excellent surface quality are always difficult to realize by using robocasting. Besides, robocasting usually requires the preparation of ceramic pastes with high solid loading and excellent rheological properties firstly, which also brings certain technical difficulties and scientific challenges.

\subsubsection{Extrusion free forming (EFF)}

The extrusion free forming (EFF) technology of ceramics, also named as filament printing or layered extrusion forming, is illustrated in Fig. 9(f). Actually, the principles of EFF and robocasting are basically the same, except that researchers give them different definition names. Generally, the process of EFF has three steps: Firstly, ceramic paste or slurry with high solid loading is prepared from ceramic raw materials mixed with solvents, dispersants, and so on. Then, the ceramic paste or slurry is extruded through a nozzle by means of mechanical extrusion or air pressure. After extrusion, a 3D ceramic green body is obtained, and the final ceramic products are obtained through hightemperature debinding and sintering.

Gómez-Gómez et al. [71] used EFF to prepare a 3D $\mathrm{SiC}$ ceramic green body, and finally achieved a porous hierarchical pore structured $\mathrm{SiC}$ ceramic component with a total porosity of $65 \%-85 \%$ through partial SPS method, as shown in Fig. 20(a). After that, they used a flame test to explore the possibility of its application as a new type of thermal protection material, as shown in Fig. 20(b). Besides, they also used EFF to prepare an ordered $3 \mathrm{D}$ porous $\mathrm{SiC}$ structure (as shown in Fig. 20(c)), and further explored the influences of the skeleton distribution and rod orientation on its mechanical properties in detail. And it was found that the $3 \mathrm{D}$ porous $\mathrm{SiC}$ ceramic structure had better specific strength and specific stiffness compared with traditional ceramic structures.

Most importantly, EFF can effectively realize the manufacturing of short fiber reinforced $\mathrm{SiC}$ ceramic matrix composites. By adding short fibers, such as chopped carbon fibers, into the $\mathrm{SiC}$ ceramic paste, $\mathrm{SiC}$ ceramic matrix composite reinforced by chopped carbon fibers can be obtained by EFF and sintering. What is particularly interesting is that when chopped carbon fibers are extruded through the EFF nozzle, the chopped carbon fiber will show an excellent orientation characteristic of directional arrangement due to the shearing effect during extrusion, as shown in Fig. 21, which is conducive to the fabrication of anisotropic chopped carbon fiber reinforced $\mathrm{SiC}$ ceramic matrix composites to achieve reinforcement in a specific direction. Zhang et al. [72] once used $\mathrm{SiC}$ ceramic 

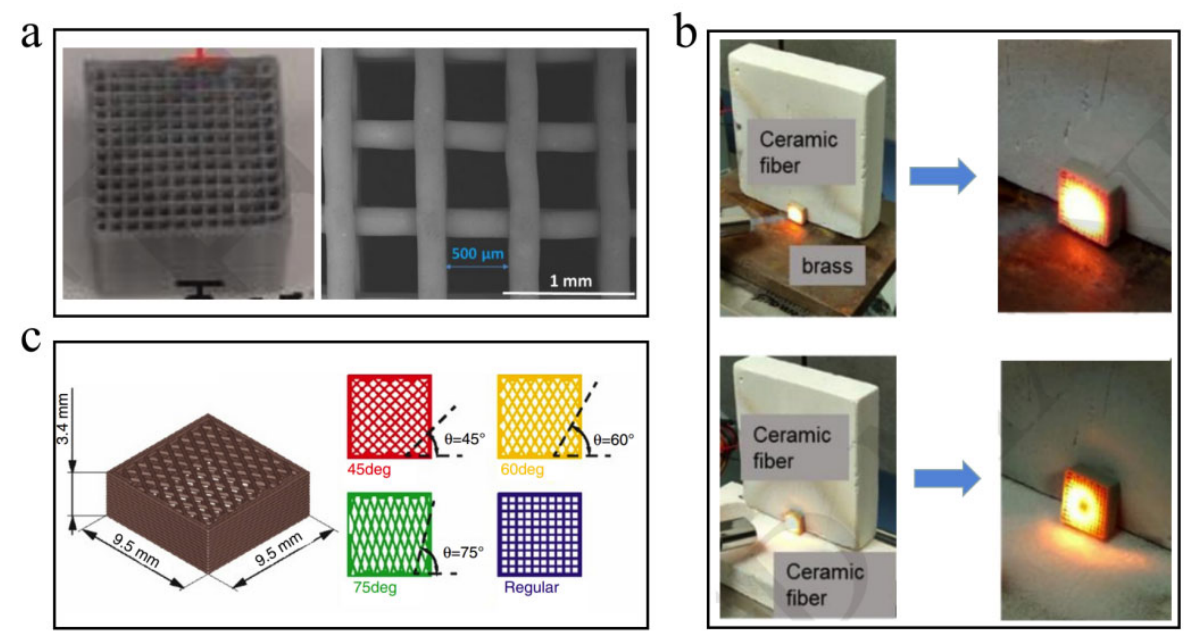

Fig. 20 EFF of $\mathrm{SiC}$ ceramic (a) highly-porous hierarchical SiC structures; (b) thermal protection application; (c) effects of rod orientation. Reproduced with permission from Ref. [71], (C) SECV 2020.

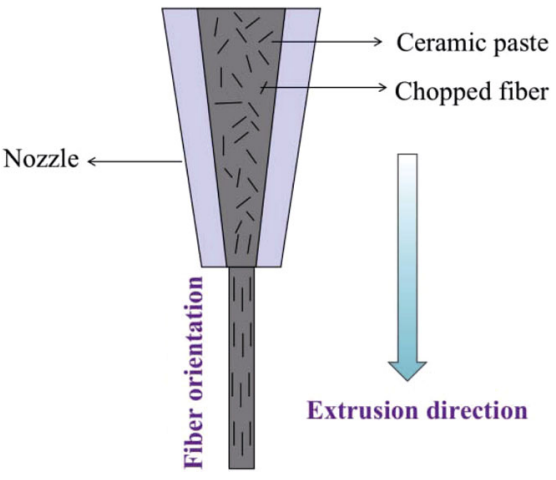

Fig. 21 Chopped carbon fiber orientation during EFF.

particles, carbon black, and chopped carbon fibers as raw materials to prepare ceramic paste. Then, chopped carbon fiber reinforced $\mathrm{SiC}$ ceramic matrix composites $\left(\mathrm{C}_{\mathrm{sf}} / \mathrm{SiC}\right)$ were prepared by EFF, LSI, and sintering, as shown in Fig. 22(a). It was found that the chopped carbon fiber among the $\mathrm{C}_{\mathrm{sf}} / \mathrm{SiC}$ composite presented an obvious orientation distribution behavior, and the maximum bending strength of the composite reached up to $300 \mathrm{MPa}$. A similar study was also reported by McClain et al. [73]. This research team used ceramic precursors mixed with $45 \mathrm{wt} \%$ chopped carbon fibers and $10 \mathrm{wt} \%$ carbon black to prepare a ceramic precursor paste. After EFF and high temperature pyrolysis, they successfully prepared chopped carbon fiber reinforced $\mathrm{SiC}$ ceramic matrix composites, as shown in Fig. 22(b). These studies demonstrated the possibility of the EFF for manufacturing fiber-reinforced ceramic matrix composite nozzle structures.

Similar to robocasting, EFF has the advantages of low equipment requirements, simple processes, and strong material applicability; therefore, it has received more and more research for the additive manufacturing of ceramic. However, for EFF, its manufacturing precision is always relatively limited, and there are many difficulties when manufacturing ceramic with high quality and complex geometries. In addition, EFF also requires ceramic pastes with high solid loading and excellent rheological properties, which also brings

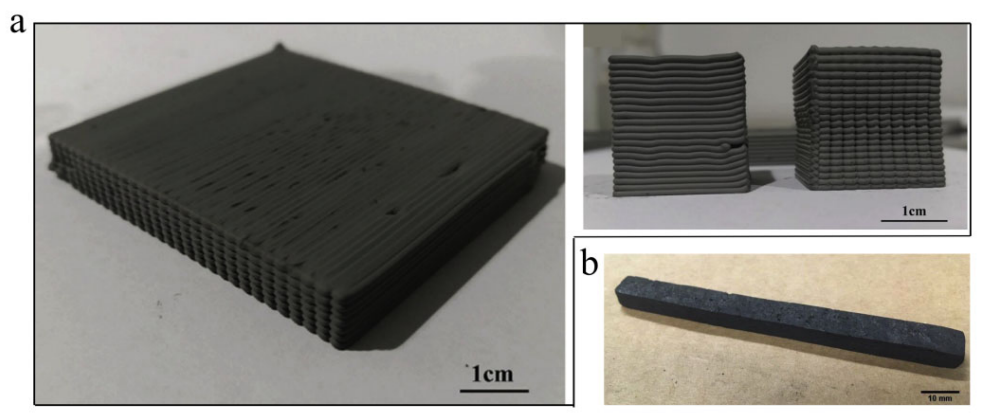

Fig. 22 EFF of SiC ceramic: (a) Work published by Zhang et al. Reproduced with permission from Ref. [72], (C) Elsevier Ltd and Techna Group S.r.1. 2019. (b) Work published by McClain et al. Reproduced with permission from Ref. [73], (C) Monique Suzanne McClain 2019. 
technical difficulties and scientific challenges.

\section{4 Slurry or ink based direct AM technologies}

\subsubsection{Stereolithography (SL)}

The stereolithography (SL) technology of ceramics, which is drawn by the polymer light curing technology, is one of the most promising ceramic additive manufacturing technologies that have been developed in recent years. The general process of SL of ceramic is consisted of the following stages. Firstly, photosensitive ceramic-resin slurry with high solid loading, low viscosity, and stable dispersion state is prepared by adding ceramic powders and dispersant into a resin system composed of photosensitive resin monomer and photoinitiator. Figure 23 illustrates the network forming mechanism during SL of ceramics. By means of a specific purple or ultraviolet light, the photoinitiator induces the polymerization of the photosensitive resin monomer to form a polymer cross-linked network, and thus fixes the ceramic particles to form a 3D ceramic green body. After that, final ceramic part is obtained after debinding and sintering at high temperature [74].

Usually, the SL of ceramic can generally be divided into two types: stereolithography apparatus (SLA) and digital light processing (DLP) $[6,12]$. Among them, SLA is relatively mature and is currently the most widely used SL technology for ceramics. During SLA, the slurry is cured by a point light source, and the forming platform is moved down by controlling. Usually, the platform is placed in slurry tank, and the slurry is irradiated and cured through a monochromatic light beam point by point, and then layer by layer. After each layer is formed, the platform is lowered a certain distance and the curing process is repeated for several cycles (as shown in Fig. 9(h)). Finally, 3D ceramic green body is obtained, and the final ceramic

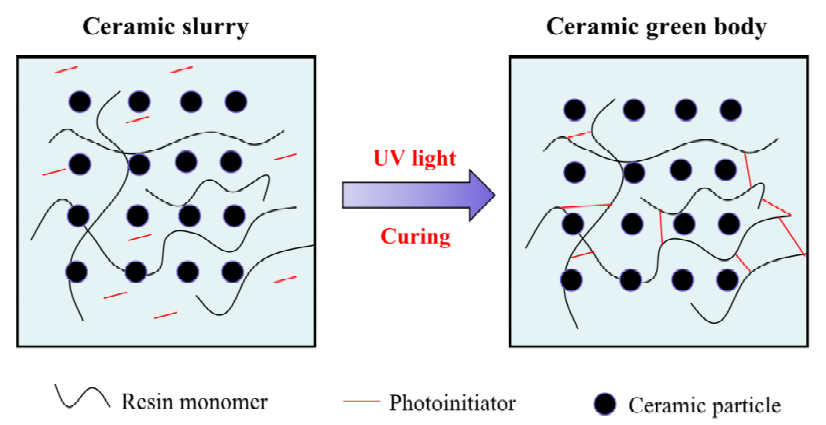

Fig. 23 Curing mechanism during stereolithography of ceramics. product is gotten after high-temperature debinding and sintering. DLP is a rapidly developing new additive manufacturing technology for ceramics. Its forming direction is opposite to SLA. During DLP, the platform is controlled and lifted up. Besides, the slurry is cured by a space light source during DLP. The light device is below the slurry tank, and projects a specific light to the slurry from a transparent window on the bottom of the slurry tank. The distance between the forming platform and the bottom of the slurry tank is controlled to maintain a fixed layer thickness. Then the curing is conducted layer by layer, as shown in Fig. 9(i), and green body is obtained. At last, the final ceramic component is obtained after debinding and sintering. It can be found that the forming speed of SLA is much slower than that of DLP, owing to that the light source for SLA and DLP is point light source and space light source, respectively. Therefore, DLP has a higher precision and faster forming speed than SLA. In addition, because the printing body is pulled up during DLP, only a small amount of slurry is needed in the slurry tank, which largely reduces the material cost (in fact, currently, some commercial SLA equipment are reported to begin to use the "move-up" method) [75].

At present, the SLA of SiC ceramic mainly focuses on the fabrication of precursor derived $\mathrm{SiC}$ related ceramics, such as SiOC ceramic, $\mathrm{SiCN}$ ceramic, and so on. As early as 2005, Friedel et al. [76] developed a selective laser curing (SLC) technology, which was similar to SLA, to prepare precursor derived ceramics (PDCs) by using a $\mathrm{CO}_{2}$ laser. The photosensitive slurry used here was a mixture of polymethylsilsesquioxane (PMS) ceramic precursor and $\mathrm{SiC}$ ceramic filler particles. Then, green body was produced by using the so-called SLC technology, as shown in Fig. 24(a). After high temperature pyrolysis, porous $\mathrm{SiC}$ ceramic was obtained (as shown in Fig. 24(b)). Finally, LSI was conducted based on the porous ceramic to obtain the final SiC ceramic product (as shown in Fig. 24(c)). In their study, the as-prepared $\mathrm{SiC}$ ceramic achieved a high density, and no obvious pores were detected. The bending strength was as high as $220 \mathrm{MPa}$. Park et al. [77] also prepared $\mathrm{SiC}$ ceramic from allyl hydrogenated polycarbosilane (AHPCS), a multi-functional inorganic polymer precursor. The ceramic green body was prepared by means of a two-photon absorption fabrication technology, and then pyrolyzed to obtain micron-sized 3D SiC ceramic components, such as mirco-hemispheres, micro-channels, micro-cones, microlattices, micro- 

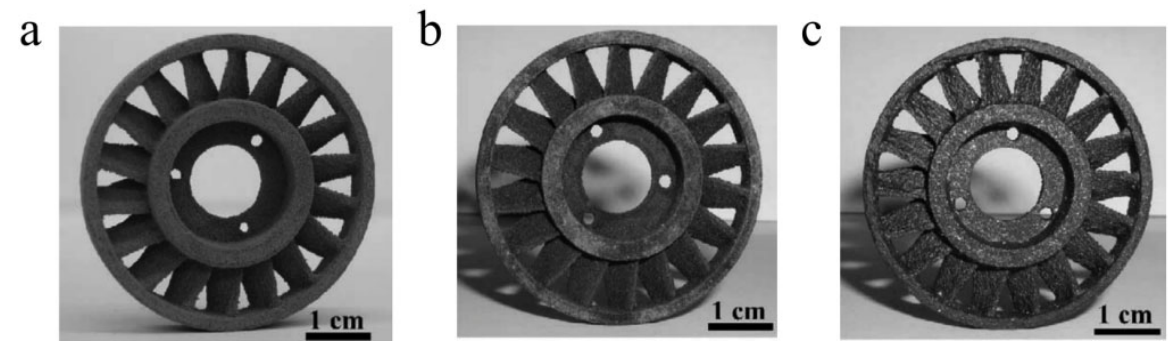

Fig. 24 SLA of SiC ceramic turbine wheel: (a) green body; (b) pyrolyzed body; (c) SiC body. Reproduced with permission from Ref. [76], (C) Elsevier Ltd. 2004.
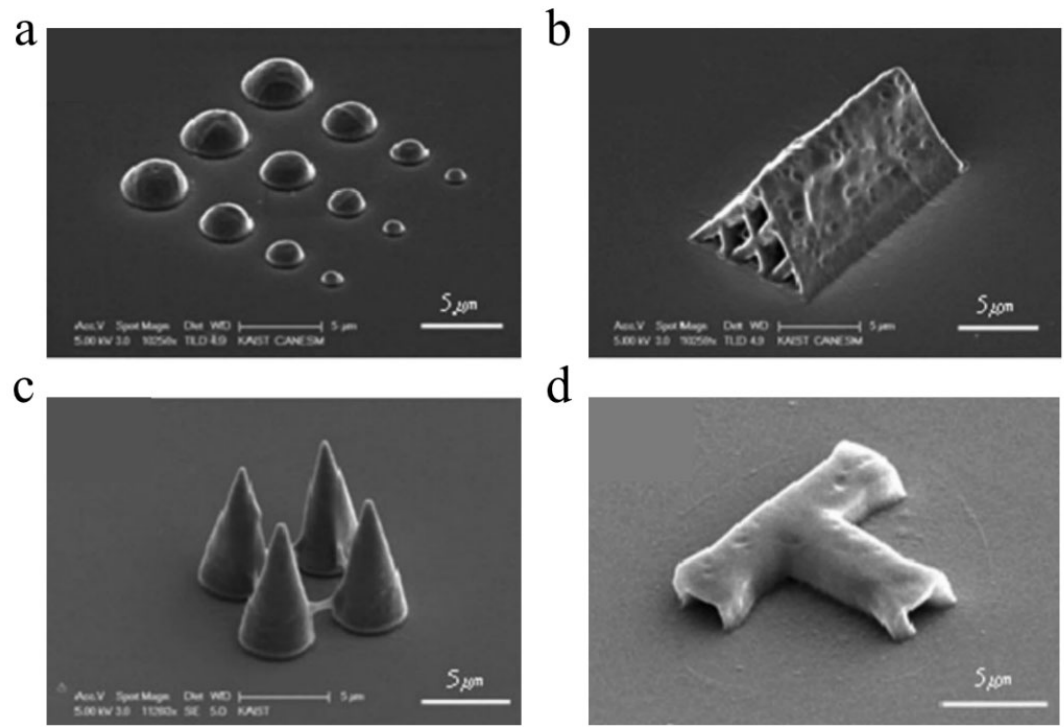

Fig. 25 Two-photon absorption fabrication of SiC ceramic micro-nano devices: (a) mirco-hemispheres; (b) micro-channels; (c) micro-cones; (d) microscale micro-channels. Reproduced with permission from Ref. [77], (C) The Royal Society of Chemistry 2009.

honeycomb, and so on, as shown in Fig. 25. From this study [77], the two-photon absorption fabrication technology showed good prospect for the manufacturing of micro-nano $\mathrm{SiC}$ ceramic devices with nearly zero shrinkage.

Inspiringly, in 2016, Eckel et al. [78] reported their research work on the SL of precursor derived ceramics in Science. They used light-curable siloxane as the precursor, and obtained $\mathrm{SiOC}$ ceramic components by using SLA technology combined with high temperature debinding. It was verified in their work that the as-prepared porous $\mathrm{SiOC}$ ceramic structure exhibited good heat-resistant behavior, as shown in Fig. 26. After that, the application of SLA technology to prepare $\mathrm{SiOC}, \mathrm{SiCN}$, or other precursor derived ceramics has become hot. The unique molecular structure of the polymer precursors can be modified by photo-curable groups and converted into ceramic at a relatively lower temperature. Therefore, it has become one of the most important research fields for SL additive manufacturing of ceramics. De Hazan et al. [79] firstly prepared a photo-curable precursor-resin slurry by mixing allyl hydrogenated polycarbosilane (AHPCS) with multifunctional acrylic resin, and subsequently obtained $\mathrm{SiC}$-rich ceramic with high precision by using SLA and following pyrolysis at $1200-1300{ }^{\circ} \mathrm{C}$, as shown in Fig. 27(a). Besides, Ligon et al. [80] used the silazane precursor to prepare a green body by using SLA, and finally got complex-shaped $\mathrm{SiCN}$ ceramic components with high-precision after pyrolysis at $1000{ }^{\circ} \mathrm{C}$, as shown in Fig. 27(b). The three-point bending strength of the as-prepared $\mathrm{SiCN}$ ceramic reached up to $890 \mathrm{MPa}$, and the HV1.0 hardness was as high as 1550 . Chen et al. [81] also tried to apply the $\left[\mathrm{SiH}_{2} \mathrm{CH}_{2}\right]_{n}$ acrylate functional group to modify liquid hyperbranched polycarbosilane (LHBPCS) precursor, and finally got a new precursor with high photo-activity and high ceramic yield which was suitable for the following SLA. Then they prepared $\mathrm{SiC}$ ceramic components by using SLA and pyrolysis at $1000{ }^{\circ} \mathrm{C}$, as shown in Fig. 27(c). 
As stated above, compared with SLA, DLP has higher molding accuracy, faster forming speed, and lower raw material cost. Therefore, it has become a hot spot in the research field of SL additive manufacturing of $\mathrm{SiC}$ ceramic in the past one or two years. Wang et al. [82] used thermosetting precursor with a high $\mathrm{Si}$ content and high ceramic yield as raw material, then modified the precursor with the help of thiol click chemistry methods, and finally obtained green body with high precision and complex shapes through DLP technology. At last, they obtained SiOC ceramic products after the green body was pyrolyzed at $1100{ }^{\circ} \mathrm{C}$,
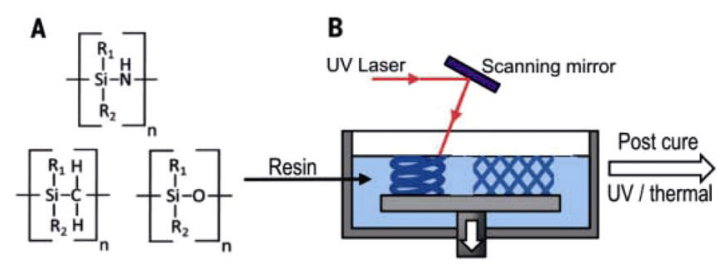

UV curable monomers
\& UV photo initiator

Stereolithography or self-propagating \& UV photo initiator photo-polymerization

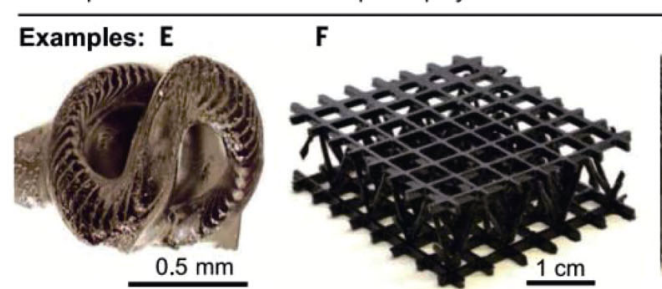

as shown in Fig. 28(a). Besides, Schmidt et al. [83] innovatively combined 3D macro-stereolithography DLP technology with two-photon lithography (TPL) or two-photon polymerization (TPP) technology for the first time, and reported the manufacturing of SiOC ceramic and its structures (as shown in Fig. 28(b)). Actually, TPL or TPP is different from SL technology in many aspects, especially the processing mechanism; however, there has been no report of the TPL or TPP of $\mathrm{SiC}$ ceramic till now. In the opinion of the authors, the TPL or TPP of SiC ceramic with higher precision up to sub-micron scale and even nanoscale is an important
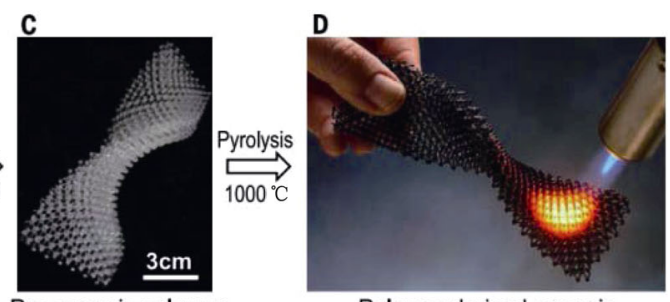

Polymer-derived ceramic
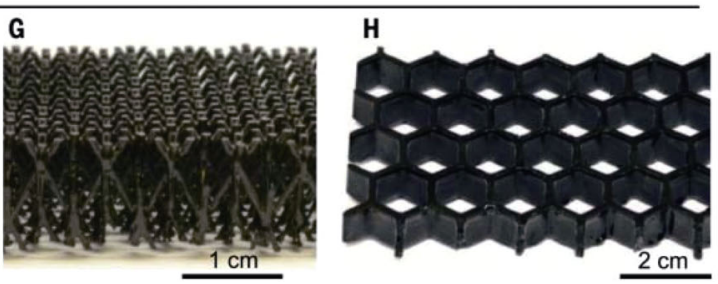

Fig. 26 SLA of polymer-derived SiOC ceramics: (A) UV-curable preceramic monomers are mixed with photoinitiator; (B) the resin is exposed with UV light in an SLA 3D printer or through a patterned mask; (C) a preceramic polymer part is obtained; (D) pyrolysis converts the polymer into a ceramic; (E-H) SLA-prepared 3D components. Reproduced with permission from Ref. [78], (C) American Association for the Advancement of Science 2016.

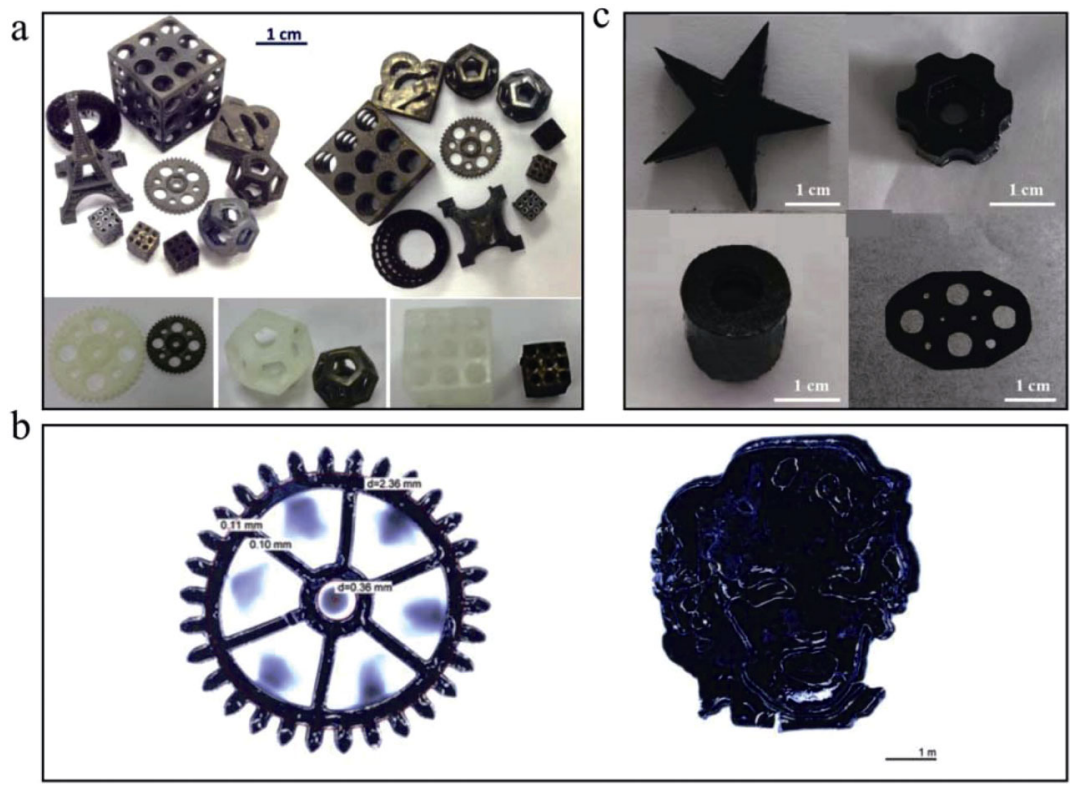

Fig. 27 SLA of polymer-derived ceramics: (a) SiC-rich ceramic. Reproduced with permission from Ref. [79], (C) Elsevier Ltd. 2017. (b) SiCN ceramic. Reproduced with permission from Ref. [80], (C) Elsevier Ltd and Techna Group S.r.l. 2018. (c) SiC ceramic. Reproduced with permission from Ref. [81], (C) Elsevier Ltd and Techna Group S.r.1. 2020. 

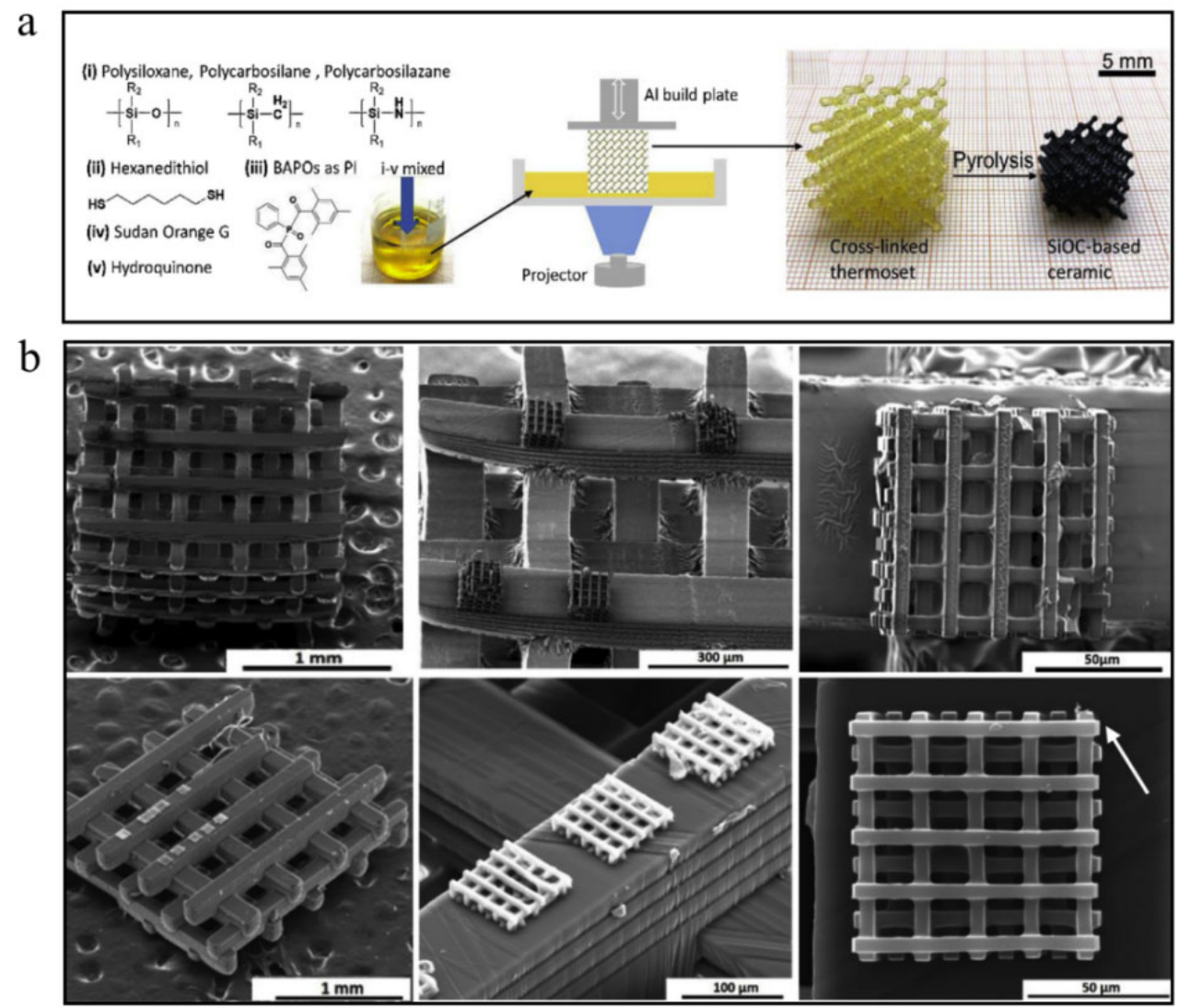

Fig. 28 DLP of polymer-derived SiOC ceramics: (a) Porous SiOC structure. Reproduced with permission from Ref. [82], (C) Elsevier B.V. 2019. (b) Micron and mesoscale SiOC structures. Reproduced with permission from Ref. [83], (C) Elsevier B.V. 2019.

research topic in the field of additive manufacturing of $\mathrm{SiC}$ ceramic.

However, it must be noted that, although polymer precursors are very conducive to SL additive manufacturing, the as-prepared $\mathrm{SiC}$ ceramic usually faces the disadvantages of insufficient density and poor mechanical properties. Besides, most of the commercial polymer precursor materials are extreme costly. Therefore, how to directly use $\mathrm{SiC}$ ceramic powder to prepare a photosensitive ceramic-resin slurry and finally realize its SL additive manufacturing has become a hot research topic and attracted much attention in the past years. He et al., the authors of this review, successfully used $\mathrm{SiC}$ ceramic powder to prepare a photo-curable SiC ceramic slurry with high solid loading, low viscosity, and stable dispersion state. Then, they further successfully achieved complex-shaped $\mathrm{SiC}$ ceramic components with high precision and good quality by using DLP and following sintering. Besides, they also tried a lot of innovation works on the densification and toughening for the DLP-prepared SiC ceramic [84-87].

Firstly, the preparation of a photosensitive $\mathrm{SiC}$ ceramic-resin slurry with high solid, low viscosity, and stable dispersion behavior is the basis to realize the SL additive manufacturing. Ding et al. [84] systematically studied the dispersion mechanism for photosensitive SiC-resin slurry, revealed the influences of particle size, morphology, and light absorbency on the curing behavior of SiC ceramic slurry, as shown in Fig. 29.

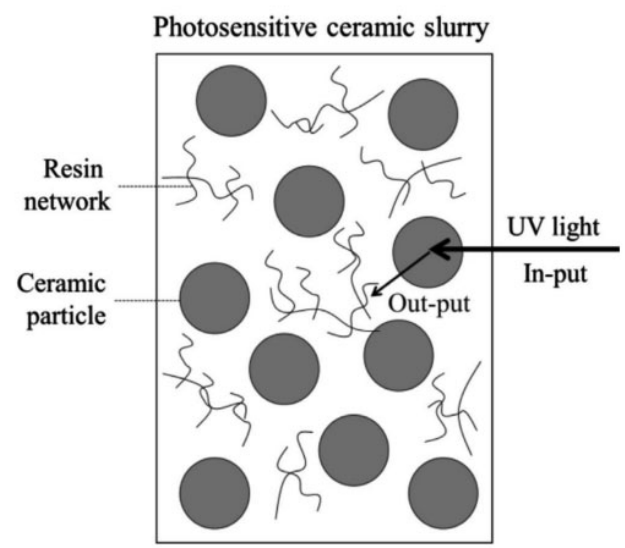

Fig. 29 Schematic drawing of the curing mechanism of SiC-resin slurry. Reproduced with permission from Ref. [84], (C) The American Ceramic Society 2019. 
After that, the influences of photosensitive resin monomer, dispersant, particle size distribution, and ball milling on the dispersion and rheological behaviors of SiC-resin slurry were studied in detail, and finally a SiC-resin slurry with high curing capacity, low viscosity, and good stability was prepared [85]. After obtaining the high-performance SiC-resin slurry, how to realize the stereolithography additive manufacturing and the following densification was an extremely important key point. Based on the as-obtained SiCresin slurry, He et al. [86] used DLP to realize the preparation of complex-shaped $\mathrm{SiC}$ ceramic green bodies with high precision and high quality, as shown in Fig. 30. Subsequently, the team explored the possibility of using PIP for promoting the sintering and densification of $\mathrm{SiC}$ ceramic, as shown in Fig. 31. After DLP and PIP, the relative density of the final SiC ceramic reached up to about $84.8 \%$, and the three-point bending strength reached up to $204.6 \mathrm{MPa}$, showing good densification prospects and application future in engineering fields, such as lightweight space mirrors, and so on (as shown in Fig. 32) [87].

It can be seen from the above that the ceramics, such as $\mathrm{SiC}$ and $\mathrm{SiOC}$, prepared by SL have the advantages of high precision, high surface quality, and high performance. Therefore, SL has broad application prospects for the manufacturing of complex-shaped $\mathrm{SiC}$ ceramic products, and therefore received more and more attentions. However, it should be also pointed out that most of the current SL researches are still focused
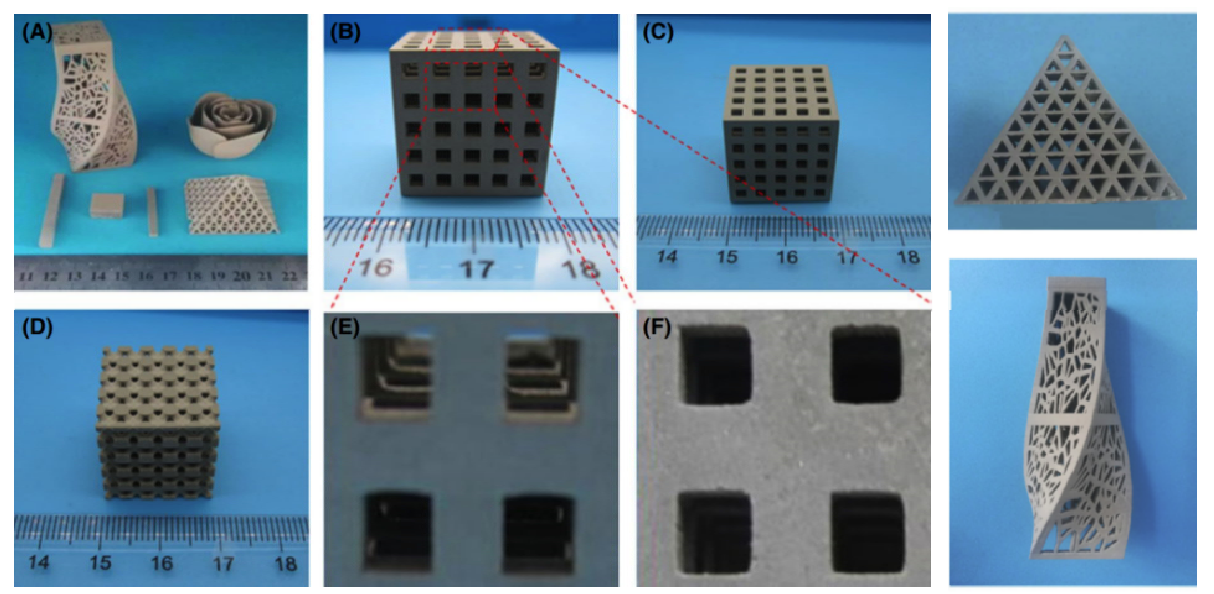

Fig. $30 \mathrm{SiC}$ green bodies by DLP. Reproduced with permission from Ref. [86], (C) Elsevier Ltd and Techna Group S.r.l. 2019.

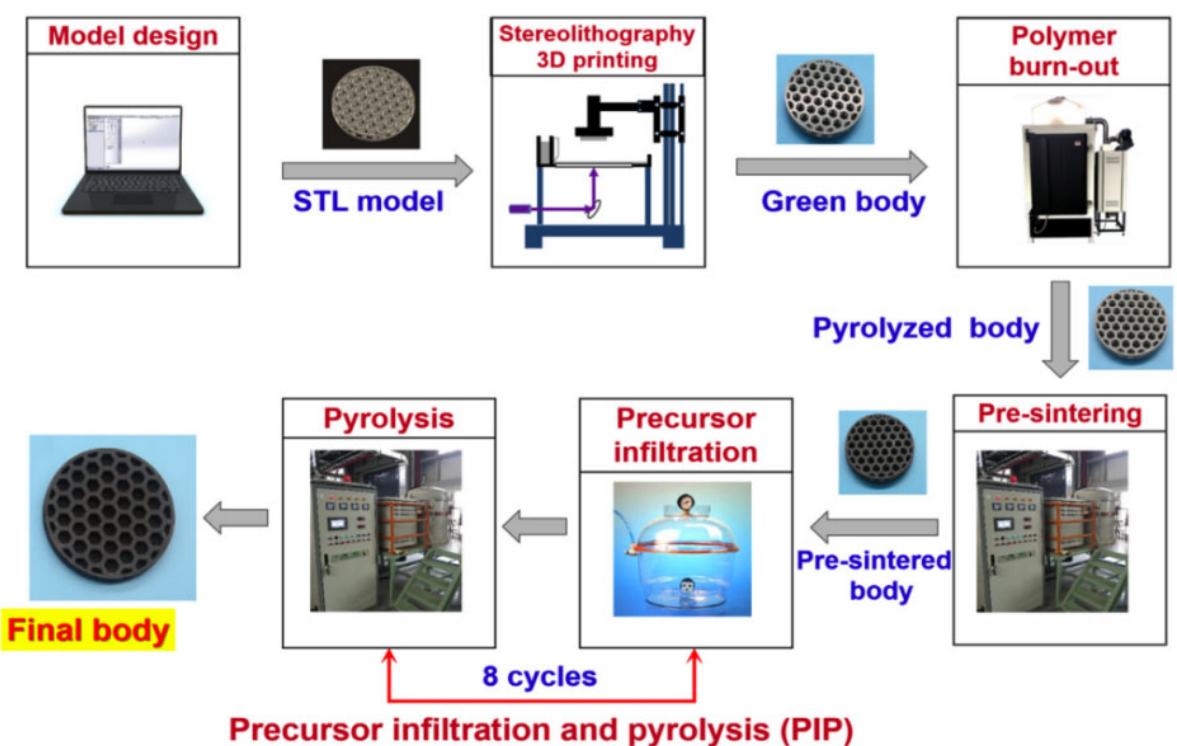

Fig. 31 Fabrication flow chart of SiC ceramic by DLP and PIP. Reproduced with permission from Ref. [87], (C) Elsevier Ltd and Techna Group S.r.1. 2020. 


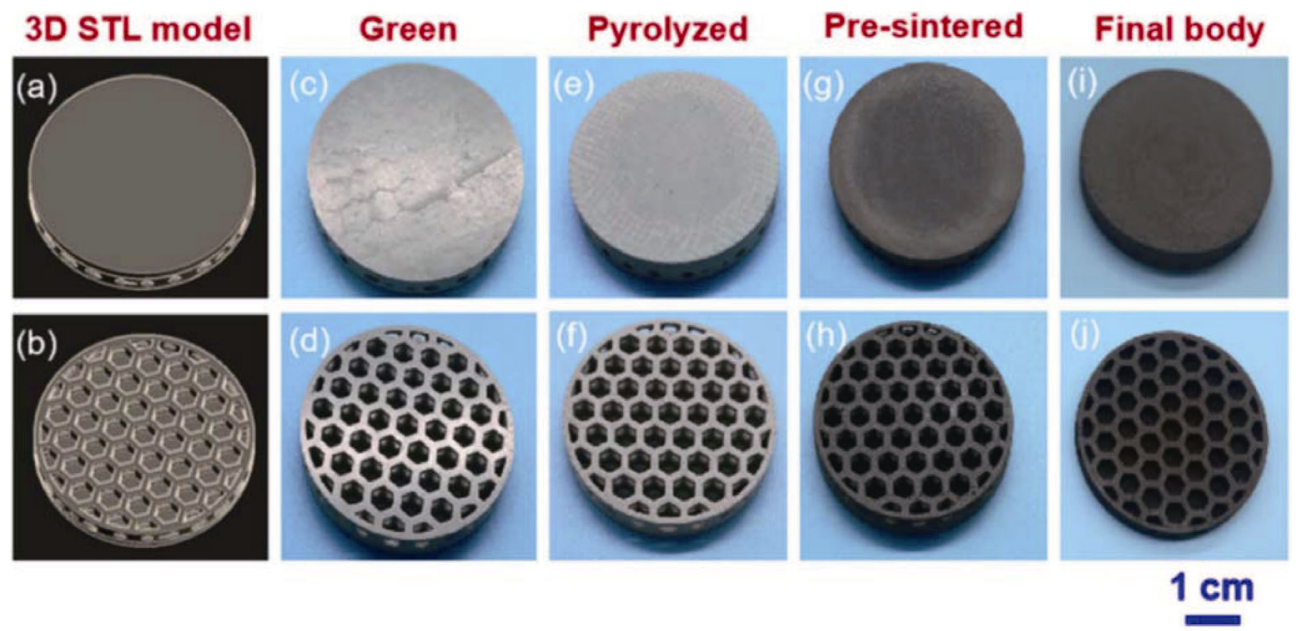

Fig. 32 Lightweight SiC ceramic optical mirror by DLP and PIP. Reproduced with permission from Ref. [87], (C) Elsevier Ltd and Techna Group S.r.l. 2020.

on precursor derived $\mathrm{SiC}$ or $\mathrm{SiOC}$ ceramics, which usually facing the disadvantages of low density and poor strength. The research on the SL of SiC ceramic from photosensitive ceramic slurry is still very rare. The mechanism for the SL of ceramic slurry still needs to be further explored. In addition, the SL-prepared $\mathrm{SiC}$ ceramic usually limits to its density (usually less than $90 \%$ relative density) and strength (usually about $200 \mathrm{MPa}$ in bending strength). There is an urgent need to develop efficient densification and strengthening approaches for the SL-prepared SiC ceramic. This is the key issue that needs to be focused on during the SL of $\mathrm{SiC}$ ceramic, and details will be expanded in the following Section 4 of this review.

\subsubsection{Direct ink writing (DIW)}

Direct ink writing (DIW) of ceramic is similar to robocasting or EFF. Robocasting and EFF use ceramic paste as raw material, whereas DIW uses ceramic ink as raw material. The difference between ceramic paste and ceramic ink is the solid loading. Simply, the solid loading of ceramic ink is much lower than that of ceramic paste. During DIW, ceramic powder is firstly mixed with solvent and binder to form a ceramic ink, which is then extruded or injected through a nozzle to form the required ceramic body. After high temperature debinding and sintering, the required ceramic components are obtained (as shown in Fig. 9(g)).

It was reported that Larson et al. [88] tried to use DIW to prepare SiC ceramic for optical component application. They used $\mathrm{SiC}$ ceramic powder as the raw material, and systematically studied the effects of the composition on the viscosity and rheological properties of the $\mathrm{SiC}$ ceramic ink, and finally obtained a low-viscosity $\mathrm{SiC}$ ceramic ink. Then, SiC ceramic green body was formed by DIW. After debinding and liquid phase sintering at $1800{ }^{\circ} \mathrm{C}$, typical $\mathrm{SiC}$ ceramic products such as fans and nozzles were obtained, as shown in Fig. 33(a). In addition, many researchers also tried the DIW of SiC ceramic from polymer precursors. Chen et al. [89] used polycarbosilane (PCS) precursor with a molecular weight of $1500 \mathrm{~g} / \mathrm{mol}$ and $\mathrm{n}$-hexane to form an ink, and studied the effects of nozzle diameter and PCS content on the writing-ability of the ink, as shown in Fig. 33(b). Subsequently, uncured PCS precursor green body was prepared by using DIW. After drying, oxidative cross-linking, and curing at $200{ }^{\circ} \mathrm{C}$, cured PCS precursor body was obtained. After pyrolysis at $1400{ }^{\circ} \mathrm{C}$, final $\mathrm{SiC}$ ceramic was produced, as shown in Fig. 33(c).

Usually, the mechanical properties of DIW-prepared $\mathrm{SiC}$ ceramic are relatively low. Till now, many researchers have tried to add whiskers, nanowires, chopped fibers, or other second phase reinforcement to achieve the strengthening and toughening. Xiong et al. [90] reported to mix PCS precursor with n-hexane and $\mathrm{SiC}$ whiskers to prepare an ink. Then, $\mathrm{SiC}_{\mathrm{w}} / \mathrm{PCS}$ green body was prepared by DIW and following drying, oxidative cross-linking and solidification. Finally, $\mathrm{SiC}_{\mathrm{w}} / \mathrm{SiC}$ ceramic was prepared after pyrolysis at $1200{ }^{\circ} \mathrm{C}$ (as shown in Fig. 34(a)). The flexural strength of the as-prepared $\mathrm{SiC}_{\mathrm{w}} / \mathrm{SiC}$ ceramic reached $33.2 \mathrm{MPa}$, and the compressive strength reached $30.6 \mathrm{MPa}$, which was much higher than their previous reports. Meanwhile, they further improved the densification of the $\mathrm{SiC}_{\mathrm{w}} /$ $\mathrm{SiC}$ ceramic through $\mathrm{CVI}$ by using $\mathrm{CH}_{3} \mathrm{SiCl}_{3}$ (MTS) 


\section{a}

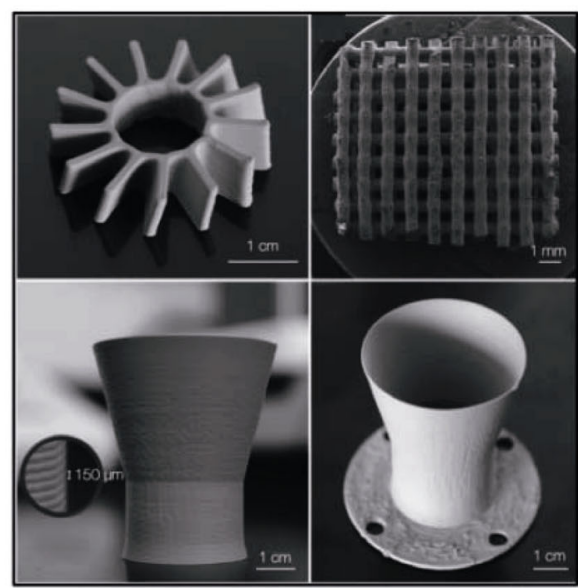

b

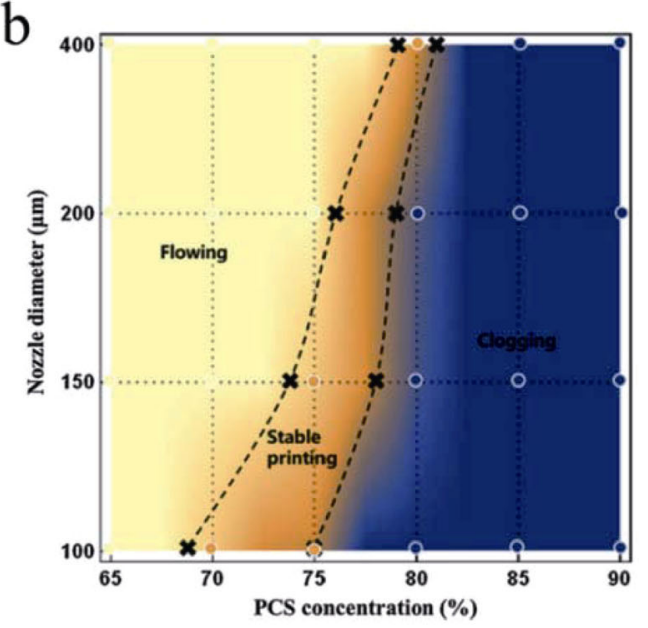

$\mathrm{C}$

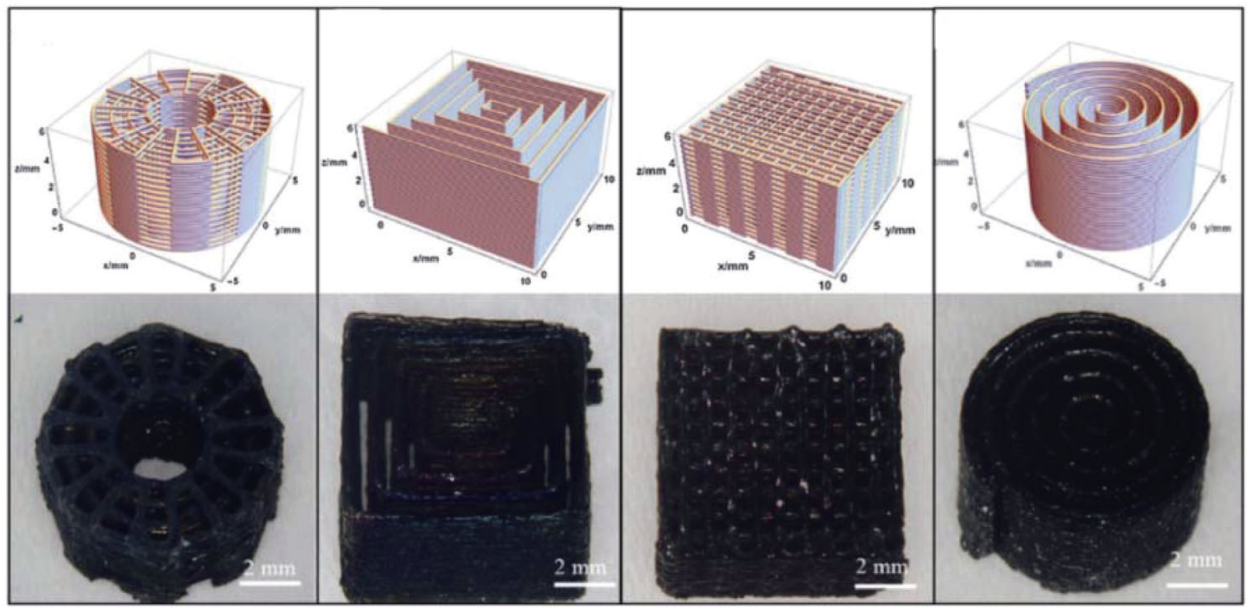

Fig. 33 DIW of SiC ceramic: (a) DIW of SiC ceramic. Reproduced with permission from Ref. [88], (C) WILEY-VCH Verlag GmbH \& Co. KGaA, Weinheim 2015. (b) Writing-ability of ceramic ink; (c) DIW of polymer derived SiC ceramic. Reproduced with permission from Ref. [89], (C) Elsevier Ltd. 2018.

as the Si source, as shown in Fig. 34(b). The tensile of the as-prepared $\mathrm{SiC}_{\mathrm{w}} / \mathrm{SiC}$ ceramic finally reached up to 47.3 MPa [91].

The above-mentioned reports mainly focused on the DIW of precursor derived SiC ceramic. Recently, there have been several reports on the DIW of SiC ceramic from ceramic slurry. Zhu et al. [92] prepared high-strength oriented $\mathrm{SiC}$ nanowire (SiCNW) reinforced SiC ceramic by using DIW. They firstly prepared a porous SiCNW framework through DIW, then realized the $\mathrm{SiC}$ ceramic matrix into the porous SiCNW framework by using CVI, and finally obtained a porous $\mathrm{SiCNW} / \mathrm{SiC}$ ceramic (as shown in Fig. 34(c)), The as-prepared porous $\mathrm{SiCNW} / \mathrm{SiC}$ ceramic had a porosity of $41.3 \%$ and a compressive strength of $390 \mathrm{MPa}$.

Xia et al. [93] also realized $\mathrm{SiC}$ ceramic ink and chopped carbon fiber ink from $\mathrm{SiC}$ ceramic powder, chopped carbon fiber, PEG, TMAH, and water. Then, these two inks were simultaneously ejected through a co-axial nozzle. Finally, a $\mathrm{C}_{\mathrm{f}} / \mathrm{SiC}$ composite "coreshell" structure, with the chopped carbon fiber as the "core" and SiC ceramic as the "shell", were prepared by using DIW combined with PIP process, as shown in Fig. 34(d). The as-prepared $\mathrm{C}_{\mathrm{f}} / \mathrm{SiC}$ "core-shell" composite had a porosity of $30.9 \%-34.8 \%$, a bending strength of $84-123 \mathrm{MPa}$, and a fracture toughness 1.46-2.71 $\mathrm{MPa} \cdot \mathrm{m}^{1 / 2}$. In addition, they also prepared a $\mathrm{SiC}$ interface layer on the surface of chopped carbon fibers through CVI for the $\mathrm{C}_{\mathrm{f}} / \mathrm{SiC}$ "core-shell" structure, and then used LSI to get the final $\mathrm{C}_{\mathrm{f}} / \mathrm{SiC}$ "core-shell" structure ceramic. The fabrication process was presented in Fig. 34(e), and the final $\mathrm{C}_{\mathrm{f}} / \mathrm{SiC}$ "core-shell" structure was shown in Fig. 34(f). Through these treatments, the bending strength increased to $274 \mathrm{MPa}$, and the fracture toughness increased to $5.82 \mathrm{MPa} \cdot \mathrm{m}^{1 / 2}$ [94].

It can be seen from the above discussion that DIW is 

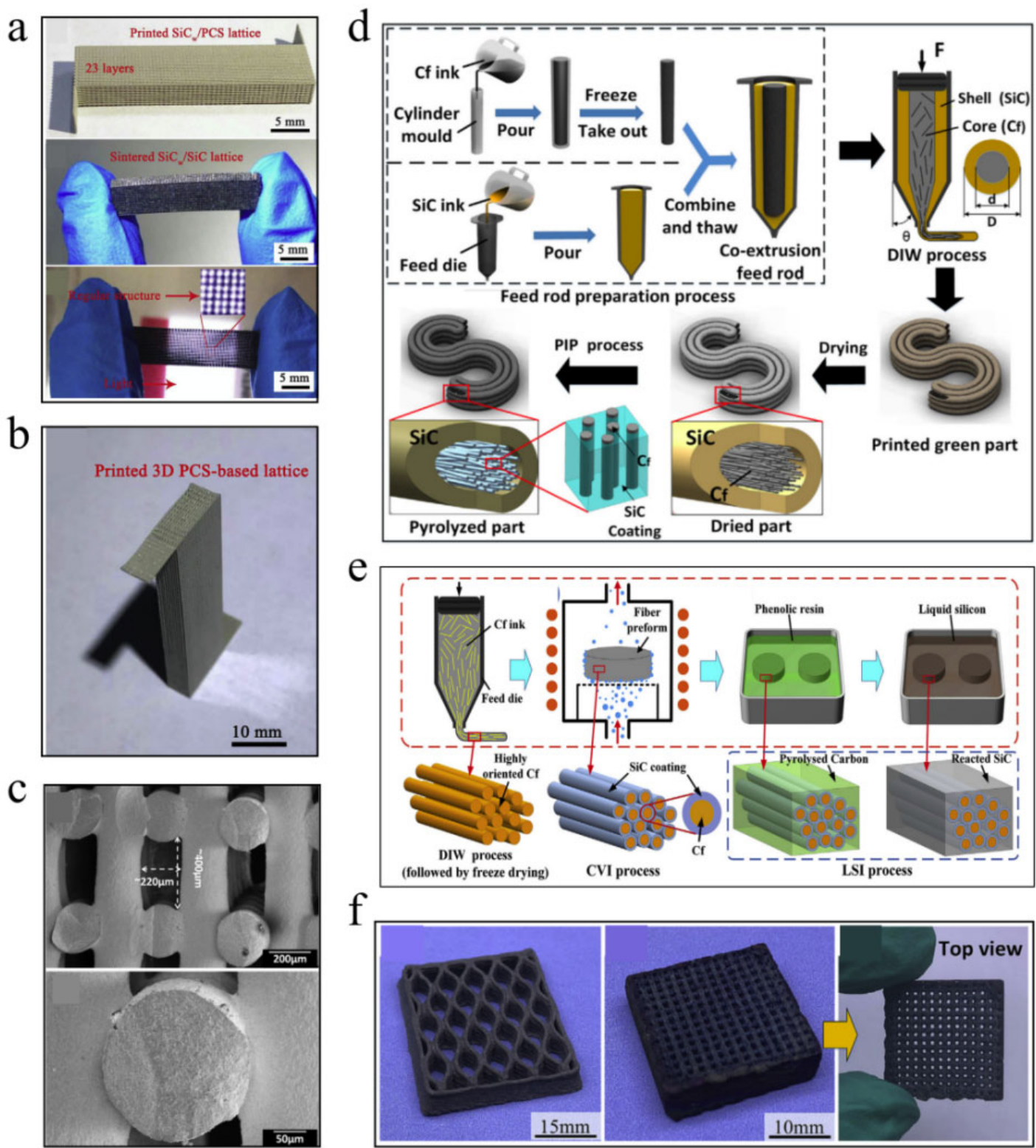

Fig. 34 DIW of second phase reinforced $\mathrm{SiC}$ ceramic: (a) $\mathrm{SiC}_{\mathrm{w}} / \mathrm{SiC}$ ceramic. Reproduced with permission from Ref. [90], (C) Elsevier B.V. 2019. (b) $\mathrm{SiC}_{\mathrm{w}} / \mathrm{SiC}$ ceramic. Reproduced with permission from Ref. [91], (C) Elsevier Ltd and Techna Group S.r.l. 2019. (c) SiCNW/SiC ceramic. Reproduced with permission from Ref. [92], (C) Elsevier Ltd and Techna Group S.r.l. 2019. (d) Fabrication flow chart of $\mathrm{C}_{\mathrm{f}} / \mathrm{SiC}$ core-shell ceramic. Reproduced with permission from Ref. [93], (C) Acta Materialia Inc. 2019. (e) Fabrication flow chart of $\mathrm{C}_{\mathrm{f}} / \mathrm{SiC}$ core-shell ceramic, (f) $\mathrm{C}_{\mathrm{f}} / \mathrm{SiC}$ core-shell ceramic. Reproduced with permission from Ref. [94], (C) Elsevier Ltd and Techna Group S.r.1. 2019.

similar to robocasting or EFF. It has the advantages of low equipment requirement, convenient operation, and low cost. Hence, it has broad application prospects in the field of additive manufacturing of SiC ceramic and other related materials. However, DIW equipment is always simple and the control accuracy is usually low, resulting in low manufacturing accuracy. Therefore, there are great difficulties in the manufacturing of fine and complex-shaped $\mathrm{SiC}$ ceramic. How to develop high precision DIW equipment is the most important development direction in the future.

In summary, both advantages and disadvantages exist for each direct additive manufacturing technology of $\mathrm{SiC}$ ceramic. Table 1 lists the comparison of the manufacturing accuracy and processing characteristics for each direct additive manufacturing technology of $\mathrm{SiC}$ ceramic. Normally, the processing accuracy for SLS, SLM, and LPBF is usually $\mu \mathrm{m}-\mathrm{mm}$. However, due to 
Table 1 Comparison of various direct additive manufacturing technologies of $\mathrm{SiC}$ ceramic

\begin{tabular}{ccc}
\hline $\begin{array}{c}\text { Raw material } \\
\text { state }\end{array}$ & $\begin{array}{c}\text { Additive manufacturing } \\
\text { technology }\end{array}$ & $\begin{array}{c}\text { Forming } \\
\text { accuracy }\end{array}$ \\
\hline \multirow{2}{*}{ Powder } & Selective laser sintering, SLS & $\mu \mathrm{m}-\mathrm{mm}$ \\
& Selective laser melting, SLM & $\mu \mathrm{m}-\mathrm{mm}$ \\
& Laser powder bed fusion, LPBD & $\mu \mathrm{m}-\mathrm{mm}$ \\
Bire/sheet & 3D printing, 3DP & $\mu \mathrm{m}-\mathrm{mm}$ \\
& Laminated object manufacturing, LOM & $\mu \mathrm{mm}-\mathrm{mm}$ \\
\hline \multirow{2}{*}{ Paste } & Robocasting & $\mu \mathrm{mm}-\mathrm{mm}$ \\
& Extrusion free forming, EFF & $\mu \mathrm{m}-\mathrm{mm}$ \\
\hline \multirow{2}{*}{ Slurry/ink } & Direct ink writing, DIW & $\mu \mathrm{m}-\mathrm{mm}$ \\
& Stereolithography, SL & $\mathrm{nm}-\mu \mathrm{m}$ \\
\hline
\end{tabular}

the high melting point of $\mathrm{SiC}$, it is difficult to melt or sinter $\mathrm{SiC}$ ceramic particles; therefore substances with flow melting point are generally needed to add or coat on the surface of $\mathrm{SiC}$ ceramic particles. Moreover, the large temperature gradient during SLS, SLM, or LPBF easily leads to large thermal stress inside the material, resulting in inevitable defects and cracks, which further induces the low density and low strength of as-prepared $\mathrm{SiC}$ ceramic. The precision of the $\mathrm{SiC}$ ceramic prepared by $\mathrm{BJ}$ or $3 \mathrm{DP}$ is poor, generally only at the $\mathrm{mm}$ level, and the interface is obvious and the strength is low. The processing accuracy for $\mathrm{SiC}$ ceramic prepared by FDM or LOM is also poor, only at the $\mathrm{mm}$ level, and it is generally necessary to prepare $\mathrm{SiC}$ ceramic into wires or sheets firstly, which increase the processing complexity and material defects. And the processing precision for $\mathrm{SiC}$ ceramic prepared by the EFF and robocasting is $\mu \mathrm{m}-\mathrm{mm}$, and the interface among the material is obvious, resulting that its strength is very low. In addition, the processing precision of the DIW-prepared $\mathrm{SiC}$ ceramic is at the $\mu \mathrm{m}-\mathrm{mm}$ level, and both the density and strength of the as-prepared $\mathrm{SiC}$ ceramic are low. The $\mathrm{SiC}$ ceramic prepared by stereolithography exhibits high process accuracy, which can reach $n m-\mu m$ level, and the asprepared $\mathrm{SiC}$ ceramic has high density and mechanical strength, so it is gradually received more and more attention from scholars.

\section{Challenges}

Based on the previous summary of the current additive manufacturing technologies of $\mathrm{SiC}$ ceramic, and the technical advantages and disadvantages for each technology, the following challenges and opportunities can be concluded.

\section{1 Densification and strengthening}

Both the additive manufacturing equipment developing [97] and fundamental researches (including sintering, densification, and strengthening) [98,99] are very important for the additive manufacturing of ceramics. Most importantly, at present, no matter what additive manufacturing technology is used, the as-prepared $\mathrm{SiC}$ ceramic faces certain density and strength problems. Table 2 lists and compares the relative density, bending strength, modulus, and other key performance parameters of $\mathrm{SiC}$ ceramic prepared by different additive manufacturing technologies. It can be seen from Table 2 that the density of the as-obtained $\mathrm{SiC}$ ceramic is generally difficult to be completely dense, even mostly less than $90 \%$ of relative density. The strength of the as-obtained $\mathrm{SiC}$ ceramic is relatively low. And the bending strength to is difficult to exceed $350 \mathrm{MPa}$, or even $250 \mathrm{MPa}$. Figure 35 shows the comparison of the relative density and mechanical strength of $\mathrm{SiC}$ ceramic prepared by various additive manufacturing technologies with those prepared by traditional methods. Generally speaking, $\mathrm{SiC}$ ceramic is traditionally prepared by pressureless sintering, reaction sintering, hot pressing sintering, and other approaches. Zhang et al. [100] used gel casting to prepare $\mathrm{SiC}$ ceramic green bodies. After pressureless sintering at $2200{ }^{\circ} \mathrm{C}$, the as-obtained $\mathrm{SiC}$ ceramic had a density of $98 \%$ and a three-point bending strength of $531 \mathrm{MPa}$. Song et al. [101] used reaction sintering to prepare $\mathrm{SiC}_{\mathrm{w}} / \mathrm{SiC}$ ceramic with a relative density of over $90 \%$ and a three-point bending strength of $290 \mathrm{MPa}$. Ma et al. [102] prepared a carbon nanotube reinforced nano$\mathrm{SiC}$ ceramic with a relative density of $94.7 \%$ and a three-point bending strength of $375.8 \mathrm{MPa}$ by using hot pressing method. It was also reported that Dong et al. [103] used hot pressing to prepare SiC chopped fiber reinforced $\mathrm{SiC}$ ceramic. The as-obtained ceramic had a relative density of $96.7 \%$ and a three-point bending strength of $710 \mathrm{MPa}$. It can be seen that, compared with $\mathrm{SiC}$ ceramic materials prepared by traditional approaches, $\mathrm{SiC}$ ceramic obtained by additive manufacturing still needs great improvement in terms of both relative density and mechanical strength. 
Table 2 Comparison of the relative density and strength of SiC ceramic fabricated by different additive manufacturing techniques

\begin{tabular}{|c|c|c|c|c|c|c|c|}
\hline No. & Material & AM technology & Following detail & $\begin{array}{c}\text { Relative density } \\
(\%)\end{array}$ & $\begin{array}{l}\text { Strength } \\
\text { (MPa) }\end{array}$ & $\begin{array}{c}\text { Modulus } \\
(\mathrm{GPa})\end{array}$ & Ref. \\
\hline 1 & RB-SiC & SLS & Reactive sintering & & $162^{\mathrm{a}}$ & 285 & [49] \\
\hline 2 & RB-SiC & SLS & CIP+LSI & - & $348^{\mathrm{a}}$ & - & [47] \\
\hline 3 & RB-SiC & SLS & LSI & - & $\sim 360^{\mathrm{a}}$ & - & [95] \\
\hline 4 & $\mathrm{SiC}$ & SLS & PIP & 80.9 & $220^{\mathrm{a}}$ & - & {$[50]$} \\
\hline 5 & $\mathrm{C}_{\mathrm{sf}} / \mathrm{SiC}^{1}$ & SLS & LSI & - & $239^{\mathrm{a}}$ & - & [48] \\
\hline 6 & RB-SiC & BJ & LSI & $75-85$ & $358-380^{\mathrm{b}}$ & - & [59] \\
\hline 7 & RB-SiC & BJ & $\mathrm{CVI} / \mathrm{CVD}$ & $85-87$ & $\sim 135^{\mathrm{c}}$ & - & [57] \\
\hline 8 & $\mathrm{SiC}_{\mathrm{w}} / \mathrm{SiC}^{2}$ & BJ & CVI & 84 & $200^{\mathrm{a}}$ & 458 & {$[56]$} \\
\hline 9 & $\mathrm{SiC}$ & 3DP & Pressureless sintering & 45 & $9.74^{\mathrm{d}}$ & - & {$[61]$} \\
\hline 10 & RB-SiC & LOM & LSI & - & $315^{\mathrm{c}}$ & - & {$[66]$} \\
\hline 11 & $\mathrm{SiC}$ & Robocasting & SPS & 97 & - & - & [67] \\
\hline 12 & RB-SiC & Robocasting & LSI & 98 & $224^{\mathrm{c}}$ & 356 & [68] \\
\hline 13 & RB-SiC & EFF & LSI & - & $300^{\mathrm{a}}$ & - & [72] \\
\hline 14 & $\mathrm{SiC}$ & EFF & SPS & $15-40$ & - & - & {$[96]$} \\
\hline 15 & $\mathrm{SiC}$ & SL & PIP & 82.6 & $184.2^{\mathrm{a}}$ & - & {$[86,87]$} \\
\hline 16 & $\mathrm{SiC}_{\mathrm{w}} / \mathrm{SiC}^{2}$ & DIW & CVI & - & $47.3^{\mathrm{a}}$ & - & [91] \\
\hline 17 & $\mathrm{SiC}_{\mathrm{nw}} / \mathrm{SiC}^{3}$ & DIW & Pressureless sintering & 58.7 & $390^{\mathrm{e}}$ & - & [92] \\
\hline 18 & $\mathrm{C}_{\mathrm{s} f} / \mathrm{SiC}^{1}$ & DIW & CVI+PIP & - & $274^{\mathrm{a}}$ & - & [94] \\
\hline
\end{tabular}

${ }^{1}$ Chopped carbon fiber, ${ }^{2} \mathrm{SiC}$ whisker, ${ }^{3} \mathrm{SiC}$ nano wire.

${ }^{\mathrm{a}} 3$-point flexural strength, ${ }^{\mathrm{b}}$ Weibull strength, ${ }^{\mathrm{c}}$-point flexural strength, ${ }^{\mathrm{d}}$ Ring bending strength, ${ }^{\mathrm{e}}$ compressive strength.

Now, on the one hand, in view of the key challenge of low density for additive manufactured $\mathrm{SiC}$ ceramic, LSI, PIP, CVD, CVI, and other densification methods, or reaction sintering, SPS and other novel sintering approaches, are used to promote the densification of
$\mathrm{SiC}$ ceramic, as shown in Fig. 36. On the other hand, in view of the key challenge of poor mechanical strength for additive manufactured $\mathrm{SiC}$ ceramic, the current strengthening and toughening strategies mainly have two aspects: Firstly, the relative density of additive

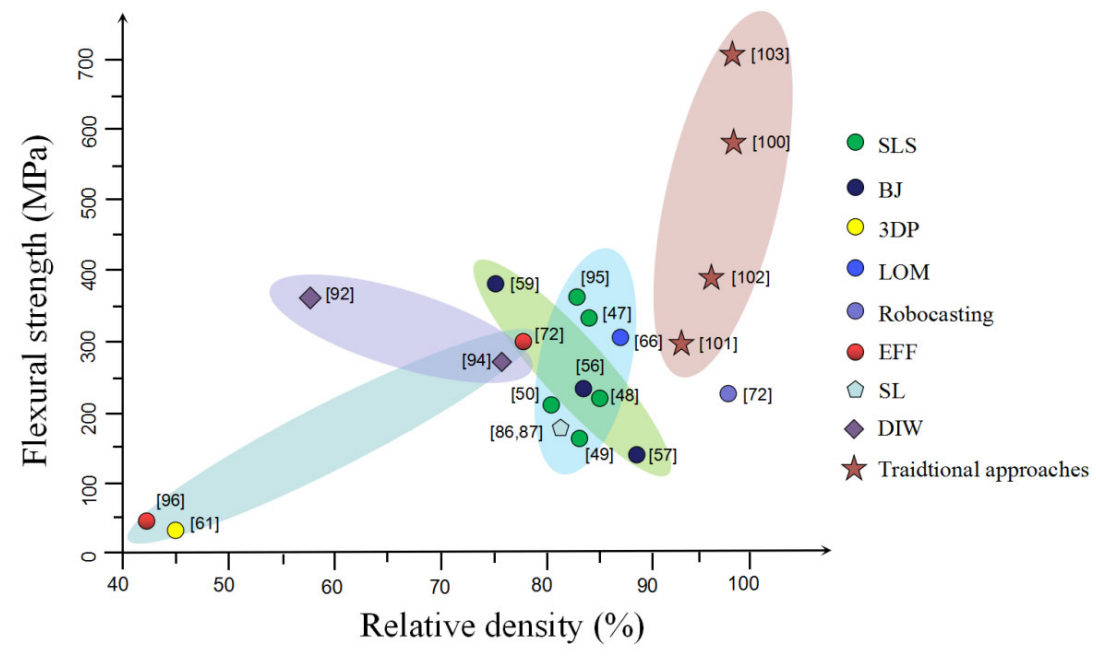

Fig. 35 Comparison of the relative density, mechanical properties of $\mathrm{SiC}$ ceramic by different additive manufacturing technologies. 


\section{Densification and strengthening-toughening approaches for additive manufactured $\mathrm{SiC}$ ceramic}

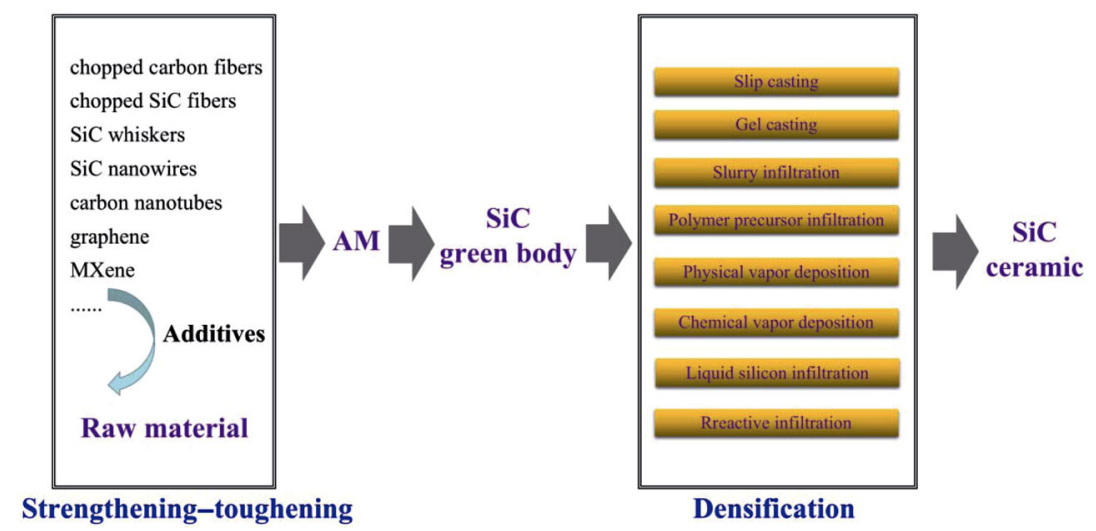

Fig. 36 Densification and strengthening-toughening approaches for additive manufactured SiC ceramic.

manufactured $\mathrm{SiC}$ ceramic can be improved through a variety of densification strategies. Secondly, by adding a second phase into the $\mathrm{SiC}$ ceramic matrix, such as chopped carbon fibers, chopped $\mathrm{SiC}$ fibers, $\mathrm{SiC}$ whiskers, $\mathrm{SiC}$ nanowires, carbon nanotubes, graphene, MXene, or other two-dimensional or one-dimensional materials, the mechanical properties of additive manufactured $\mathrm{SiC}$ ceramic, including mechanical strength, fracture toughness, modulus, etc., can be greatly improved (as shown in Fig. 36). The works listed in Table 2 cover both the densification and strengthening-toughening attempts for additive manufactured $\mathrm{SiC}$ ceramic. However, it is worth noting that these densification strategies and strengtheningtoughening strategies currently used are still not enough to completely solve the density and strength challenges for the additive manufacturing of $\mathrm{SiC}$ ceramic. Development of innovative densification and strengthening-toughening methods, especially development of innovative densification theory and strengthening-toughening mechanism, has important scientific significance and application value for solving these key challenges.

\section{2 Defect characterization and controlling}

The thermal stress during SLS, interface issues during $\mathrm{EFF}$, dispersion and rheological issues during SL, and so on, easily induce a lot of manufacturing defects among the ceramic body after additive manufacturing, which will finally affect the properties and the life of the ceramic products. For example, during SLS, the balling phenomenon, the distribution of stress field caused by temperature gradient, and the limitation of printing accuracy caused by the fluidity of powder, easily induced defects and cracks among the final ceramic products. How to realize the quantitative characterization of the internal defects among additive manufactured ceramic, and then further analyze the defect generation mechanism and develop corresponding defect control methods, have become an important research challenge and development opportunity for the additive manufacturing of ceramic in the future.

At present, a variety of internal manufacturing defect characterization methods have been developed for additive manufactured metals. Among them, the micro-CT non-destructive testing method has the advantages of non-destructive, high detection accuracy, quick and convenient response, which has been widely used and promoted in many additive manufactured metals (as shown in Fig. 37(a)). For example, it was reported that Liu et al. [104] used X-ray CT (XCT) non-destructive testing method to characterize a SLM-prepared Ti6Al4V alloy (as shown in Fig. 37(b)). During this study, the characteristics and quantity of manufacturing defects inside the Ti6Al4V alloy were quantitatively characterized. Most importantly, the reason and mechanism for the defects were analyzed, and the additive manufacturing process was therefore optimized and the defects were under control, as shown in Fig. 38. Although many scholars have applied micro-CT non-destructive testing method to study the defect characterization and controlling for additive manufactured metals; however, in the field of additive manufacturing of ceramic, there is still little research on the micro-CT non-destructive testing. About the quantitative characterization and controlling 
methods of the internal manufacturing defects for additive manufactured ceramics, only a few scholars tried to use CT to carry out the characterization.
Saâdaoui et al. [105] and Khaldoun et al. [106] firstly combined a novel SL technology (lithographybased ceramic manufacturing, LCM) with pressureless
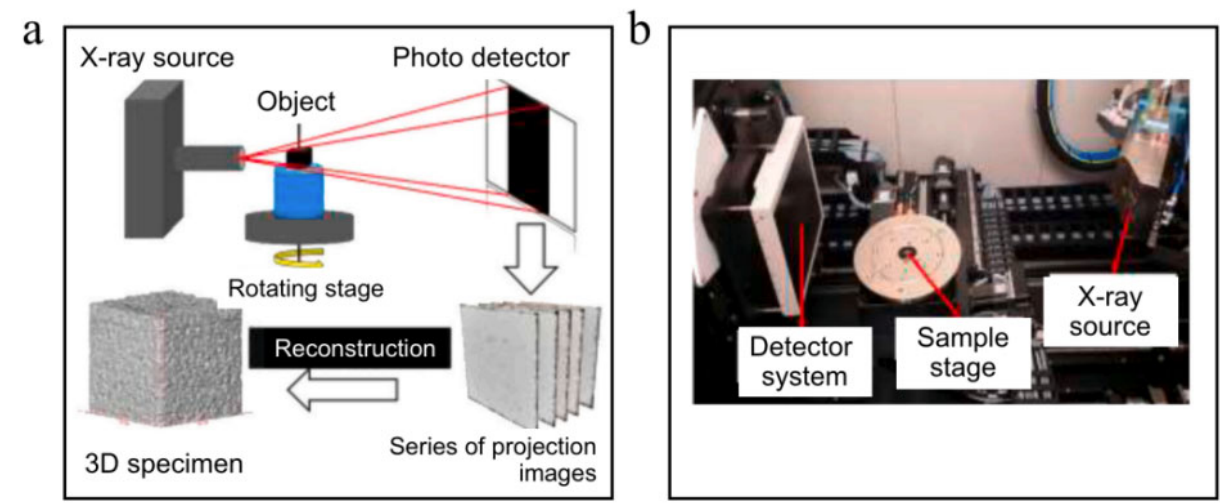

Fig. 37 (a) Schematic of industrial X-ray tomography; (b) main components of 3D CT X-ray computed tomography. Reproduced with permission from Ref. [104], (C) Elsevier B.V. 2020.

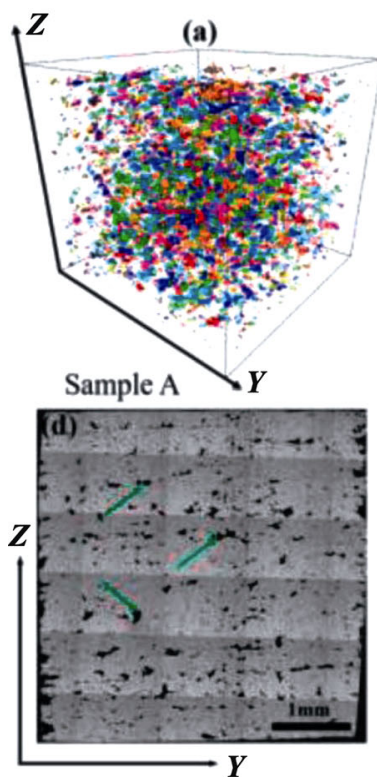

(b)

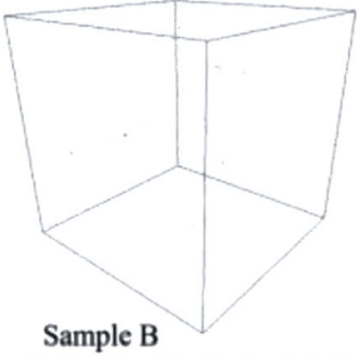

(e)

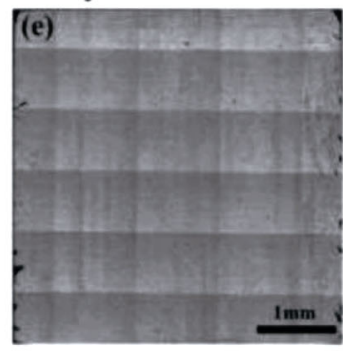

(c)

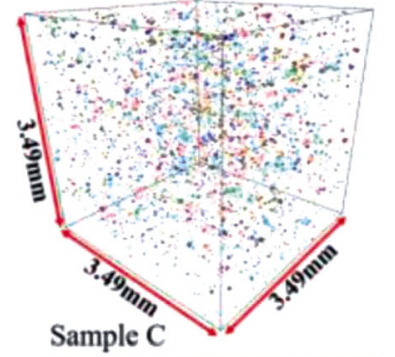

Sample C

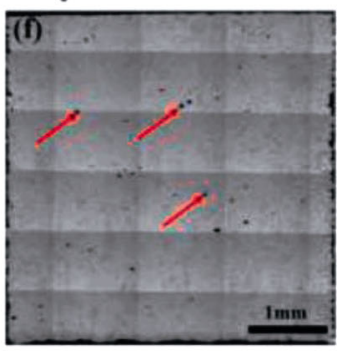

Fig. 38 XCT analysis of different additive manufactured materials. Reproduced with permission from Ref. [104], (C) Elsevier B.V. 2020.

a

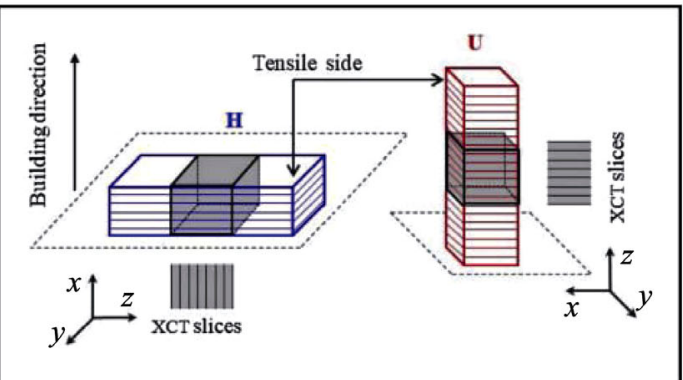

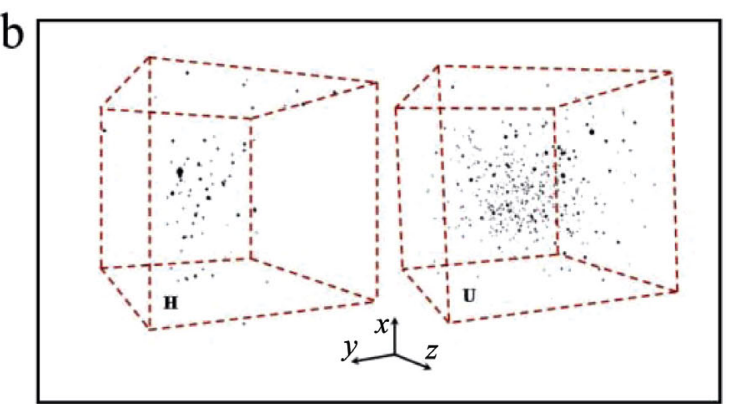

Fig. 39 (a) Schematic representation of the horizontal $(\mathrm{H})$ and upright $(\mathrm{U})$ architectures showing the orientation of the material layers in relation to the tensile side and the direction, $z$, of XCT scans completed over a length of $10 \mathrm{~mm}$ at the center of the specimens (colored area). (b) 3D XCT reconstructions showing the pore distribution in $\mathrm{H}$ and $\mathrm{U}$ samples (observation volume: $2.2 \mathrm{~mm} \times 2.5 \mathrm{~mm} \times 2.5 \mathrm{~mm})$. Reproduced with permission from Ref. [105], (C) Elsevier Ltd. 2019 . 
sintering to prepare a dense $3 \mathrm{Y}$-TZP ceramic. Then, XCT scanning non-destructive testing of the 3Y-TZP ceramic was conducted to quantitatively characterize its internal manufacturing defects in different manufacturing directions, as shown in Fig. 39. The intrinsic relationships between the predicted strength and effective strength were analyzed and discussed based on the internal manufacturing defects from XCT results (as shown in Fig. 40). It was found that the $\mathrm{XCT}$ derived strength was in good agreement with the effective strength from this study, which shows the good perspective of $\mathrm{CT}$ in the prediction of additive manufactured ceramics. Recently, Diener et al. [107] also reported the $\mathrm{X}-\mathrm{CT}$ investigation on the residual pore structure in $\mathrm{Si}_{3} \mathrm{~N}_{4}$ bars manufactured by DIW using different printing patterns (as shown in Fig. 41), and tried to establish the relationship between the residual pore structure and the printing parameters. Most importantly, except X-CT, some other nondestructive testing technologies are under studying, which should also attract much attention for the defect characterization of additive manufactured $\mathrm{SiC}$ ceramic.

\section{3 Additive manufacturing of ceramic matrix composites}

Continuous fiber reinforcement is an effective way to strengthen and toughen $\mathrm{SiC}$ ceramic. At present, the commonly used continuous fibers include continuous carbon fiber [108,109] and continuous SiC fiber [110]. Traditional fabrication process of continuous fiber

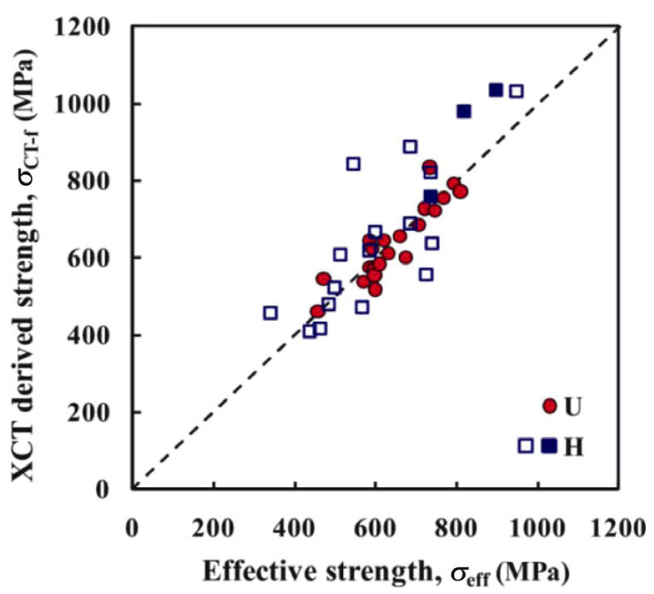

Fig. 40 Correlation between the effective and the XCT derived strengths. Open symbols correspond to surface defects and solid ones to volume defects (i.e., agglomerates for $\mathrm{U}$ samples and pores for $\mathrm{H}$ samples). Reproduced with permission from Ref. [105], (c) Elsevier Ltd. 2019.

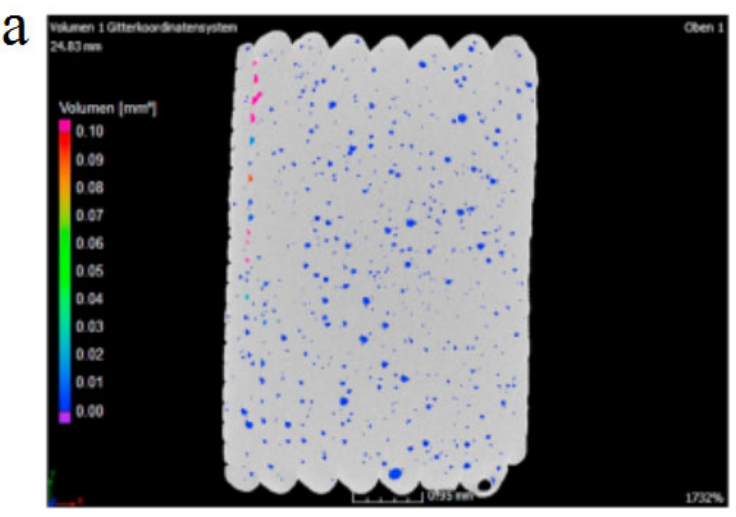

$\mathrm{b}$

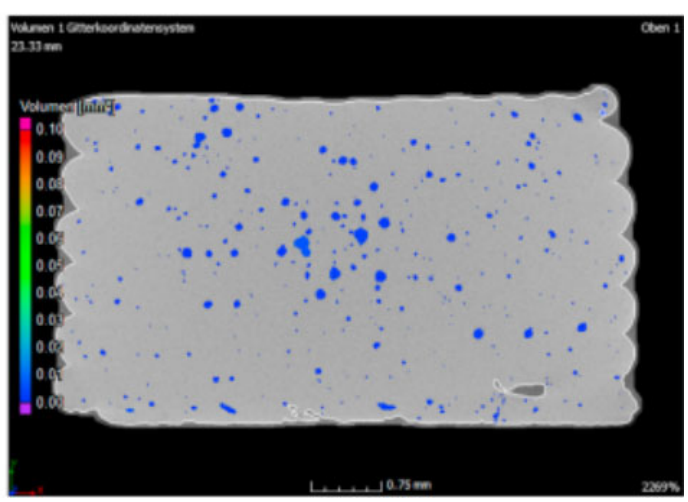

Fig. 41 Micro X-CT images of $\mathrm{Si}_{3} \mathrm{~N}_{4}$ bars manufactured by DIW: top view of (a) aligned bar; (b) hexagonal bar. Reproduced with permission from Ref. [107], (C) The Authors 2020.

reinforced $\mathrm{SiC}$ ceramic matrix composites usually requires two stages: fiber preform preparation and ceramicization. Generally, the preparation of fiber preforms is achieved by some traditional manufacturing technologies, such as layup, puncture, weaving, and so on. And ceramicization is generally achieved by processing such as PIP, high-temperature LSI, CVI, and so on. However, traditional manufacturing technologies usually have complicated process procedures, long processing cycles, and high processing costs. In recent years, the development of additive manufacturing has provided new ideas and technical approaches for the fabrication of continuous fiber reinforced ceramic matrix composites.

The research on additive manufacturing of continuous fiber reinforced composites is currently mainly concentrated in the field of polymer matrix composites. At present, the principle of additive manufacturing of the continuous fiber reinforced polymer matrix composites is shown in Fig. 42 [111]. This technical principle is generally similar to the principle of FDM technology. The continuous fiber and the polymer matrix (usually a 


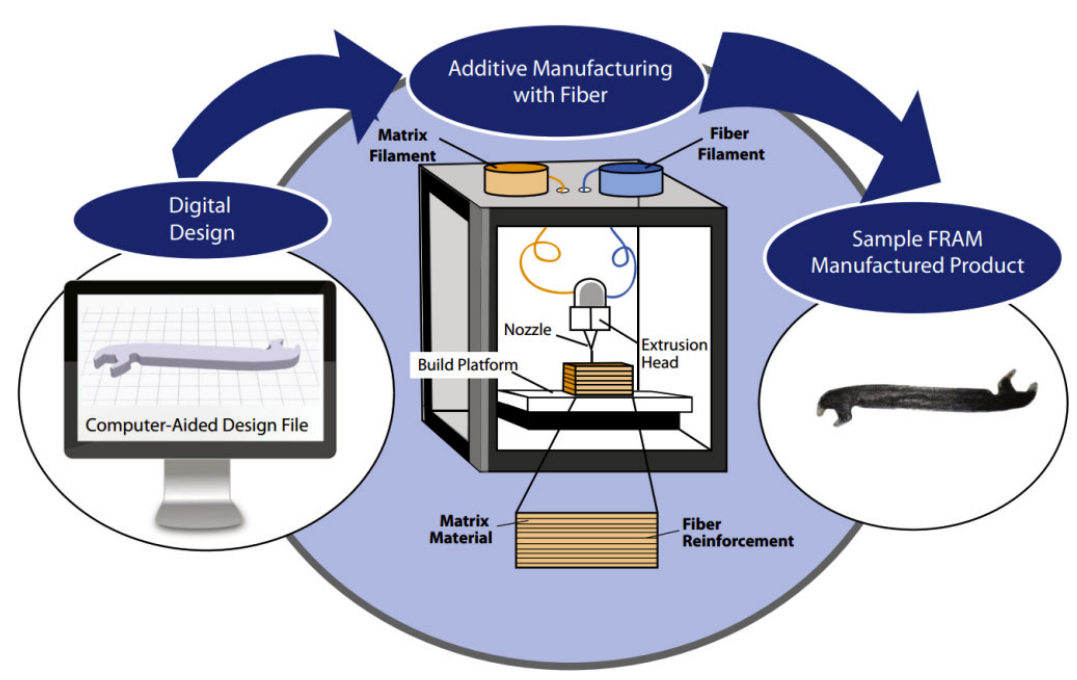

Fig. 42 Schematic layout of continuous fiber reinforced polymer matrix composites. Reproduced with permission from Ref. [111], (C) Springer-Verlag London Ltd., part of Springer Nature 2019.

thermoplastic polymer matrix, but also can be a thermosetting matrix) are combined and sprayed out by two nozzles or through-axis nozzles. Then the polymer matrix is solidified, and the final composite is manufactured layer by layer. For this technology, the most widely realized fiber types are mainly continuous carbon fiber, Kevlar fiber, nylon fiber, PLA fiber, and so on. The matrix used here is usually a thermoplastic polymer or a thermosetting polymer. The current status and progress of additive manufacturing technology of continuous fiber reinforced composite materials will not be repeated in this article. For detailed introduction, please refer to the relevant research work and review in recent years [111-115]. Although most of the additive manufacturing studies of continuous fiber reinforced composites are concentrated on polymer matrix composites, scholars have begun to explore the possibility of additive manufacturing of short fiber reinforced ceramic matrix composites [48,94,116], but unfortunately, there is no research on additive manufacturing of continuous fiber reinforced ceramic matrix composites now. Due to the excellent material properties and wide application prospects of continuous fiber reinforced $\mathrm{SiC}$ ceramic matrix composites, the research on its additive manufacturing technology will receive more and more attention, which will also be an important challenge and development opportunity for $\mathrm{SiC}$ ceramic.

\section{4 Structural and functional design}

One of the biggest advantages of additive manufacturing technology is that it can realize the structural design of materials. At present, structural design has received extensive attention and a lot of researches have been done for the additive manufacturing of polymers and metals. Various structures, including lattice structures, fractal structures, topological structures, and other novel structure configurations, are increasingly applied to structural design for the additive manufacturing of polymers and metals; however, the structural design for the additive manufacturing of ceramics is still rare. In 2020, Pelanconi et al. [117] systematically reviewed the computer aided design (CAD) evolution towards ceramic cellular architectures produced by hybrid additive manufacturing. The $\mathrm{CAD}$, finite element modelling (FEM), and other design tools, show great potential during the additive manufacturing of ceramic cellular architectures. As early as 2015, Szczurek et al. [118] designed and prepared the first carbon periodic cellular architectures from 3D printing, which promoted the structural design studies in this field, and gave some theological understanding to the structural design of ceramics during additive manufacturing. GómezGómez et al. [71] designed and prepared $\mathrm{SiC}$ ceramic woodpile structure by using a additive manufacturing technology called filament printing, and discussed the influences of the extrusion path angle on the mechanical properties of the structure, as shown in Fig. 20(c). Figure 43 shows DLP-prepared $\mathrm{ZrO}_{2}$ ceramic lattice structures reported by Zhao et al. [119]. They carefully designed $\mathrm{ZrO}_{2}$ ceramic lattice structures with different lattice configurations (octet truss structure, Kelvin structure, and so on) and structure sizes (as shown in Fig. 43(a)), and prepared them by 
using DLP and pressureless sintering (as shown in Fig. 43(b)). After that, the influences of the lattice configuration on the bending strength of the $\mathrm{ZrO}_{2}$ ceramic lattice structure were experimentally evaluated and discussed. In addition, they also prepared the 3D octet-truss structures (as shown in Figs. 44(a) and 44(b)) of different $\mathrm{ZrO}_{2}$ ceramic lattice structures by DLP, and discussed the influences of structure configuration and size on the mechanical properties of these structures [120]. More interestingly, Mei et al. $[121,122]$ also prepared $\mathrm{Al}_{2} \mathrm{O}_{3}$ ceramic lattice structures with different structural configurations by SLA (as shown in Fig. 45). After that, a SiC coating was prepared on the surface of the lattice structure by CVI. And the mechanical properties of the $\mathrm{Al}_{2} \mathrm{O}_{3}-\mathrm{SiC}$ ceramic structure were investigated. Unfortunately, it must say that there are still few and preliminary reports on the structural design based on the additive manufacturing of ceramics. It neither considers the optimal design of the entire structure under mechanical load-bearing conditions, lacks feasible structural design theories and methods, or does not thoroughly reveal the mapping relationship between the structure and mechanical properties, and lacks its damage mechanism and failure mechanism. Research on the structural design for the additive manufacturing of ceramic (especially additive manufacturing of $\mathrm{SiC}$ ceramic) will be one of the important research directions in this field in the future.

Another advantage of additive manufacturing technology is that it can realize the functional design of materials and structures. Mei et al. [123] and Xiao et al. [124] have made good attempts during the additive manufacturing of ceramics. They firstly designed $\mathrm{Al}_{2} \mathrm{O}_{3}$ ceramic lattice structure with a special electromagnetic absorbing structure (as shown in Fig. 46(a)) in response

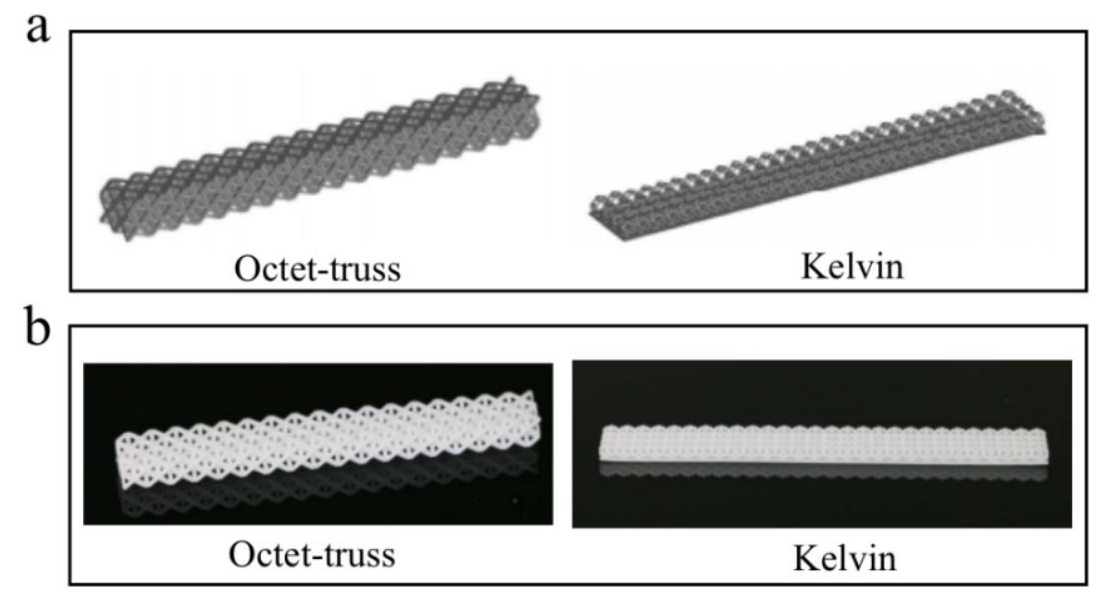

Fig. 43 (a) 3D models with different structures; (b) $\mathrm{ZrO}_{2}$ ceramic cellular structures. Reproduced with permission from Ref. [119], (C) The Author(s) 2019.
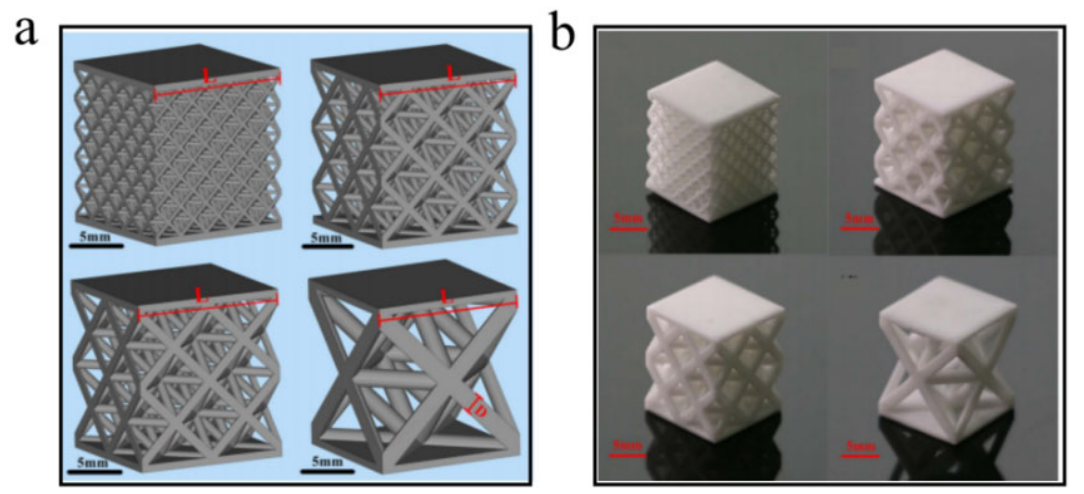

Fig. 44 (a) 3D models with different structures; (b) $\mathrm{ZrO}_{2}$ ceramic 3D octet-truss structures. Reproduced with permission from Ref. [120], (C) The Author(s) 2020. 


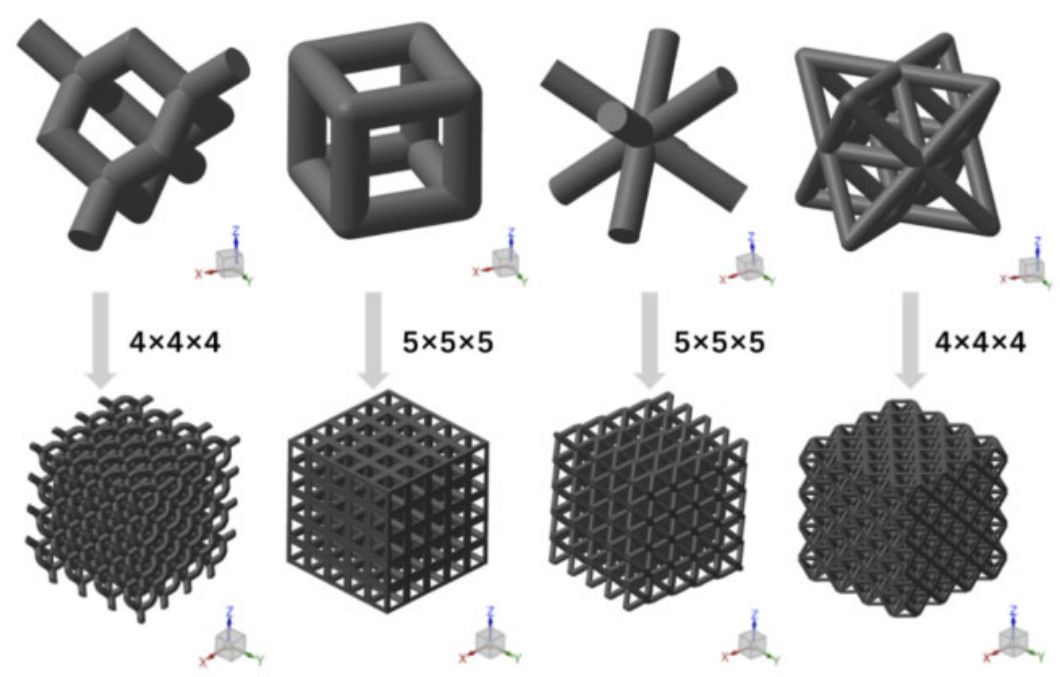

Fig. 45 3D models for $\mathrm{Al}_{2} \mathrm{O}_{3}$ ceramic cellular structures. Reproduced with permission from Ref. [121], (C) Elsevier B.V. 2019.
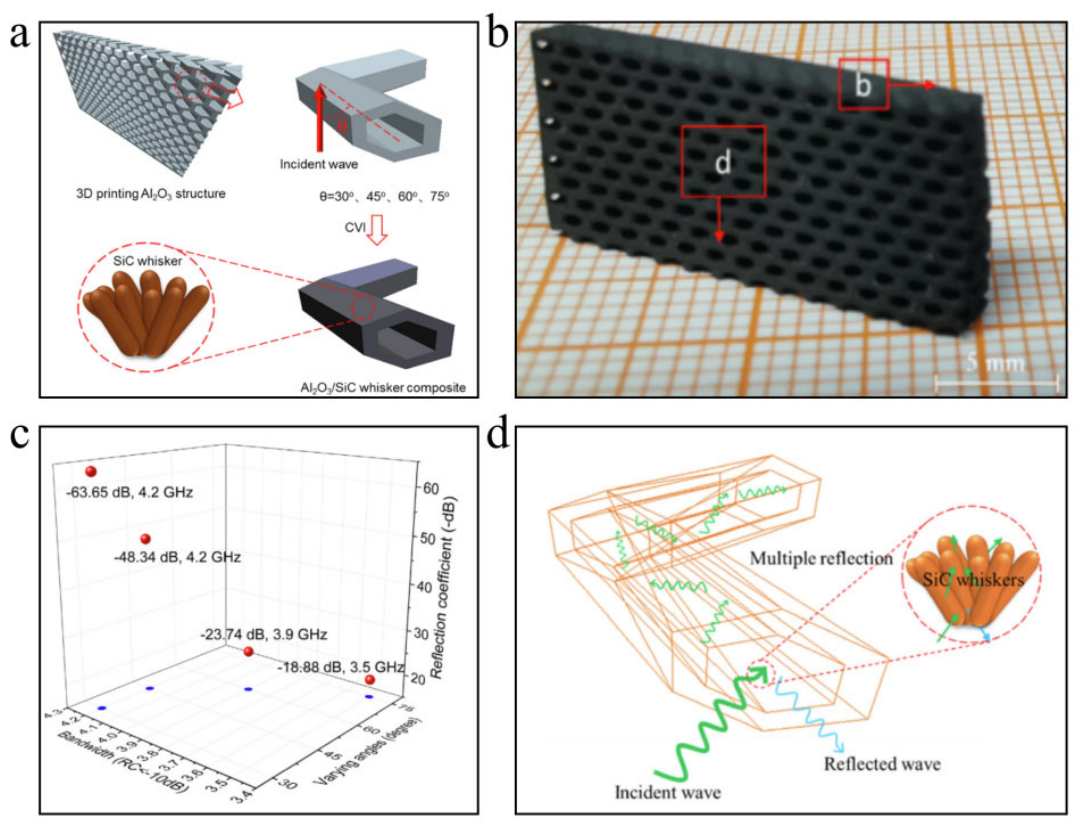

Fig. 46 (a) Structural designed model; (b) $\mathrm{Al}_{2} \mathrm{O}_{3}-\mathrm{SiC}_{\mathrm{w}}$ ceramic cellular structures; (c) excellent electromagnetic wave (EMW) absorption behavior; (d) electromagnetic wave (EMW) absorption mechanism. Reproduced with permission from Ref. [123], (C) Elsevier B.V. 2019.

to the electromagnetic absorption requirements of high-temperature environments. Then, they fabricated $\mathrm{Al}_{2} \mathrm{O}_{3}$ ceramic lattice structure through $\mathrm{SL}$, and subsequently prepared $\mathrm{SiC}$ whiskers on the surface of $\mathrm{Al}_{2} \mathrm{O}_{3}$ ceramic lattice structure by $\mathrm{CVI}$ (as shown in Fig. 46(b)). The as-obtained $\mathrm{Al}_{2} \mathrm{O}_{3}-\mathrm{SiC}_{\mathrm{w}}$ ceramic lattice structure exhibited a good electromagnetic absorption performance (as shown in Fig. 46(c)). And the authors further analyzed the electromagnetic absorption mechanism of the $\mathrm{Al}_{2} \mathrm{O}_{3}-\mathrm{SiC}_{\mathrm{w}}$ ceramic lattice structure (as shown in Fig. 46(d)) [123]. Although this research was not strictly $\mathrm{SiC}$ ceramic, it provided reference and thinking for the functional design of additive manufacturing of ceramic. In the future, researches on the functional design for additive manufacturing of ceramic will be the most important hot spot in this field.

From the above, it can be seen that additive manufacturing can not only realize the high-efficiency, low-cost, and rapid preparation of complex-shaped ceramic components, but also realize the structural and functional design for ceramic. More importantly, the 
biggest advantage of additive manufacturing is the ability to unify materials, structures and functions together to achieve the integration of design and manufacturing, the integration of materials and structures, and the integration of structures and functions [125-127]. Therefore, the important development direction for the additive manufacturing of ceramic in the future will be the research on the design and manufacturing integration, material and structure integration, and structure and function integration, which will surely bring the disruptive change for the design, manufacturing, and application of traditional ceramics.

\section{5 Simulation, 4D printing, and other novel technologies}

In addition, there are some novel research directions in the field of material additive manufacturing of ceramics, such as the simulation technology and 4D printing of ceramics. At present, the processing simulation research for the additive manufacturing of metals has become more common [128]. The research on processing simulation played a great role in revealing the forming mechanism for the additive manufacturing of metals. In recent years, advanced simulation technologies, including digital twins [129], big data [130], and machine learning [131], have also gradually received attentions and applications for the additive manufacturing research of metals; however, the simulation for the material additive manufacturing of ceramic has not been reported. This will be an important research direction in this field in the future, and it will definitely play a role in the development and promotion of the additive manufacturing technology of ceramic.

In addition, 4D printing has also received widespread attention in recent years. Compared with 3D printing, 4D printing can avoid manufacturing complex 3D shapes directly, but firstly print lower-dimensional shapes, and then enable other dimensions at the target location with the required performance. Therefore, 4D printing has a wide range of potential applications in the fields of biomedicine, smart wearable equipment, assembled buildings, aerospace, art, and entertainment [132]. At present, 4D printing technology of shape memory polymers and shape memory alloys has received a lot of research. Here, the authors will not summary the details about the concept and research status of $4 \mathrm{D}$ printing. However, due to the small deformation and high brittleness of ceramics, 4D printing based on ceramic materials is currently rare. Fortunately, Liu et al. [133] and Zhang et al. [134] have conducted exploratory research in the field of 4D printing of ceramics recently. In 2018, Liu et al. [133] studied the 4D printing of ceramics. They first developed a 4D printing design of large deformable structures based on polymer elastomers, and then used DIW to prepare polymer elastomers. The DIWprepared elastomer structure could deform according to the presetting structure configuration under the excitation of external field, and finally the elastomer structure was converted into the ceramic structure by high temperature carbonization. The research flow chart of Liu et al.'s work is shown in Fig. 47. Although the research was still relatively preliminary, and it was not strictly true that the deformation of the ceramic itself was realized, but the research has pioneered the research direction for the $4 \mathrm{D}$ printing of ceramic. Zhang et al. [134] also studied the 4D printing of ceramics. They directly prepared multi- ceramic triangle structures with tunable thermal expansion by using DLP-based 4D printing, as shown in Fig. 48. They opened the study on the 4D printing of ceramics with tunable functions. The development of the 4D printing of ceramic will inevitably broaden the traditional application fields and possibilities of ceramics, which will also be a very important research direction for the of additive manufacturing of ceramics in the future.

In conclusion, the additive manufacturing of ceramics faces great challenges and opportunities in terms of design theory and methods, additive manufacturing equipment, additive manufacturing technologies, shape controlling and forming mechanism, and structural function integration. The deepening in this field will promote the development for the additive manufacturing technology of ceramic, and finally promote the engineering application of ceramic materials.

\section{Summary and perspective}

$\mathrm{SiC}$ ceramic has excellent properties combining low density, excellent mechanical and thermal properties, good thermal oxidation and chemical stability, and therefore is widely used in different military and engineering fields, such as aerospace, armor, space mirror, nuclear, chemical industry and semiconductor, and so on. The emergence of additive manufacturing 


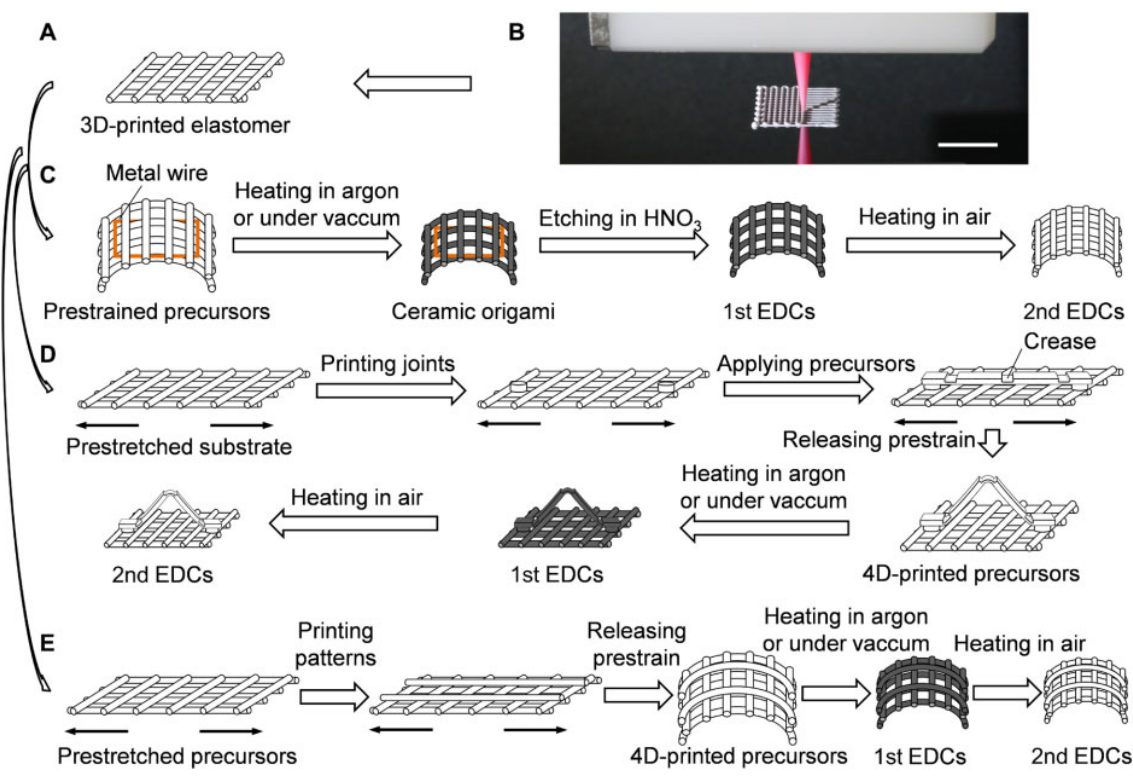

Fig. 47 4D printing of ceramic: (A) 3D-printed elastomeric lattices; (B) DIW of inks; (C) ceramic structures derived from 3D-printed elastomers; (D, E) two 4D printing methods, including method 1 (D) and method 2 (E), together with heat treatment, convert 3D-printed elastomer into 4D-printed ceramics. Reproduced with permission from Ref. [133], (C) The Authors 2018.

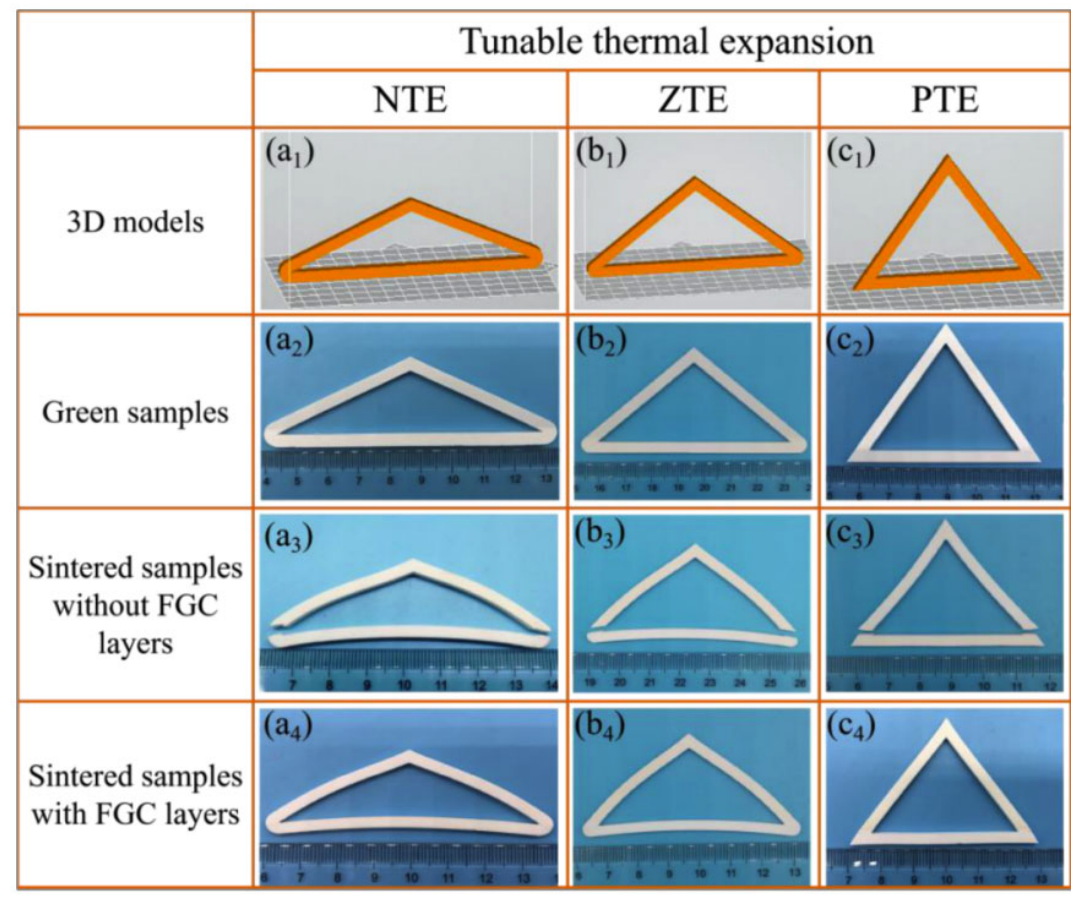

Fig. 48 3D models, green samples, sintered samples without FGC layers, and sintered samples with FGC layers of the multi-ceramic structures: $\left(a_{1}-a_{4}\right)$ negative thermal expansion, $\left(b_{1}-b_{4}\right)$ zero thermal expansion, and $\left(c_{1}-c_{4}\right)$ positive thermal expansion. Reproduced with permission from Ref. [134], (c) Elsevier Ltd. 2020.

technologies provides a new approach for the fabrication of $\mathrm{SiC}$ ceramic and its structures. In this paper, the additive manufacturing technologies of the $\mathrm{SiC}$ ceramic, including indirect additive manufacturing technology and direct additive manufacturing technology developed in recent years, are systematically reviewed.
The key scientific and technological challenges for the additive manufacturing of $\mathrm{SiC}$ ceramic are summarized, and the future research opportunities are analyzed. This review is aimed to provide a guide for the research on the additive manufacturing of $\mathrm{SiC}$ ceramic and other structural ceramic materials. 


\section{Acknowledgements}

This work was mainly financially supported by the National Natural Science Foundation of China (No. 51772028).

\section{References}

[1] Liu GW, Zhang XZ, Yang J, et al. Recent advances in joining of SiC-based materials (monolithic $\mathrm{SiC}$ and $\mathrm{SiC}_{\mathrm{f}} / \mathrm{SiC}$ composites): Joining processes, joint strength, and interfacial behavior. $J$ Adv Ceram 2019, 8: 19-38.

[2] Chen XW, Cheng GF, Zhang JM, et al. Residual stress variation in $\mathrm{SiC}_{\mathrm{f}} / \mathrm{SiC}$ composite during heat treatment and its effects on mechanical behavior. $J$ Adv Ceram 2020, 9: $567-575$.

[3] Liu JW, Zhou XB, Tatarko $\mathrm{P}$, et al. Fabrication, microstructure, and properties of $\mathrm{SiC} / \mathrm{Al}_{4} \mathrm{SiC}_{4}$ multiphase ceramics via an in situ formed liquid phase sintering. $J$ Adv Ceram 2020, 9: 193-203.

[4] Eom JH, Kim YW, Raju S. Processing and properties of macroporous silicon carbide ceramics: A review. $J$ Asian Ceram Soc 2013, 1: 220-242.

[5] Nastic A, Merati A, Bielawski M, et al. Instrumented and Vickers indentation for the characterization of stiffness, hardness and toughness of zirconia toughened $\mathrm{Al}_{2} \mathrm{O}_{3}$ and SiC armor. J Mater Sci Technol 2015, 31: 773-783.

[6] Shen ZW, Hu DA, Yang G, et al. Ballistic reliability study on SiC/UHMWPE composite armor against armorpiercing bullet. Compos Struct 2019, 213: 209-219.

[7] Khodaei M, Yaghobizadeh O, Naghavi Alhosseini SH, et al. The effect of oxide, carbide, nitride and boride additives on properties of pressureless sintered SiC: A review. J Eur Ceram Soc 2019, 39: 2215-2231.

[8] Lewis JA. Colloidal processing of ceramics. J Am Ceram Soc 2000, 83: 2341-2359.

[9] Wu CJ, Pang JZ, Li BZ, et al. High-speed grinding of HIP-SiC ceramics on transformation of microscopic features. Int J Adv Manuf Technol 2019, 102: 1913-1921.

[10] Wang X, Jiang M, Zhou ZW, et al. 3D printing of polymer matrix composites: A review and prospective. Compos Part B: Eng 2017, 110: 442-458.

[11] Frazier WE. Metal additive manufacturing: A review. $J$ Mater Eng Perform 2014, 23: 1917-1928.

[12] Chen ZW, Li ZY, Li JJ, et al. 3D printing of ceramics: A review. J Eur Ceram Soc 2019, 39: 661-687.

[13] Zhang D, Liu XF, Qiu JR. 3D printing of glass by additive manufacturing techniques: A review. Front Optoelectron 2020, https://doi.org/10.1007/s12200-020-1009-z.

[14] Barberi J, Baino F, Fiume E, et al. Robocasting of $\mathrm{SiO}_{2}$-based bioactive glass scaffolds with porosity gradient for bone regeneration and potential load-bearing applications. Materials 2019, 12: E2691.

[15] Melcher R, Martins S, Travitzky N, et al. Fabrication of $\mathrm{Al}_{2} \mathrm{O}_{3}$-based composites by indirect 3D-printing. Mater
Lett 2006, 60: 572-575.

[16] Zhang KQ, Xie C, Wang G, et al. High solid loading, low viscosity photosensitive $\mathrm{Al}_{2} \mathrm{O}_{3}$ slurry for stereolithography based additive manufacturing. Ceram Int 2019, 45: $203-$ 208.

[17] Xing HY, Zou B, Li SS, et al. Study on surface quality, precision and mechanical properties of $3 \mathrm{D}$ printed $\mathrm{ZrO}_{2}$ ceramic components by laser scanning stereolithography. Ceram Int 2017, 43: 16340-16347

[18] Zhang KQ, He RJ, Xie C, et al. Photosensitive $\mathrm{ZrO}_{2}$ suspensions for stereolithography. Ceram Int 2019, 45: 12189-12195.

[19] Zhang KQ, He RJ, Ding GJ, et al. Digital light processing of 3Y-TZP strengthened $\mathrm{ZrO}_{2}$ ceramics. Mater Sci Eng: A 2020, 774: 138768.

[20] Yan S, Huang YF, Zhao DK, et al. 3D printing of nano-scale $\mathrm{Al}_{2} \mathrm{O}_{3}-\mathrm{ZrO}_{2}$ eutectic ceramic: Principle analysis and process optimization of pores. Addit Manuf 2019, 28: 120-126.

[21] Mei H, Zhao X, Zhou SX, et al. 3D-printed oblique honeycomb $\mathrm{Al}_{2} \mathrm{O}_{3} / \mathrm{SiC}_{\mathrm{w}}$ structure for electromagnetic wave absorption. Chem Eng J 2019, 372: 940-945.

[22] Liu XY, Zou B, Xing HY, et al. The preparation of $\mathrm{ZrO}_{2}-\mathrm{Al}_{2} \mathrm{O}_{3}$ composite ceramic by SLA-3D printing and sintering processing. Ceram Int 2020, 46: 937-944.

[23] Kulkarni A, Sorarù GD, Pearce JM. Polymer-derived SiOC replica of material extrusion-based 3-D printed plastics. Addit Manuf 2020, 32: 100988.

[24] Zocca A, Gomes CM, Staude A, et al. SiOC ceramics with ordered porosity by 3D-printing of a preceramic polymer. J Mater Res 2013, 28: 2243-2252.

[25] Jana P, Santoliquido O, Ortona A, et al. Polymer-derived $\mathrm{SiCN}$ cellular structures from replica of $3 \mathrm{D}$ printed lattices. J Am Ceram Soc 2018, 101: 2732-2738.

[26] Gyak KW, Vishwakarma NK, Hwang YH, et al. 3D-printed monolithic SiCN ceramic microreactors from a photocurable preceramic resin for the high temperature ammonia cracking process. React Chem Eng 2019, 4: 1393-1399.

[27] Chen QH, Zou B, Lai QG, et al. A study on biosafety of HAP ceramic prepared by SLA-3D printing technology directly. J Mech Behav Biomed Mater 2019, 98: 327335.

[28] Feng CW, Zhang KQ, He RJ, et al. Additive manufacturing of hydroxyapatite bioceramic scaffolds: Dispersion, digital light processing, sintering, mechanical properties, and biocompatibility. J Adv Ceram 2020, 9: 360-373.

[29] Wei YH, Zhao DY, Cao QL, et al. Stereolithographybased additive manufacturing of high-performance osteoinductive calcium phosphate ceramics by a digital light-processing system. ACS Biomater Sci Eng 2020, 6: 1787-1797.

[30] Cox SC, Jamshidi P, Eisenstein NM, et al. Adding functionality with additive manufacturing: Fabrication of 
titanium-based antibiotic eluting implants. Mater Sci Eng: C 2016, 64: 407-415.

[31] Warnke PH, Seitz H, Warnke F, et al. Ceramic scaffolds produced by computer-assisted 3D printing and sintering: Characterization and biocompatibility investigations. $J$ Biomed Mater Res Part B: Appl Biomater 2010, 93B: 212-217.

[32] Stumpf M, Travitzky N, Greil P, et al. Sol-gel infiltration of complex cellular indirect 3D printed alumina. $J$ Eur Ceram Soc 2018, 38: 3603-3609.

[33] Taboas JM, Maddox RD, Krebsbach PH, et al. Indirect solid free form fabrication of local and global porous, biomimetic and composite 3D polymer-ceramic scaffolds. Biomaterials 2003, 24: 181-194.

[34] Chen FJ, Liu K, Sun HJ, et al. Fabrication of complicated silicon carbide ceramic components using combined 3D printing with gelcasting. Ceram Int 2018, 44: 254-260.

[35] Tu TZ, Jiang GJ. SiC reticulated porous ceramics by 3D printing, gelcasting and liquid drying. Ceram Int 2018, 44: 3400-3405.

[36] Zhang H, Yang Y, Hu KH, et al. Stereolithography-based additive manufacturing of lightweight and high-strength $\mathrm{C}_{\mathrm{f}} / \mathrm{SiC}$ ceramics. Addit Manuf 2020, 34: 101199.

[37] Saggio-Woyansky J, Scott C, Minnear W. Processing of porous ceramics. Am Ceram Soc Bull 1992, 71: 16741682.

[38] Fey T, Betke U, Rannabauer S, et al. Reticulated replica ceramic foams: Processing, functionalization, and characterization. Adv Eng Mater 2017, 19: 1700369.

[39] Ortona A, D'Angelo C, Gianella S, et al. Cellular ceramics produced by rapid prototyping and replication. Mater Lett 2012, 80: 95-98.

[40] Rezaei E, Barbato M, Gianella S, et al. Pressure drop and convective heat transfer in different SiSiC structures fabricated by indirect additive manufacturing. $J$ Heat Transf 2020, 142: 032702.

[41] Pelanconi M, Rezaei E, Ortona A, et al. Cellular ceramic architectures produced by hybrid additive manufacturing: A review on the evolution of their design. J Ceram Soc Jpn 2020, 128: 595-604.

[42] Ortona A, Trimis D, Uhlig V, et al. SiSiC heat exchangers for recuperative gas burners with highly structured surface elements. Int J Appl Ceram Technol 2014, 11: 927-937.

[43] Ding GJ, He RJ, Zhang KQ, et al. Stereolithography 3D printing of $\mathrm{SiC}$ ceramic with potential for lightweight optical mirror. Ceram Int 2020, 46: 18785-18790.

[44] Nelson JC, Vail NK, Barlow JW, et al. Selective laser sintering of polymer-coated silicon carbide powders. Ind Eng Chem Res 1995, 34: 1641-1651.

[45] Evans RS, Bourell DL, Beaman JJ, et al. Rapid manufacturing of silicon carbide composites. Rapid Prototyp J 2005, 11: 37-40.

[46] Exner H, Horn M, Streek A, et al. Laser micro sintering: A new method to generate metal and ceramic parts of high resolution with sub-micrometer powder. Virtual Phys Prototyp 2008, 3: 3-11.

[47] Liu $\mathrm{K}, \mathrm{Wu} \mathrm{T}$, Bourell $\mathrm{DL}$, et al. Laser additive manufacturing and homogeneous densification of complicated shape SiC ceramic parts. Ceram Int 2018, 44: 21067-21075.

[48] Fu H, Zhu W, Xu ZF, et al. Effect of silicon addition on the microstructure, mechanical and thermal properties of $\mathrm{C}_{\mathrm{f}} / \mathrm{SiC}$ composite prepared via selective laser sintering. $J$ Alloys Compd 2019, 792: 1045-1053.

[49] Meyers S, de Leersnijder L, Vleugels J, et al. Direct laser sintering of reaction bonded silicon carbide with low residual silicon content. J Eur Ceram Soc 2018, 38: 3709-3717.

[50] Xu TT, Cheng S, Jin LZ, et al. High-temperature flexural strength of $\mathrm{SiC}$ ceramics prepared by additive manufacturing. Int J Appl Ceram Technol 2020, 17: 438-448.

[51] Sun XM, Zeng T, Zhou YK, et al. 3D printing of porous $\mathrm{SiC}$ ceramics added with $\mathrm{SiO}_{2}$ hollow microspheres. Ceram Int 2020, 46: 22797-22804.

[52] King D, Middendorf J, Cissel K, et al. Selective laser melting for the preparation of an ultra-high temperature ceramic coating. Ceram Int 2019, 45: 2466-2473.

[53] Wits WW, de Smit M, Al-Hamdani K, et al. Laser powder bed fusion of a magnesium-SiC metal matrix composite. Procedia CIRP 2019, 81: 506-511.

[54] Wei C, Chueh YH, Zhang XJ, et al. Easy-to-remove composite support material and procedure in additive manufacturing of metallic components using multiple material laser-based powder bed fusion. J Manuf Sci Eng 2019, 141: 071002.

[55] Wei C, Gu H, Zhang XJ, et al. Hybrid ultrasonic and mini-motor vibration-induced irregularly shaped powder delivery for multiple materials additive manufacturing. Addit Manuf 2020, 33: 101138.

[56] Lv X, Ye F, Cheng LF, et al. Fabrication of SiC whisker-reinforced $\mathrm{SiC}$ ceramic matrix composites based on $3 \mathrm{D}$ printing and chemical vapor infiltration technology. J Eur Ceram Soc 2019, 39: 3380-3386.

[57] Baux A, Goillot A, Jacques S, et al. Synthesis and properties of macroporous $\mathrm{SiC}$ ceramics synthesized by 3D printing and chemical vapor infiltration/deposition. $J$ Eur Ceram Soc 2020, 40: 2834-2854.

[58] Fleisher A, Zolotaryov D, Kovalevsky A, et al. Reaction bonding of silicon carbides by Binder Jet 3D-Printing, phenolic resin binder impregnation and capillary liquid silicon infiltration. Ceram Int 2019, 45: 18023-18029.

[59] Zocca A, Lima P, Diener S, et al. Additive manufacturing of $\mathrm{SiSiC}$ by layerwise slurry deposition and binder jetting (LSD-print). J Eur Ceram Soc 2019, 39: 3527-3533.

[60] Zhu SX, Michael HC, Mrityunjay S. Additive manufacturing of silicon carbide-based ceramics by 3-D printing technologies. In: Advanced Processing and Manufacturing Technologies for Nanostructured and Multifunctional Materials II. Hoboken, NJ, USA: John 
Wiley \& Sons, Inc., 2015: 133-144.

[61] Polzin C, Günther D, Seitz H. 3D printing of porous $\mathrm{Al}_{2} \mathrm{O}_{3}$ and $\mathrm{SiC}$ ceramics. J Ceram Sci Technol 2015, 6: 141-146.

[62] Duan WY, Yin XW, Cao FX, et al. Absorption properties of twinned $\mathrm{SiC}$ nanowires reinforced $\mathrm{Si}_{3} \mathrm{~N}_{4}$ composites fabricated by 3d-prining. Mater Lett 2015, 159: 257-260.

[63] Singh N, Singh R, Kumar R, et al. Recycled HDPE reinforced $\mathrm{Al}_{2} \mathrm{O}_{3}$ and $\mathrm{SiC}$ three dimensional printed patterns for sandwich composite material. Eng Res Express 2019, 1: 015007.

[64] Masuda H, Ohta Y, Kitayama M. Additive manufacturing of $\mathrm{SiC}$ ceramics with complicated shapes using the FDM type 3D-printer. J Mater Sci Chem Eng 2019, 7: 1-12.

[65] Travitzky N, Windsheimer H, Fey T, et al. Preceramic paper-derived ceramics. J Am Ceram Soc 2008, 91: 3477-3492.

[66] Windsheimer $\mathrm{H}$, Travitzky N, Hofenauer A, et al. Laminated object manufacturing of preceramic-paperderived Si-SiC composites. Adv Mater 2007, 19: 45154519.

[67] Cai KP, Román-Manso B, Smay JE, et al. Geometrically complex silicon carbide structures fabricated by robocasting. J Am Ceram Soc 2012, 95: 2660-2666.

[68] Wahl L, Lorenz M, Biggemann J, et al. Robocasting of reaction bonded silicon carbide structures. $J$ Eur Ceram Soc 2019, 39: 4520-4526.

[69] Feilden E, Glymond D, Saiz E, et al. High temperature strength of an ultra high temperature ceramic produced by additive manufacturing. Ceram Int 2019, 45: 18210-18214.

[70] Elizarova IS, Vandeperre L, Saiz E. Conformable green bodies: Plastic forming of robocasted advanced ceramics. J Eur Ceram Soc 2020, 40: 552-557.

[71] Gómez-Gómez A, Moyano JJ, Osendi MI, et al. The effect of rod orientation on the strength of highly porous filament printed 3D SiC ceramic architectures. Boletin de la Sociedad Española de Cerámica y Vidrio 2021, 60: 119-127.

[72] Zhang H, Yang Y, Liu B, et al. The preparation of SiC-based ceramics by one novel strategy combined 3D printing technology and liquid silicon infiltration process. Ceram Int 2019, 45: 10800-10804.

[73] McClain MS, Gunduz IE, Son SF. Additive manufacturing of carbon fiber reinforced silicon carbide solid rocket nozzles. In: Proceedings of the AIAA Scitech 2019 Forum, 2019: AIAA 2019-0408.

[74] Halloran JW. Ceramic stereolithography: Additive manufacturing for ceramics by photopolymerization. Annu Rev Mater Res 2016, 46: 19-40.

[75] Santoliquido O, Colombo P, Ortona A. Additive Manufacturing of ceramic components by Digital Light Processing: A comparison between the "bottom-up" and the "top-down" approaches. J Eur Ceram Soc 2019, 39: 2140-2148.

[76] Friedel T, Travitzky N, Niebling F, et al. Fabrication of polymer derived ceramic parts by selective laser curing. $J$ Eur Ceram Soc 2005, 25: 193-197.

[77] Park S, Lee DH, Ryoo HI, et al. Fabrication of three-dimensional $\mathrm{SiC}$ ceramic microstructures with near-zero shrinkage via dual crosslinking induced stereolithography. Chem Commun 2009: 4880-4882.

[78] Eckel ZC, Zhou C, Martin JH, et al. Additive manufacturing of polymer-derived ceramics. Science 2016, 351: 58-62.

[79] De Hazan Y, Penner D. SiC and SiOC ceramic articles produced by stereolithography of acrylate modified polycarbosilane systems. J Eur Ceram Soc 2017, 37: 5205-5212.

[80] Ligon SC, Blugan G, Kuebler J. Maskless lithography of silazanes for fabrication of ceramic micro-components. Ceram Int 2019, 45: 2345-2350.

[81] Chen JS, Wang YJ, Pei XL, et al. Preparation and stereolithography of $\mathrm{SiC}$ ceramic precursor with high photosensitivity and ceramic yield. Ceram Int 2020, 46: 13066-13072.

[82] Wang XF, Schmidt F, Hanaor D, et al. Additive manufacturing of ceramics from preceramic polymers: A versatile stereolithographic approach assisted by thiol-ene click chemistry. Addit Manuf 2019, 27: 80-90.

[83] Schmidt J, Brigo L, Gandin A, et al. Multiscale ceramic components from preceramic polymers by hybridization of vat polymerization-based technologies. Addit Manuf 2019, 30: 100913 .

[84] Ding GJ, He RJ, Zhang KQ, et al. Stereolithographybased additive manufacturing of gray-colored $\mathrm{SiC}$ ceramic green body. J Am Ceram Soc 2019, 102: 7198-7209.

[85] Ding GJ, He RJ, Zhang KQ, et al. Dispersion and stability of $\mathrm{SiC}$ ceramic slurry for stereolithography. Ceram Int 2020, 46: 4720-4729.

[86] He RJ, Ding GJ, Zhang KQ, et al. Fabrication of SiC ceramic architectures using stereolithography combined with precursor infiltration and pyrolysis. Ceram Int 2019, 45: 14006-14014.

[87] Ding GJ, He RJ, Zhang KQ, et al. Stereolithography 3D printing of $\mathrm{SiC}$ ceramic with potential for lightweight optical mirror. Ceram Int 2020, 46: 18785-18790.

[88] Larson CM, Choi JJ, Gallardo PA, et al. Direct ink writing of silicon carbide for microwave optics. Adv Eng Mater 2016, 18: 39-45.

[89] Chen HH, Wang XF, Xue FD, et al. 3D printing of $\mathrm{SiC}$ ceramic: Direct ink writing with a solution of preceramic polymers. J Eur Ceram Soc 2018, 38: 5294-5300.

[90] Xiong HW, Zhao LZ, Chen HH, et al. 3D SiC containing uniformly dispersed, aligned SiC whiskers: Printability, microstructure and mechanical properties. $J$ Alloys Compd 2019, 809: 151824.

[91] Xiong HW, Chen HH, Chen ZK, et al. 3D-SiC decorated with $\mathrm{SiC}$ whiskers: Chemical vapor infiltration on the porous 3D-SiC lattices derived from polycarbosilanebased suspensions. Ceram Int 2020, 46: 6234-6242. 
[92] Zhu Q, Dong X, Hu JB, et al. High strength aligned SiC nanowire reinforced $\mathrm{SiC}$ porous ceramics fabricated by $3 \mathrm{D}$ printing and chemical vapor infiltration. Ceram Int 2020, 46: 6978-6983.

[93] Xia YL, Lu ZL, Cao JW, et al. Microstructure and mechanical property of $\mathrm{C}_{\mathrm{f}} / \mathrm{SiC}$ core/shell composite fabricated by direct ink writing. Scripta Mater 2019, 165: $84-88$.

[94] Lu ZL, Xia YL, Miao K, et al. Microstructure control of highly oriented short carbon fibres in $\mathrm{SiC}$ matrix composites fabricated by direct ink writing. Ceram Int 2019, 45: 17262-17267.

[95] Song SC, Gao ZQ, Lu BH, et al. Performance optimization of complicated structural $\mathrm{SiC} / \mathrm{Si}$ composite ceramics prepared by selective laser sintering. Ceram Int 2020, 46: 568-575.

[96] Gómez-Gómez A, Moyano JJ, Román-Manso B, et al. Highly-porous hierarchical $\mathrm{SiC}$ structures obtained by filament printing and partial sintering. J Eur Ceram Soc 2019, 39: 688-695.

[97] Hu KH, Wei YM, Lu ZG, et al. Design of a shaping system for stereolithography with high solid loading ceramic suspensions. 3D Print Addit Manuf 2018, 5: 311-318.

[98] Li H, Liu YS, Liu YS, et al. Effect of sintering temperature in argon atmosphere on microstructure and properties of $3 \mathrm{D}$ printed alumina ceramic cores. $J A d v$ Ceram 2020, 9: 220-231.

[99] Li H, Liu YS, Liu YS, et al. Influence of debinding holding time on mechanical properties of 3D-printed alumina ceramic cores. Ceram Int 2021, 47: 4884-4894.

[100] Zhang JX, Jiang DL, Lin QL, et al. Properties of silicon carbide ceramics from gelcasting and pressureless sintering. Mater Des 2015, 65: 12-16.

[101] Song N, Zhang HB, Liu H, et al. Effects of SiC whiskers on the mechanical properties and microstructure of $\mathrm{SiC}$ ceramics by reactive sintering. Ceram Int 2017, 43: 6786-6790.

[102] Ma RZ, Wu J, Wei BQ, et al. Processing and properties of carbon nanotubes-nano-SiC ceramic. J Mater Sci 1998, 33: 5243-5246.

[103] Dong SM, Katoh Y, Kohyama A. Preparation of SiC/SiC composites by hot pressing, using tyranno-SA fiber as reinforcement. J Am Ceram Soc 2003, 86: 26-32.

[104] Liu W, Chen CY, Shuai SS, et al. Study of pore defect and mechanical properties in selective laser melted $\mathrm{Ti}_{6} \mathrm{Al}_{4} \mathrm{~V}$ alloy based on X-ray computed tomography. Mater Sci Eng: A 2020, 797: 139981.

[105] Saâdaoui M, Khaldoun F, Adrien J, et al. X-ray tomography of additive-manufactured zirconia: Processing defects - Strength relations. J Eur Ceram Soc 2020, 40: 3200-3207.

[106] Khaldoun F, Saâdaoui M, Adrien J, et al. Flexural strength and X-ray computed tomography analysis of zirconia specimens processed by additive manufacturing. In:
Proceedings of the 16th European Inter-Regional Conference of Ceramics, 2018.

[107] Diener S, Franchin G, Achilles N, et al. X-ray microtomography investigations on the residual pore structure in silicon nitride bars manufactured by direct ink writing using different printing patterns. Open Ceram 2021, 5: 100042 .

[108] Arai Y, Inoue R, Goto K, et al. Carbon fiber reinforced ultra-high temperature ceramic matrix composites: A review. Ceram Int 2019, 45: 14481-14489.

[109] Binner J, Porter M, Baker B, et al. Selection, processing, properties and applications of ultra-high temperature ceramic matrix composites, UHTCMCs - a review. Int Mater Rev 2020, 65: 389-444.

[110] Wang PR, Liu FQ, Wang $\mathrm{H}$, et al. A review of third generation $\mathrm{SiC}$ fibers and $\mathrm{SiC}_{\mathrm{f}} / \mathrm{SiC}$ composites. $J$ Mater Sci Technol 2019, 35: 2743-2750.

[111] Fidan I, Imeri A, Gupta A, et al. The trends and challenges of fiber reinforced additive manufacturing. Int J Adv Manuf Technol 2019, 102: 1801-1818.

[112] Balla VK, Kate KH, Satyavolu J, et al. Additive manufacturing of natural fiber reinforced polymer composites: Processing and prospects. Compos Part B: Eng 2019, 174: 106956.

[113] Wang X, Jiang M, Zhou Z, et al. Additive manufacturing of natural fiber reinforced polymer composites: Processing and prospects. Compos B 2017, 110: 442-458.

[114] Kabir SMF, Mathur K, Seyam AFM. A critical review on 3D printed continuous fiber-reinforced composites: History, mechanism, materials and properties. Compos Struct 2020, 232: 111476.

[115] van de Werken N, Tekinalp H, Khanbolouki P, et al. Additively manufactured carbon fiber-reinforced composites: State of the art and perspective. Addit Manuf 2020, 31: 100962.

[116] Lu ZL, Cao JW, Song ZQ, et al. Research progress of ceramic matrix composite parts based on additive manufacturing technology. Virtual Phys Prototyp 2019, 14: 333-348.

[117] Pelanconi M, Rezaei E, Ortona A. Cellular ceramic architectures produced by hybrid additive manufacturing: A review on the evolution of their design. J Ceram Soc Jpn 2020, 128: 595-604.

[118] Szczurek A, Ortona A, Ferrari L, et al. Carbon periodic cellular architectures. Carbon 2015, 88: 70-85.

[119] Zhao WM, Wang C, Zhao Z. Bending strength of 3D-printed zirconia ceramic cellular structures. IOP Conf Ser: Mater Sci Eng 2019, 678: 012019.

[120] Zhao WM, Wang C, Xing BH, et al. Mechanical properties of zirconia octet truss structures fabricated by DLP 3D printing. Mater Res Express 2020, 7: 085201.

[121] Mei H, Zhao RS, Xia YZ, et al. Ultrahigh strength printed ceramic lattices. $J$ Alloys Compd 2019, 797: 786-796.

[122] Mei H, Huang WZ, Zhao YZ, et al. Strengthening three-dimensional printed ultra-light ceramic lattices. $J$ 
Am Ceram Soc 2019, 102: 5082-5089.

[123] Mei H, Zhao X, Zhou SX, et al. 3D-printed oblique honeycomb $\mathrm{Al}_{2} \mathrm{O}_{3} / \mathrm{SiC}_{\mathrm{w}}$ structure for electromagnetic wave absorption. Chem Eng J 2019, 372: 940-945.

[124] Xiao SS, Mei H, Han DY, et al. 3D printed SiC nanowire reinforced composites for broadband electromagnetic absorption. Ceram Int 2019, 45: 11475-11483.

[125] Yang S, Zhao YF. Additive manufacturing-enabled design theory and methodology: A critical review. Int $J A d v$ Manuf Technol 2015, 80: 327-342.

[126] Yang Y, Song X, Li XJ, et al. Recent progress in biomimetic additive manufacturing technology: From materials to functional structures. Adv Mater 2018, 30: 1706539.

[127] Tang YL, Zhao YF. A survey of the design methods for additive manufacturing to improve functional performance. Rapid Prototyp J 2016, 22: 569-590.

[128] Rodgers TM, Madison JD, Tikare V. Simulation of metal additive manufacturing microstructures using kinetic Monte Carlo. Comput Mater Sci 2017, 135: 78-89.

[129] Tang YL, Zhao YF. A survey of the design methods for additive manufacturing to improve functional performance. Rapid Prototyp J 2016, 22: 569-590.

[130] DebRoy T, Zhang W, Turner J, et al. Building digital twins of 3D printing machines. Scripta Mater 2017, 135: $119-124$

[131] Majeed A, Lv J, Peng T. A framework for big data driven process analysis and optimization for additive manufacturing. Rapid Prototyp J 2019, 25: 308-321.

[132] Mitchell A, Lafont U, Hołyńska M, et al. Additive manufacturing-A review of 4D printing and future applications. Addit Manuf 2018, 24: 606-626.

[133] Liu G, Zhao Y, Wu G, et al. Origami and 4D printing of elastomer-derived ceramic structures. Sci $A d v$ 2018, 4: eaat0641.

[134] Zhang KQ, Wei K, Chen JX, et al. Stereolithography additive manufacturing of multi-ceramic triangle structures with tunable thermal expansion. $J$ Eur Ceram Soc 2021, 41: 2796-2806.

Open Access This article is licensed under a Creative Commons Attribution 4.0 International License, which permits use, sharing, adaptation, distribution and reproduction in any medium or format, as long as you give appropriate credit to the original author(s) and the source, provide a link to the Creative Commons licence, and indicate if changes were made.

The images or other third party material in this article are included in the article's Creative Commons licence, unless indicated otherwise in a credit line to the material. If material is not included in the article's Creative Commons licence and your intended use is not permitted by statutory regulation or exceeds the permitted use, you will need to obtain permission directly from the copyright holder.

To view a copy of this licence, visit http://creativecommons.org/licenses/by/4.0/. 